\title{
Targeting the HSP60/10 chaperonin systems of Trypanosoma brucei as a strategy for treating African sleeping sickness.
}

Sanofar Abdeen, ${ }^{\mathrm{a}}$ Nilshad Salim, ${ }^{\mathrm{a}}$ Najiba Mammadova, ${ }^{\mathrm{a} \dagger}$ Corey M. Summers, ${ }^{\mathrm{a}}{ }^{\dagger}$ Karen GoldsmithPestana, ${ }^{\mathrm{b}}$ Diane McMahon-Pratt, ${ }^{\mathrm{b}}$ Peter G. Schultz, ${ }^{\mathrm{c}}$ Arthur L. Horwich, ${ }^{\mathrm{d}}$ Eli Chapman, ${ }^{\mathrm{e}}$ and Steven M. Johnson $^{\text {a* }}$

${ }^{a}$ Indiana University, School of Medicine, Department of Biochemistry and Molecular Biology, 635 Barnhill Dr., Indianapolis, IN, 46202

${ }^{\mathrm{b}}$ Yale School of Public Health, Department of Epidemiology of Microbial Diseases, 60 College St., New Haven, CT, 06520

${ }^{\mathrm{c}}$ The Scripps Research Institute, Department of Chemistry, 10550 North Torrey Pines Rd., La Jolla, CA 92037

${ }^{\mathrm{d}}$ HHMI, Department of Genetics, Yale School of Medicine, Boyer Center for Molecular Medicine, 295 Congress Ave., New Haven, CT, 06510

${ }^{\mathrm{e}}$ The University of Arizona, College of Pharmacy, Department of Pharmacology and Toxicology, 1703 E. Mabel St., Tucson, AZ 85721

\section{Present addresses:}

${ }^{\dagger}$ Department of Genetics, Development and Cell Biology, Iowa State University, 1210 Molecular Biology Building, Pannel Dr, Ames, IA 50011

$\$$ Department of Kinesiology, Iowa State University, 235 Barbara E. Forker Building, Beach Rd, Ames, IA 50011

*Correspondence: johnstm@iu.edu, Tel: 317-274-2458, Fax: 317-274-4686

KEYWORDS: GroEL, GroES, HSP60, HSP10, molecular chaperone, chaperonin, proteostasis, small molecule inhibitors, antibiotics, parasites, Trypanosoma brucei, African Sleeping Sickness. 


\section{Abstract}

Trypanosoma brucei are protozoan parasites that cause African sleeping sickness in humans (also known as Human African Trypanosomiasis - HAT). Without treatment, T. brucei infections are fatal. There is an urgent need for new therapeutic strategies as current drugs are toxic, have complex treatment regimens, and are becoming less effective owing to rising antibiotic resistance in parasites. We hypothesize that targeting the HSP60/10 chaperonin systems in T. brucei is a viable antitrypanosomal strategy as parasites rely on these stress response elements for their development and survival. We recently discovered several hundred inhibitors of the prototypical HSP60/10 chaperonin system from E. coli, termed GroEL/ES. One of the most potent GroEL/ES inhibitors we discovered was compound 1. While examining the PubChem database, we found that a related analog, 2e-p, exhibited cytotoxicity to Leishmania major promastigotes, which are trypanosomatids highly related to Trypanosoma brucei. Through initial counter-screening, we found that compounds $\mathbf{1}$ and $\mathbf{2 e - p}$ were also cytotoxic to Trypanosoma brucei parasites $\left(\mathrm{EC}_{50}=7.9\right.$ and $3.1 \mu \mathrm{M}$, respectively). These encouraging initial results prompted us to develop a library of inhibitor analogs and examine their anti-parasitic potential in vitro. Of the 49 new chaperonin inhibitors developed, 39\% exhibit greater cytotoxicity to $T$. brucei parasites than parent compound $\mathbf{1}$. While many analogs exhibit moderate cytotoxicity to human liver and kidney cells, we identified molecular substructures to pursue for further medicinal chemistry optimization to increase the therapeutic windows of this novel class of chaperonin-targeting antiparasitic candidates. An intriguing finding from this study is that suramin, the first-line drug for treating early stage $T$. brucei infections, is also a potent inhibitor of GroEL/ES and HSP60/10 chaperonin systems. 
Parasitic infections, such as those that cause African sleeping sickness (also known as Human African Trypanosomiasis - HAT), Chagas disease, leishmaniasis, toxoplasmosis, and malaria, cause significant morbidity and mortality worldwide. While antibiotic resistance continues to mount, a pressing issue is that some of these diseases have never benefited from adequate antibiotic availability in the first place. Such is the case for HAT, which is caused by infection with the parasitic protozoa, Trypanosoma brucei. Transmission of T. brucei between mammalian hosts occurs through an insect vector, the tsetse fly (genus Glossina). HAT is endemic to the region between the Sahara and Kalahari deserts, where $\sim 70$ million people are at risk of contracting the disease. ${ }^{1-4}$ Around 10,000 new cases of HAT are reported each year, although the actual number is likely much higher owing to insufficient reporting. ${ }^{5}$ Two sub-species of parasites are responsible for HAT: T. brucei gambiense and T. brucei rhodesiense. While the general symptoms of HAT are similar, the speed of disease progression differs markedly between the two organisms: T.b. gambiense causes a more gradual onset of symptoms over the course of months to years, while T.b. rhodesiense causes acute disease that progresses within weeks to months. ${ }^{5,6}$ Without treatment, both infections are fatal. Disease progression occurs in two stages. The first is termed the early, haemolymphatic stage, where parasites enter and spread in the bloodstream, lymph nodes, and systemic organs. Symptoms of this stage can include itching, fever, headaches, malaise, joint pains, and severe swelling of the lymph nodes. After a variable time period (weeks for T.b. rhodesiense and months for T.b. gambiense), parasites cross the blood-brain barrier and enter the central nervous system. Once this occurs, HAT is considered to be in the late, encephalitic stage, which is characterized by disruption of the sleep cycle and progressive mental deterioration leading to coma, systemic organ failure, and death.

None of the current drugs (Figure 1) are ideal for treating HAT as they all suffer from varying pharmacological deficiencies. While first line treatments of suramin (T.b. rhodesiense) or pentamidine (T.b. gambiense) are often effective for the early systemic stage of disease, they are ineffective against 
the later CNS stage once parasites have crossed the blood-brain barrier. ${ }^{5}$ Eflornithine, nifurtimox, and melarsoprol can treat CNS-stage T.b. gambiense infection, but only melarsoprol is effective against T.b. rhodesiense. Melarsoprol is itself toxic and leads to the death of $\sim 5 \%$ of patients. ${ }^{5,7,8}$ These drugs also have poor oral bioavailability, which necessitates frequent IV and/or IM injections. Unfortunately, no new drugs have been developed against T. brucei since the advent of eflornithine in the 1970s. Due to associated toxicities, the complexity of treatment regimens, and the rise of resistance to current HAT therapies, there is an urgent need to develop safe, effective, and easily administered treatments. ${ }^{9}$ Towards this goal, we are investigating modulating the protein homeostasis pathways of $T$. brucei as a viable antibiotic strategy.

Figure 1. Structures of drugs currently used to treat African sleeping sickness.
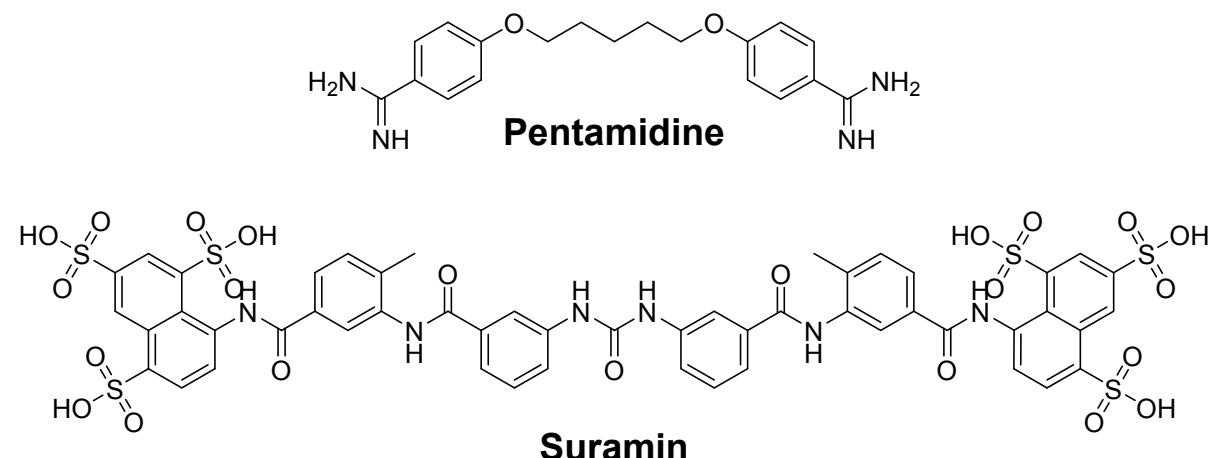

Suramin

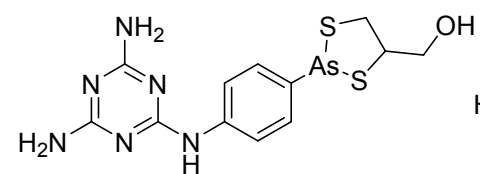

Melarsoprol

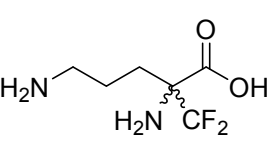

Eflornithine

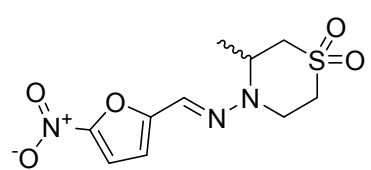

Nifurtimox

Molecular chaperones are key modulators of protein homeostasis as they are essential in helping many proteins fold into their functional forms and assist with their degradation. ${ }^{10-12}$ HSP60/10 chaperonins are unique members of the molecular chaperone family that are generally found in eukaryotic mitochondria and bacterial cytosol (also known as GroEL/ES). Through a series of events driven by ATP binding and hydrolysis, unfolded substrate proteins are bound within the central cavity of the HSP60 ring and encapsulated by the HSP10 co-chaperonin lid structure, triggering protein folding in 
a sequestered chamber. ${ }^{13-15}$ HSP60/10 chaperonins are viable antibiotic targets because cells rely on them to survive. ${ }^{16-19}$ Notably, many organisms have multiple HSP60 isoforms that they modulate to adapt to their environments. ${ }^{19-25}$ For instance, $T$. brucei have three HSP60 isoforms (Figure 2A). ${ }^{26,27}$ While studies have indicated that HSP60 is associated with the mitochondrial matrix, kinetoplast, and flagellar pocket of T. brucei, the distribution and function of each HSP60 isoform are not well characterized. ${ }^{25,28-30}$ However, recent studies have identified that expression of the HSP60 isoforms vary depending on the life cycle stage of the parasite and that depletion of each single variant can result in decreased growth and/or survival (Figure 2B). ${ }^{26,27}$ The HSP60.1 isoform appears to be the canonical chaperonin system in T. brucei since it is essential, while the 60.2 and 60.3 isoforms are not. ${ }^{26}$ This is further supported by the fact that only the HSP60.1 isoform contains the C-terminal GGM-repeat motif that is typically found in canonical chaperonin systems. ${ }^{23,28,31,32}$ Collectively, these results suggest that T. brucei may be susceptible to HSP60-targeting antibiotics. Targeting the HSP60/10 chaperonins for antibiotic development would be a unique polypharmacological strategy as one drug could potentially inhibit the three chaperonin isoforms and have the cascading effect of modulating hundreds of downstream proteins. Thus, it may be difficult for T. brucei to develop resistance to such a broadlyacting class of antibiotics.

Figure 2. A. Homology comparison of the three T. brucei HSP60 isoforms to E. coli GroEL (left) and the canonical T. brucei HSP60.1 isoform (right). Human mitochondrial HSP60 is also shown for comparison. AA = Amino Acids. B. Previous studies report that genetic knock-down of any of the three HSP60 isoforms inhibit parasite growth (normalized to uninduced control parasites). ${ }^{26}$

\begin{tabular}{lcc} 
A. & \multicolumn{2}{c}{$\%$ Identity (Similarity) Compared to: } \\
\cline { 2 - 3 } & E. coli GroEL & T. brucei HSP60.1 \\
\hline E. coli GroEL (548 AA) & $100 \%$ & $53 \%(69 \%)$ \\
T. brucei HSP60.1 (562 AA) & $53 \%(69 \%)$ & $100 \%$ \\
T. brucei HSP60.2 (541 AA) & $43 \%(59 \%)$ & $48 \%(66 \%)$ \\
T. brucei HSP60.3 (594 AA) & $40 \%(55 \%)$ & $55 \%(74 \%)$ \\
\hline Human HSP60 (547 AA) & $48 \%(61 \%)$ & $53 \%(73 \%)$ \\
\hline
\end{tabular}

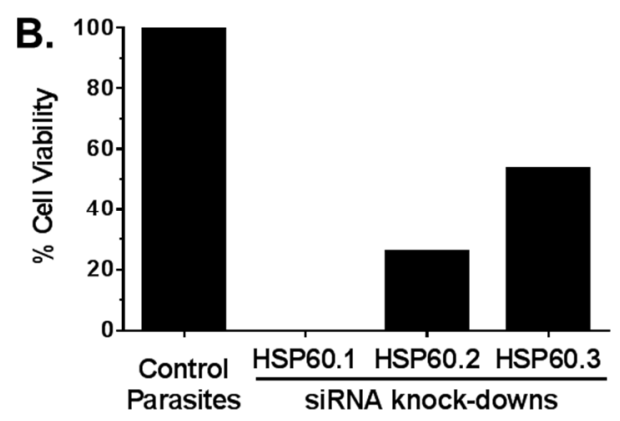


Figure 3. Compound 1 was an initial hit that emerged from our recent high-throughput screening for GroEL/ES inhibitors. ${ }^{33}$ Compound 2e-p is a related analog found in the PubChem database (CID \#1098316) that has reported bioactivity in only 8 of the 285 assays it has been evaluated in. ${ }^{34}$ One assay that $\mathbf{2 e - p}$ is reported active in is against Leishmania major promastigotes, which are parasites closely related to Trypanosoma brucei. Analogs of compound 2e-p under development herein retain the benzoxazole core, while exploring a variety of sulfonamide end-capping substructures $(\mathbf{R})$. Notes on compound nomenclature: i) the number corresponds to the alkyl or aryl group adjacent to the sulfonamide linker; ii) the letter corresponds to the substituent present on the phenyl group for the compound 2 series of analogs; and iii) $\boldsymbol{o}, \boldsymbol{m}$, and $\boldsymbol{p}$ correspond to ortho, meta, and para-positioning of the respective substituents on the phenyl rings.

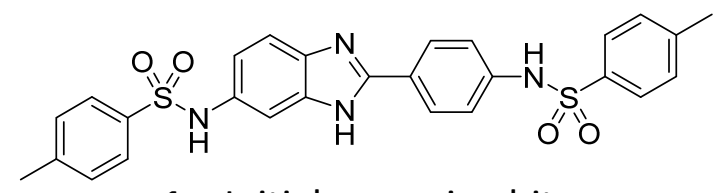

1 - Initial screening hit

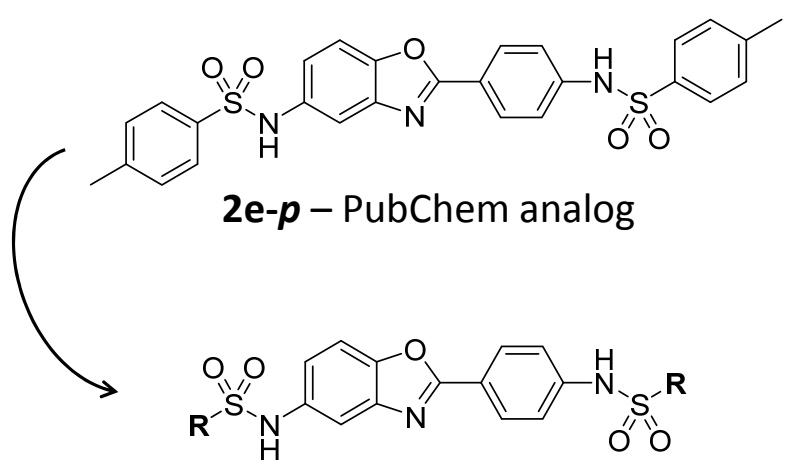

Analogs with variable sulfonamide end caps $(\mathbf{R})$

We previously performed high-throughput screening and discovered 235 small molecule inhibitors of the E. coli GroEL/ES chaperonin system. ${ }^{33}$ We have since found that several of our chaperonin inhibitors exhibit antibiotic effects against Gram-positive and Gram-negative bacteria. ${ }^{35}$ One of the most potent GroEL/ES inhibitors that we discovered was compound 1 (Figure 3), which inhibited both the substrate refolding and ATPase functions of the chaperonin system. ${ }^{33,35}$ Unfortunately, compound 1 was inactive against the panel of bacteria we tested against, suggesting it may not be a good candidate for antibacterial development. ${ }^{35}$ However, we found a related analog in the PubChem database where the benzimidazole core is replaced by a benzoxazole (Figure 3, compound 2e-p, PubChem CID \#1098316). ${ }^{34}$ While compound 2e-p has been evaluated in 285 assays, it was 
reported to be active in only 8 bioassays, suggesting this scaffold may be inherently selective and thus a promising candidate to explore for further drug development. Notably, 2e-p was reported as an active hit in a high-throughput screen for cytotoxic compounds against Leishmania major promastigotes. Because Leishmania are trypanosomatids highly related to Trypanosoma brucei, we postulated that compound 1 would also exhibit cytotoxicity to Trypanosoma brucei.

When we tested compound $\mathbf{1}$ in a well-established, $72 \mathrm{~h}$ cell viability assay employing the $T$. brucei brucei subspecies, we found that it elicited anti-parasitic affects $\left(\mathrm{EC}_{50} 7.9 \mu \mathrm{M}\right.$, Table 1) ${ }^{36,37}$ As controls for cell viability testing, we included the four primary HAT therapeutics pentamidine $\left(\mathrm{EC}_{50}<\right.$ $0.019 \mu \mathrm{M})$, suramin $\left(\mathrm{EC}_{50}=0.12 \mu \mathrm{M}\right)$, nifurtimox $\left(\mathrm{EC}_{50}=2.8 \mu \mathrm{M}\right)$, and eflornithine $\left(\mathrm{EC}_{50}>42 \mu \mathrm{M}\right)$. We note that for safety reasons, in these initial studies we tested hit-to-lead compounds against the $T$. brucei brucei subspecies, which infects animals but not humans, and not the T. brucei gambiense or rhodesiense strains that infect humans. However, we believe that the anti-parasitic effects of HSP60 inhibitors will likely translate to the human strains since this has been observed with other inhibitor classes. ${ }^{38-40}$ In addition, sequence alignments of the T. brucei brucei and T. brucei gambiense HSP60 isoforms obtained from the NCBI database indicate the HSP60.1 isoforms are identical between the two subspecies (as are HSP10), while the HSP60.2, and HSP60.3 isoforms differ by only two conservative amino acid substitutions each (sequences for the T. brucei rhodesiense HSP60 isoforms were not available) ${ }^{41}$ From our previous antibacterial testing, we found that compound $\mathbf{1}$ exhibited moderate cytotoxicity to human liver (THLE-3) and kidney (HEK 293) cell lines in an established cell culture assay that measures compound cytotoxicity over a $72 \mathrm{~h}$ time course. ${ }^{35}$ Therefore, in the present study, we developed a set of analogs to try to enhance their anti-parasitic effects against T. brucei while reducing off-target cytotoxicity to human liver and kidney cells. We synthesized two series of compound 1 analogs through simple coupling of sulfonyl chlorides with the 5-amino-2-(4aminophenyl)benzoxazole core (Scheme 1). ${ }^{42,43}$ The first series was designed to probe the effects of a 
variety of substituents and substitution patterns on the sulfonamide end-capping phenyl group (Table 1).

The second series was designed to probe what alkyl and aryl groups would be tolerated adjacent to the sulfonamide linkers (Table 2).

Scheme 1. General methods to synthesize inhibitor analogs. ${ }^{42,43}$ Coupling of sulfonyl chlorides with the 5-amino-2-(4-aminophenyl)benzoxazole core provided the primary bis-sulfonamide inhibitors. Three general secondary reactions were employed to further transform substituents: Series $\mathbf{2 h}-$ methoxy deprotection to hydroxyls; Series $\mathbf{2} \mathbf{j}$ - nitro reduction to amines; and Series $\mathbf{2} \mathbf{m}$ - ester hydrolysis to carboxylic acids. Refer to the Supporting Information for protocols and characterization data for specific compounds.

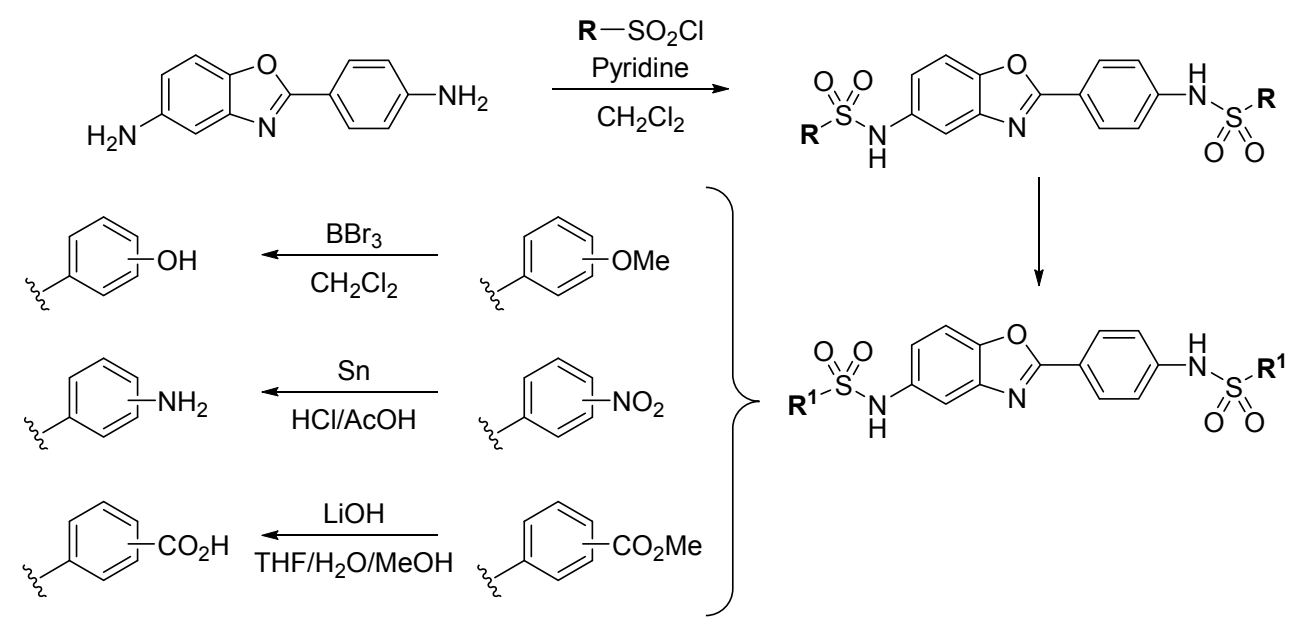


Table 1. Biochemical $\mathrm{IC}_{50}$ and cell viability $\mathrm{EC}_{50}$ results for chaperonin inhibitors based on the compound $\mathbf{2}$ scaffold where $\mathbf{R}=$ phenyl with variable ortho, meta, and para-substituents as presented. Results for the common HAT drugs are shown for comparison.

\begin{tabular}{|c|c|c|c|c|c|c|c|c|c|c|}
\hline & & & \multicolumn{5}{|c|}{ Biochemical Assay IC ${ }_{50}$ Results $(\mu M)$} & \multicolumn{3}{|c|}{ Cell Viability $E C_{50}$ Results $(\mu M)$} \\
\hline \multirow{2}{*}{\multicolumn{3}{|c|}{$\begin{array}{c}\text { Compound \& } \\
\text { Substituent }\end{array}$}} & \multirow{2}{*}{$\begin{array}{l}\text { Native MDH } \\
\text { Reporter }\end{array}$} & \multicolumn{2}{|c|}{ GroEL/ES-dMDH } & \multicolumn{2}{|c|}{ HSP60/10-dMDH } & \multirow{3}{*}{$\begin{array}{c}\text { T. brucei } \\
7.9\end{array}$} & \multirow{3}{*}{$\begin{array}{c}\begin{array}{c}\text { THLE3 } \\
\text { (Liver) }\end{array} \\
29\end{array}$} & \multirow{3}{*}{$\begin{array}{c}\text { HEK 293 } \\
\text { (Kidney) }\end{array}$} \\
\hline & & & & Refolding & ATPase & Refolding & ATPase & & & \\
\hline$-\mathrm{CH}_{3}$ & 1 & & $>63$ & 21 & 132 & 89 & 106 & & & \\
\hline \multirow[t]{2}{*}{$-H$} & $2 a$ & & $>63$ & 3.9 & 4.6 & $>100$ & $>250$ & 6.4 & 19 & 15 \\
\hline & & -0 & $>63$ & 22 & $>250$ & 77 & $>250$ & 19 & 55 & 31 \\
\hline \multirow[t]{3}{*}{$-F$} & $2 b$ & $-m$ & $>63$ & 5.3 & 5.1 & 68 & $>250$ & 10 & 20 & 24 \\
\hline & & $-p$ & $>63$ & 3.8 & 4.3 & $>100$ & $>250$ & 4.3 & 19 & 21 \\
\hline & & -0 & $>63$ & 46 & 131 & $>100$ & $>250$ & 5.9 & 24 & 75 \\
\hline \multirow[t]{3}{*}{$-\mathrm{Cl}$} & $2 c$ & $-m$ & $>63$ & 18 & $>250$ & $>100$ & $>250$ & 4.5 & 17 & 21 \\
\hline & & $-p$ & $>63$ & 23 & 35 & 96 & $>250$ & 3.2 & 18 & 13 \\
\hline & & -0 & $>63$ & 63 & 144 & $>100$ & $>250$ & 28 & 37 & 28 \\
\hline \multirow[t]{3}{*}{$-\mathrm{Br}$} & $2 d$ & $-m$ & $>63$ & 23 & 45 & $>100$ & $>250$ & 8.0 & 21 & 25 \\
\hline & & $-p$ & $>63$ & 24 & 19 & $>100$ & $>250$ & 2.4 & 16 & 22 \\
\hline & & -0 & $>63$ & $>100$ & 194 & $>100$ & $>250$ & 1.8 & 17 & 25 \\
\hline \multirow[t]{3}{*}{$-\mathrm{CH}_{3}$} & $2 e$ & $-m$ & $>63$ & 35 & $>250$ & $>100$ & $>250$ & 4.9 & 18 & 65 \\
\hline & & $-p$ & $>63$ & 36 & 46 & $>100$ & $>250$ & 3.1 & 11 & 71 \\
\hline & & -0 & $>63$ & 25 & 21 & $>100$ & $>250$ & 28 & 50 & 66 \\
\hline \multirow[t]{3}{*}{$-\mathrm{CF}_{3}$} & $2 f$ & $-m$ & $>63$ & 15 & 216 & $>100$ & $>250$ & 4.8 & 19 & 15 \\
\hline & & $-p$ & $>63$ & 35 & $>250$ & 61 & $>250$ & 4.1 & 21 & $>100$ \\
\hline & & -0 & $>63$ & 69 & $>250$ & $>100$ & $>250$ & 2.7 & $>100$ & 79 \\
\hline \multirow[t]{3}{*}{$-\mathrm{OCH}_{3}$} & $2 g$ & $-m$ & $>63$ & 48 & $>250$ & $>100$ & $>250$ & 5.1 & 15 & 28 \\
\hline & & $-p$ & $>63$ & 36 & 84 & $>100$ & $>250$ & 3.3 & $>100$ & 88 \\
\hline & & -0 & 33 & 7.5 & 36 & 13 & 33 & 5.0 & 19 & 18 \\
\hline \multirow[t]{3}{*}{$-\mathrm{OH}$} & $2 \mathrm{~h}$ & $-m$ & 47 & 0.90 & 0.79 & 19 & 61 & 8.9 & 37 & 36 \\
\hline & & $-p$ & 50 & 0.34 & 0.31 & 11 & 59 & 21 & 41 & 38 \\
\hline & & -0 & $>63$ & 3.6 & 3.1 & 75 & 194 & $>42$ & 93 & 60 \\
\hline \multirow[t]{3}{*}{$-\mathrm{NO}_{2}$} & $2 \mathbf{i}$ & $-m$ & $>63$ & 11 & $>250$ & 60 & $>250$ & 11 & 37 & 46 \\
\hline & & $-p$ & $>63$ & 26 & $>250$ & 65 & $>250$ & 15 & 36 & 59 \\
\hline & & -0 & $>63$ & 10 & $>250$ & $>100$ & $>250$ & 3.3 & 18 & 14 \\
\hline \multirow[t]{3}{*}{$-\mathrm{NH}_{2}$} & $2 j$ & $-m$ & $>63$ & 2.8 & 9.6 & 87 & 127 & 15 & 30 & 58 \\
\hline & & $-p$ & $>63$ & 1.4 & 1.7 & 68 & 224 & 22 & 38 & 59 \\
\hline & & -0 & $>63$ & 32 & $>250$ & 86 & 193 & 23 & 93 & 74 \\
\hline \multirow[t]{3}{*}{$-\mathrm{CN}$} & $2 k$ & $-m$ & $>63$ & 7.6 & 4.1 & 91 & $>250$ & 39 & 91 & 45 \\
\hline & & $-p$ & $>63$ & 37 & $>250$ & 64 & $>250$ & 16 & 79 & 45 \\
\hline & & -0 & $>63$ & 36 & 53 & $>100$ & $>250$ & 28 & $>100$ & $>100$ \\
\hline \multirow[t]{3}{*}{$-\mathrm{CO}_{2} \mathrm{CH}_{3}$} & 2I & $-m$ & $>63$ & 11 & $>250$ & 95 & $>250$ & $>42$ & 49 & $>100$ \\
\hline & & $-p$ & $>63$ & 26 & 91 & 87 & $>250$ & 23 & $>100$ & $>100$ \\
\hline & & -0 & $>63$ & $>100$ & $>250$ & $>100$ & $>250$ & $>42$ & $>100$ & $>100$ \\
\hline$-\mathrm{CO}_{2} \mathrm{H}$ & $2 m$ & $-m$ & 41 & 61 & $>250$ & 81 & $>250$ & $>42$ & $>100$ & $>100$ \\
\hline & & $-p$ & $>63$ & 83 & $>250$ & $>100$ & $>250$ & $>42$ & $>100$ & $>100$ \\
\hline Pentamic & & & $>63$ & $>100$ & $>250$ & $>100$ & $>250$ & $<0.019$ & 19 & $>100$ \\
\hline Suram & & & $>63$ & 7.9 & $>250$ & 11 & $>250$ & 0.12 & $>100$ & $>100$ \\
\hline Nifurtim & & & $>63$ & $>100$ & $>250$ & $>100$ & $>250$ & 2.8 & $>100$ & $>100$ \\
\hline Eflornith & & & $>63$ & $>100$ & $>250$ & $>100$ & $>250$ & $>42$ & $>100$ & $>100$ \\
\hline
\end{tabular}


Table 2. Biochemical $\mathrm{IC}_{50}$ and cell viability $\mathrm{EC}_{50}$ results for chaperonin inhibitors where the sulfonamide end-capping $\mathbf{R}$-groups are variable alkyl and aryl substructures as presented.

\begin{tabular}{|c|c|c|c|c|c|c|c|c|c|}
\hline \multirow{3}{*}{\multicolumn{2}{|c|}{$\begin{array}{l}\text { Compound \& } \\
\text { Substructures }\end{array}$}} & \multicolumn{5}{|c|}{ Biochemical Assay $I C_{50}$ Results ( $\left.\mu M\right)$} & \multicolumn{3}{|c|}{ Cell Viability $E C_{50}$ Results $(\mu M)$} \\
\hline & & \multirow{2}{*}{$\begin{array}{l}\text { Native MDH } \\
\text { Reporter }\end{array}$} & \multicolumn{2}{|c|}{ GroEL/ES-dMDH } & \multicolumn{2}{|c|}{ HSP60/10-dMDH } & \multirow{2}{*}{ T. brucei } & \multirow{2}{*}{$\begin{array}{l}\text { THLE3 } \\
\text { (Liver) }\end{array}$} & \multirow{2}{*}{$\begin{array}{l}\text { HEK } 293 \\
\text { (Kidney) }\end{array}$} \\
\hline & & & Refolding & ATPase & Refolding & ATPase & & & \\
\hline & $2 a$ & $>63$ & 3.9 & 4.6 & $>100$ & $>250$ & 6.4 & 19 & 15 \\
\hline & 3 & $>63$ & $>100$ & $>250$ & $>100$ & $>250$ & $>42$ & $>100$ & $>100$ \\
\hline & 4 & $>63$ & 40 & $>250$ & 97 & $>250$ & $>42$ & $>100$ & $>100$ \\
\hline & 5 & $>63$ & $>100$ & $>250$ & $>100$ & $>250$ & 18 & $>100$ & $>100$ \\
\hline & 6 & $>63$ & 4.6 & 6.7 & 57 & $>250$ & 17 & 44 & 26 \\
\hline & 7 & $>63$ & 55 & 208 & $>100$ & $>250$ & 13 & 29 & 19 \\
\hline & 8 & $>63$ & 32 & $>250$ & 66 & 212 & $>42$ & 58 & 45 \\
\hline & 9 & $>63$ & 22 & 127 & 98 & 152 & $>42$ & $>100$ & 52 \\
\hline & 10 & $>63$ & 23 & 54 & $>100$ & 144 & 2.1 & 69 & $>100$ \\
\hline & 11 & $>63$ & 3.7 & 1.7 & 62 & 127 & $>42$ & 45 & 76 \\
\hline & 12 & $>63$ & 0.81 & 0.55 & 49 & $>250$ & 25 & 30 & 95 \\
\hline & 13 & $>63$ & 40 & 67 & $>100$ & 127 & 3.7 & 55 & $>100$ \\
\hline & 14 & $>63$ & 18 & 83 & 70 & 201 & $>42$ & $>100$ & $>100$ \\
\hline
\end{tabular}

We found that the T. brucei HSP60 chaperonins could not be readily obtained from $E$. coli expression systems as they formed intractable inclusion bodies. Thus, we used E. coli GroEL/ES as a surrogate and tested compounds using our two primary biochemical assays that evaluate for inhibition of GroEL/ES-dMDH refolding and ATPase activity over time. ${ }^{35}$ These assays employed $50 \mathrm{nM}$ of GroEL oligomer (700 nM monomeric subunits) and physiological concentrations of ATP (1 mM), and thus low to sub- $\mu \mathrm{M} \mathrm{IC}_{50}$ values indicate very potent inhibitors that are functioning at near stoichiometric 
concentrations. Of the 49 new analogs, 39\% are more potent than the initial compound 1 hit (Tables 1 and 2). Aryl groups adjacent to the sulfonamide linkers generally provide the most potent GroEL/ES inhibitors. We believe the compounds directly interact with GroEL as they do not inhibit the native MDH reporter reaction (Figure 4A). Furthermore, there is a strong correlation between inhibiting the refolding and ATPase functions of the chaperonin system (Figure 4B), suggesting compounds may bind to the ATP sites of GroEL. Consistent with binding to the ATP pockets, series $\mathbf{2} \mathbf{h}$ and $\mathbf{2} \mathbf{j}$ are the most potent inhibitors as their $-\mathrm{OH}$ and $-\mathrm{NH}_{2}$ groups putatively hydrogen bond with the catalytic D398 aspartate, while series $\mathbf{2 m}$ inhibitors are the least effective putatively owing to charge-charge repulsion of their carboxylates with the D398 aspartate. Binding in such a mode would also position one of the sulfonamide linkers in proximity to mimic a phosphate group of ATP; however, the requirement of the sulfonamide linkers for potent inhibition remains to be determined. While we included the four primary HAT therapeutics pentamidine, suramin, nifurtimox, and eflornithine as putative negative controls in our biochemical assays, we were surprised to find that suramin actually inhibits the E. coli GroEL/ES chaperonin system. This result could have profound implications on suramin's mechanism of action against $T$. brucei parasites.

Figure 4. A. Compounds selectively inhibit in the E. coli GroEL/ES-dMDH refolding assay without targeting the native $\mathrm{MDH}$ reporter reaction. B. A strong correlation between $\mathrm{IC}_{50}$ values for the GroEL/ES-dMDH refolding and ATPase assays suggests the compounds interact directly with the chaperonin system, and are putatively binding to the ATP pockets. C. Chaperonin inhibitors are cytotoxic to T. brucei parasites. Correlation plots include data from compounds in both Table 1 (black circles) and Table 2 (white circles). Data plotted in the grey zones represent results beyond the assay detection limits (i.e. $>100 \mu \mathrm{M}$ for the GroEL/ES-dMDH refolding assay, $>63 \mu \mathrm{M}$ for the native $\mathrm{MDH}$ activity assay, $>250 \mu \mathrm{M}$ for the chaperonin-mediated ATPase assay, and $>42 \mu \mathrm{M}$ for the $T$. brucei cell viability assay). Results for suramin (grey square), which is a HAT drug that was found to be a potent GroEL/ES inhibitor, are shown for comparison. 
A.

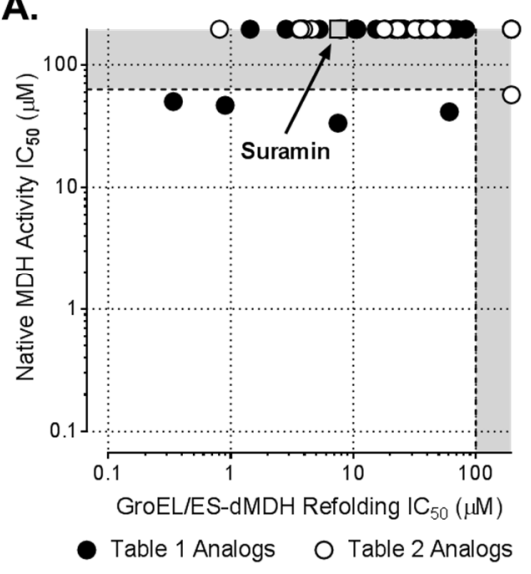

B.

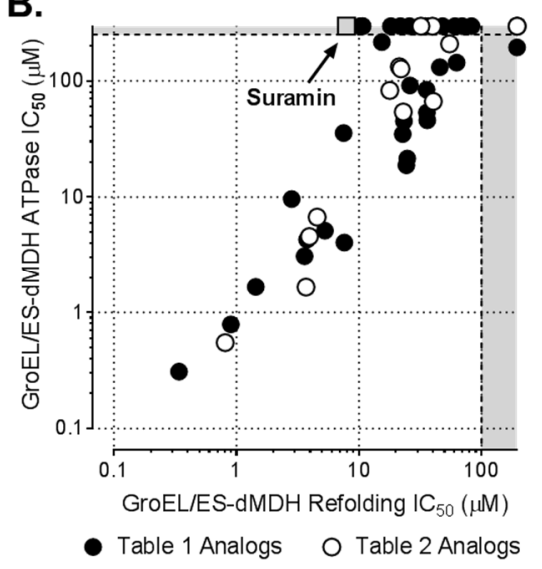

C.

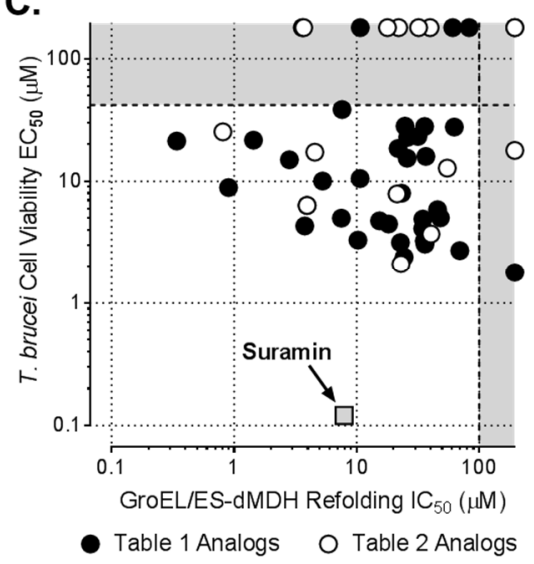

We next evaluated chaperonin inhibitors for their ability to block the proliferation of T. brucei brucei parasites and found that most of the compounds are cytotoxic (Figure 4C). The scatter in the correlation between $\mathrm{IC}_{50} / \mathrm{EC}_{50}$ values could indicate that compounds hit another target in addition to the HSP60/10 chaperonin systems in parasites. It could also be that $E$. coli GroEL/ES is not a suitable surrogate to test with in lieu of the three T. brucei HSP60/10 systems. For instance, compounds may exhibit variable structure-activity relationships (SAR) against each of the three T. brucei HSP60 isoforms, which siRNA knock-down studies suggest would have differing effects on parasite viability. ${ }^{26}$ In addition, localization differences between the three T. brucei HSP60 isoforms could significantly influence inhibitor effects against each and further complicate cytotoxicity profiles. We will investigate inhibitor mechanisms of action in parasites in future studies.

Through counter-screening against human mitochondrial HSP60/10, using procedures analogous to the GroEL/ES-based assays, we found that inhibitors are highly selective for bacterial GroEL/ES (Figure 5A). However, the high selectivity we observe raises the question of why do these compounds not inhibit human HSP60 more potently than they do, considering E. coli GroEL and human HSP60 share $\sim 95 \%$ amino acid identity in their ATP binding sites. We postulate this could be because these inhibitors bind to the trans-ring ATP pockets and allosterically lock up the double-ring GroEL, which functions through an obligate, two-stroke mechanism. This unique mode of inhibition would not be possible with human HSP60, which likely functions through a single-ring mechanism. ${ }^{44-46}$ While we 
hoped that the lack of inhibition of human mitochondrial HSP60/10 in vitro would translate to low cytotoxicity to human cells, we found that many compounds are still moderately toxic to human liver (THLE-3) and kidney (HEK 293) cells (Figure 5B). That many compounds are cytotoxic despite their being poor inhibitors of human HSP60/10 may suggest off-target effects in human cells. We will identify potential off-target pathways that these inhibitors could be modulating in future studies.

Figure 5. A. Compounds selectively inhibit the refolding cycles of the E. coli GroEL/ES over the human HSP60/10 chaperonin system. B. Many compounds exhibit moderate cytotoxicity to human liver and kidney cell lines, even though they do not inhibit the HSP60/10 refolding cycle in vitro. C. Compounds are generally more cytotoxic to $T$. brucei parasites over human liver and kidney cells. Data plotted in the grey zones represent results beyond the assay detection limits (i.e. $>100 \mu \mathrm{M}$ for the chaperonin-mediated dMDH refolding assays, $>100 \mu \mathrm{M}$ for the human liver and kidney cell cytotoxicity assays, and $>42 \mu \mathrm{M}$ for the $T$. brucei cell viability assay). Correlation plots include data from both Table 1 and 2 compounds.
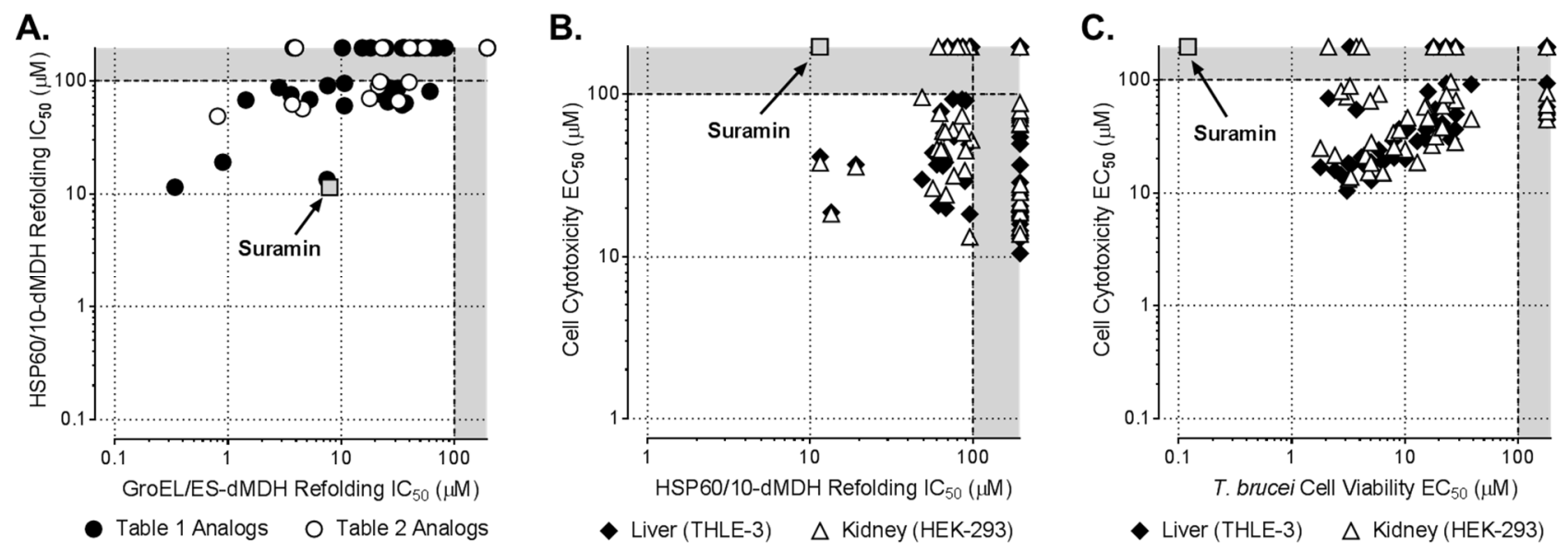

While a general trend is noted when comparing cytotoxicity of compounds to T. brucei parasites with human liver and kidney cells (Figure 5C), we found that inhibitors are usually more selective for the parasites. A few compounds exhibit moderate to high selectivity for parasites over human cells: e.g.

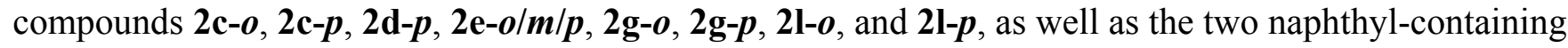
analogs, 10 and 13. Intriguingly, it appears that substituents extending outwards from the ortho and para-positions on the phenyl ring could provide an advantage for selectively targeting $T$. brucei parasites over human liver and kidney cells. These studies have importantly provided structural leads that we can pursue in future optimization studies. We will investigate how adding a variety of 
substituents to these and other aryls, as well as altering the sulfonamide linkers and the 2phenylbenzoxazole core, will affect inhibitor potency and selectivity in future studies. We appreciate that lead inhibitors are pushing the higher limits of the Lipinski criteria (e.g. compound $\mathbf{1 0}$ has a MW of $606 \mathrm{~g} / \mathrm{mol}$ and $\operatorname{clog} \mathrm{P}$ of 7.3); therefore, to develop lead candidates that overcome the pharmacological deficiencies of current HAT therapeutics, we will also need to investigate inhibitor oral bioavailability, blood-brain barrier permeability, metabolic stability, and pharmacokinetic/pharmacodynamics profiles in vitro and in vivo.

In conclusion, we have developed a new series of chaperonin inhibitors that exhibit antibiotic effects against Trypanosoma brucei parasites in cell culture. While many of these initial analogs exhibit moderate cytotoxicity to human liver and kidney cells, the SAR generated from this study has provided valuable guidance on molecular substructures to pursue for increasing the therapeutic windows of these chaperonin-targeting antibiotic candidates. We are also exploring additional hits from our previous GroEL/ES high-throughput screening to identify alternative scaffolds that selectively kill $\mathrm{T}$. brucei parasites. One of the most significant findings from this study is that the first-line therapeutic for African sleeping sickness, suramin, also inhibits both E. coli GroEL/ES and human HSP60/10. This suggests that suramin can inhibit one or all of the three T. brucei HSP60 isoforms in parasites; however, this may not be suramin's primary mechanism of action as it has been found to interact with several biological pathways. ${ }^{47-53}$ Indeed, suramin's promiscuity against several different targets (i.e. polypharmacological effects) may be why this drug has been successful against $T$. brucei parasites for the past 100 years. It will be intriguing to investigate the contribution that inhibiting the three $T$. brucei HSP60 isoforms makes to the antibiotic efficacy of suramin. Importantly, these new findings further support accumulating evidence that chaperonin-targeting drugs can be developed even though they may inhibit human HSP60/10 biochemical functions in vitro. While we are using T. brucei as the model 
parasite to identify the viability of a chaperonin-targeting antibiotic strategy, our studies will open the possibility of targeting the chaperonin systems of a wide range of eukaryotic pathogens.

Supporting Information: Supporting information associated with this article can be found in the online version, which includes tabulations of $\log \left(\mathrm{IC}_{50}\right)$ and $\log \left(\mathrm{EC}_{50}\right)$ results with standard deviations; experimental protocols for biochemical and cell-based assays; synthetic protocols and ${ }^{1} \mathrm{H}-\mathrm{NMR}, \mathrm{LC}-$ MS, and HPLC characterization data for all compounds.

Acknowledgments: We thank Dr. Marilyn Parsons from the Center for Infectious Disease Research (Seattle, WA, USA) for providing the T. brucei brucei genomic DNA that was used for cloning the HSP60 and HSP10 genes. This work was supported by an IU Biomedical Research Grant (SJ), an IU Collaborative Research Grant (SJ), startup funds from the IU School of Medicine (SJ) and the University of Arizona (EC), and the Howard Hughes Medical Institute (AH and SJ). 


\section{References:}

1. Simarro, P. P.; Cecchi, G.; Franco, J. R.; Paone, M.; Diarra, A.; Ruiz-Postigo, J. A.; Fevre, E. M.; Mattioli, R. C.; Jannin, J. G. Plos Neglect Trop D 2012, 6.

2. Rogers, D. J.; Hay, S. I.; Packer, M. J. Ann Trop Med Parasit 1996, 90, 225.

3. Hotez, P. J.; Molyneux, D. H.; Fenwick, A.; Kumaresan, J.; Sachs, S. E.; Sachs, J. D.; Savioli, L. New Engl J Med 2007, 357, 1018.

4. Fevre, E. M.; Picozzi, K.; Jannin, J.; Welburn, S. C.; Maudlin, I. Adv Parasitol 2006, 61, 167.

5. Kennedy, P. G. Lancet Neurol 2013, 12, 186.

6. Franco, J. R.; Simarro, P. P.; Diarra, A.; Jannin, J. G. Clin Epidemiol 2014, 6, 257.

7. Jacobs, R. T.; Nare, B.; Phillips, M. A. Curr Top Med Chem 2011, 11, 1255.

8. Priotto, G.; Kasparian, S.; Ngouama, D.; Ghorashian, S.; Arnold, U.; Ghabri, S.; Karunakara, U. Clin Infect Dis 2007, 45, 1435.

9. Ferrins, L.; Rahmani, R.; Baell, J. B. Future Med Chem 2013, 5, 1801.

10. Horwich, A. L. Cell 2014, 157, 285.

11. Hartl, F. U.; Bracher, A.; Hayer-Hartl, M. Nature 2011, 475, 324.

12. Saibil, H. Nat Rev Mol Cell Biol 2013, 14, 630.

13. Fenton, W. A.; Kashi, Y.; Furtak, K.; Horwich, A. L. Nature 1994, 371, 614.

14. Fenton, W. A.; Horwich, A. L. Protein science : a publication of the Protein Society 1997, 6, 743.

15. Horwich, A. L.; Farr, G. W.; Fenton, W. A. Chemical reviews 2006, 106, 1917.

16. Neckers, L.; Tatu, U. Cell Host Microbe 2008, 4, 519.

17. Alsford, S.; Turner, D. J.; Obado, S. O.; Sanchez-Flores, A.; Glover, L.; Berriman, M.; Hertz-Fowler, C.; Horn, D. Genome Res 2011, 21, 915.

18. Ojha, A.; Anand, M.; Bhatt, A.; Kremer, L.; Jacobs, W. R., Jr.; Hatfull, G. F. Cell 2005, 123, 861.

19. Hu, Y. M.; Henderson, B.; Lund, P. A.; Tormay, P.; Ahmed, M. T.; Gurcha, S. S.; Besra, G. S.; Coates, A. R. M. Infect Immun 2008, 76, 1535.

20. Zhang, X. B.; Cui, J. A.; Nilsson, D.; Gunasekera, K.; Chanfon, A.; Song, X. F.; Wang, H. N.; Xu, Y.; Ochsenreiter, T. Nucleic Acids Res 2010, 38, 7378.

21. Kong, T. H.; Coates, A. R. M.; Butcher, P. D.; Hickman, C. J.; Shinnick, T. M. Proceedings of the National Academy of Sciences of the United States of America 1993, 90, 2608.

22. Lund, P. A. Adv Microb Physiol 2001, 44, 93.

23. Kumar, C. M. S.; Mande, S. C.; Mahajan, G. Cell stress \& chaperones 2015, 20, 555.

24. Rao, T.; Lund, P. A. Fems Microbiol Lett 2010, 310, 24.

25. Folgueira, C.; Requena, J. M. Fems Microbiol Rev 2007, 31, 359.

26. Alsford, S.; Turner, D. J.; Obado, S. O.; Sanchez-Flores, A.; Glover, L.; Berriman, M.; Hertz-Fowler, C.; Horn, D. Genome Res 2011, 21, 915.

27. Zhang, X.; Cui, J.; Nilsson, D.; Gunasekera, K.; Chanfon, A.; Song, X.; Wang, H.; Xu, Y.; Ochsenreiter, T. Nucleic Acids Res 2010, 38, 7378.

28. Bringaud, F.; Peyruchaud, S.; Baltz, D.; Giroud, C.; Simpson, L.; Baltz, T. Mol Biochem Parasitol 1995, 74, 119.

29. Radwanska, M.; Magez, S.; Michel, A.; Stijlemans, B.; Geuskens, M.; Pays, E. Infect Immun 2000, 68, 848.

30. Radwanska, M.; Magez, S.; Dumont, N.; Pays, A.; Nolan, D.; Pays, E. Parasite Immunol 2000, 22, 639.

31. Colaco, C. A.; MacDougall, A. Fems Microbiol Lett 2014, 350, 20.

32. Brocchieri, L.; Karlin, S. Protein Science 2000, 9, 476.

33. Johnson, S. M.; Sharif, O.; Mak, P. A.; Wang, H. T.; Engels, I. H.; Brinker, A.; Schultz, P. G.; Horwich, A. L.; Chapman, E. Bioorganic \& medicinal chemistry letters 2014, 24, 786.

34. NCBI. PubChem Compound Database; CID=1098316, https://pubchem.ncbi.nlm.nih.gov/compound/1098316 (accessed Aug. 3, 2016).

35. Abdeen, S.; Salim, N.; Mammadova, N.; Summers, C. M.; Frankson, R.; Ambrose, A. J.; Anderson, G. G.; Schultz, P. G.; Horwich, A. L.; Chapman, E.; Johnson, S. M. Bioorganic \& medicinal chemistry letters 2016, 26, 3127. 
36. Sykes, M. L.; Baell, J. B.; Kaiser, M.; Chatelain, E.; Moawad, S. R.; Ganame, D.; loset, J. R.; Avery, V. M. PLoS Negl Trop Dis 2012, 6, e1896.

37. Sykes, M. L.; Avery, V. M. Am J Trop Med Hyg 2009, 81, 665.

38. Kaminsky, R.; Brun, R. Antimicrob Agents Ch 1998, 42, 2858.

39. Wenzler, T.; Boykin, D. W.; Ismail, M. A.; Hall, J. E.; Tidwell, R. R.; Brun, R. Antimicrob Agents Chemother 2009, 53, 4185.

40. Torreele, E.; Bourdin Trunz, B.; Tweats, D.; Kaiser, M.; Brun, R.; Mazue, G.; Bray, M. A.; Pecoul, B. PLoS Negl Trop Dis 2010, 4, e923.

41. Coordinators, N. R. Nucleic Acids Res 2016, 44, D7.

42. Johnson, S. M.; Connelly, S.; Wilson, I. A.; Kelly, J. W. Journal of medicinal chemistry 2008, 51, 6348.

43. Johnson, S. M.; Connelly, S.; Wilson, I. A.; Kelly, J. W. Journal of medicinal chemistry 2009, 52, 1115.

44. Nielsen, K. L.; McLennan, N.; Masters, M.; Cowan, N. J. Journal of bacteriology 1999, 181, 5871.

45. Nielsen, K. L.; Cowan, N. J. Molecular cell 1998, 2, 93.

46. Illingworth, M.; Ramsey, A.; Zheng, Z. D.; Chen, L. L. Journal of Biological Chemistry 2011, 286, 30401.

47. Barrett, M. P.; Boykin, D. W.; Brun, R.; Tidwell, R. R. Br J Pharmacol 2007, 152, 1155.

48. Zhang, Y. L.; Keng, Y. F.; Zhao, Y.; Wu, L.; Zhang, Z. Y. Journal of Biological Chemistry 1998, 273, 12281.

49. Hanau, S.; Rippa, M.; Bertelli, M.; Dallocchio, F.; Barrett, M. P. Eur J Biochem 1996, 240, 592.

50. Fairlamb, A. H.; Bowman, I. B. Mol Biochem Parasitol 1980, 1, 315.

51. Perie, J.; Riviere-Alric, I.; Blonski, C.; Gefflaut, T.; Lauth de Viguerie, N.; Trinquier, M.; Willson, M.; Opperdoes, F. R.; Callens, M. Pharmacol Ther 1993, 60, 347.

52. Willson, M.; Callens, M.; Kuntz, D. A.; Perie, J.; Opperdoes, F. R. Mol Biochem Parasitol 1993, 59, 201.

53. Wang, C. C. Annu Rev Pharmacol Toxicol 1995, 35, 93. 


\section{Supporting Information}

Targeting the HSP60/10 chaperonin systems of Trypanosoma brucei as a strategy for treating African sleeping sickness.

Sanofar Abdeen, Nilshad Salim, Najiba Mammadova, Corey M. Summers, Karen Goldsmith-Pestana, Diane McMahon-Pratt, Peter G. Schultz, Arthur L. Horwich, Eli Chapman, and Steven M. Johnson

*Correspondence: johnstm@iu.edu, Tel: 317-274-2458, Fax: 317-274-4686 
Table S1: Log-transformed values for Table 1 IC $_{50}$ and $\mathbf{E C}_{50}$ results .............................. S3

Table S2: Log-transformed values for Table $2 \mathrm{IC}_{50}$ and $\mathrm{EC}_{50}$ results .............................. S4

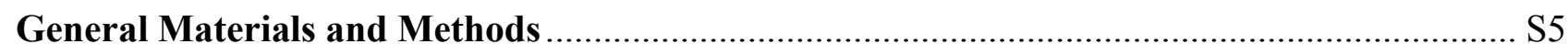

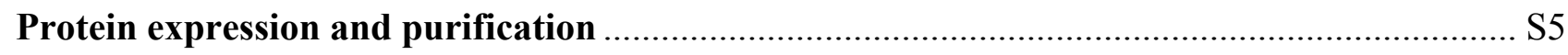

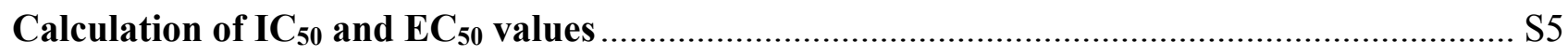

GroEL/ES and HSP60/10-mediated dMDH refolding assay protocols ................................ S5

Native MDH enzymatic activity counter-screen assay protocol ......................................... S6

Chaperonin-dependent ATPase activity assay protocol.................................................. S6

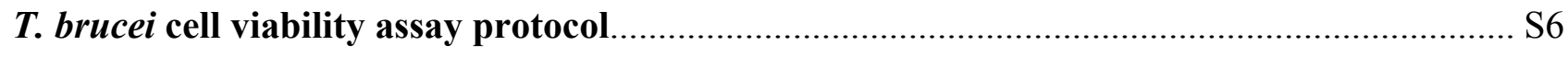

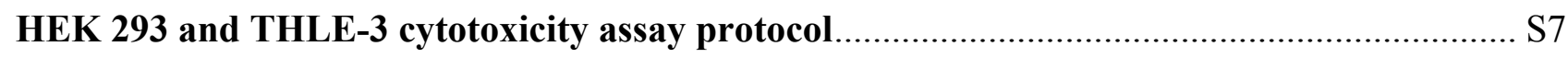

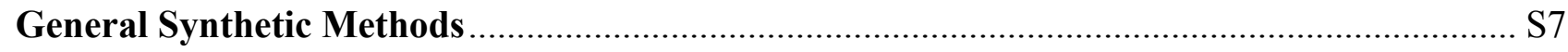

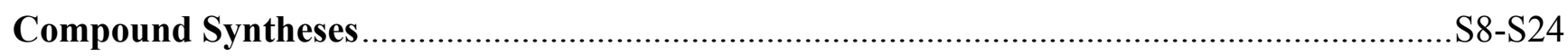

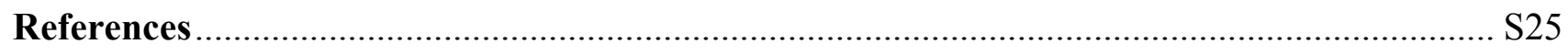


Table S1. Log-transformed values for Table $1 \mathbf{I C}_{50}$ and $\mathbf{E C}_{50}$ results. Results are presented as $\log _{\text {(IC }}$ ( $\mathrm{C}_{50}$ or $\left.\mathrm{EC}_{50} / \mu \mathrm{M}\right)$ values \pm their standard deviations (SD).

\begin{tabular}{|c|c|c|c|c|c|c|c|c|c|c|}
\hline & & & \multicolumn{5}{|c|}{ Biochemical Assay IC ${ }_{50}$ Results $(\mu M)$} & \multicolumn{3}{|c|}{ Cell Viability $E C_{50}$ Results $(\mu M)$} \\
\hline \multirow{2}{*}{\multicolumn{3}{|c|}{$\begin{array}{c}\text { Compound \& } \\
\text { Substituent }\end{array}$}} & \multirow{2}{*}{$\begin{array}{c}\text { Native MDH } \\
\text { Reporter }\end{array}$} & \multicolumn{2}{|c|}{ GroEL/ES-dMDH } & \multicolumn{2}{|c|}{ HSP60/10-dMDH } & \multirow{2}{*}{ T. brucei } & \multirow{2}{*}{$\begin{array}{l}\text { THLE3 } \\
\text { (Liver) }\end{array}$} & \multirow{2}{*}{$\begin{array}{l}\text { HEK } 293 \\
\text { (Kidney) }\end{array}$} \\
\hline & & & & Refolding & ATPase & Refolding & ATPase & & & \\
\hline$-\mathrm{CH}_{3}$ & $1 e$ & $-p$ & $>1.8$ & $1.33 \pm 0.68$ & $2.12 \pm 0.10$ & $1.95 \pm 0.08$ & $2.02 \pm 0.16$ & $0.90 \pm 0.11$ & $1.47 \pm 0.23$ & $1.53 \pm 0.24$ \\
\hline \multirow[t]{2}{*}{$-\mathrm{H}$} & $2 a$ & & $>1.8$ & $0.60 \pm 0.33$ & $0.66 \pm 0.06$ & $>2$ & $>2.4$ & $0.80 \pm 0.08$ & $1.28 \pm 0.02$ & $1.18 \pm 0.13$ \\
\hline & & -0 & $>1.8$ & $1.34 \pm 0.27$ & $>2.4$ & $1.88 \pm 0.12$ & $>2.4$ & $1.27 \pm 0.04$ & $1.74 \pm 0.05$ & $1.50 \pm 0.03$ \\
\hline \multirow[t]{3}{*}{$-F$} & $2 b$ & $-m$ & $>1.8$ & $0.72 \pm 0.17$ & $0.71 \pm 0.06$ & $1.83 \pm 0.13$ & $>2.4$ & $1.00 \pm 0.09$ & $1.30 \pm 0.04$ & $1.38 \pm 0.07$ \\
\hline & & $-p$ & $>1.8$ & $0.58 \pm 0.23$ & $0.63 \pm 0.09$ & $>2$ & $>2.4$ & $0.64 \pm 0.12$ & $1.27 \pm 0.07$ & $1.33 \pm 0.11$ \\
\hline & & -0 & $>1.8$ & $1.66 \pm 0.18$ & $2.12 \pm 0.07$ & $>2$ & $>2.4$ & $0.77 \pm 0.05$ & $1.38 \pm 0.10$ & $1.87 \pm 0.10$ \\
\hline \multirow[t]{3}{*}{$-\mathrm{Cl}$} & $2 c$ & $-m$ & $>1.8$ & $1.26 \pm 0.43$ & $>2.4$ & $>2$ & $>2.4$ & $0.65 \pm 0.13$ & $1.24 \pm 0.06$ & $1.33 \pm 0.08$ \\
\hline & & $-p$ & $>1.8$ & $1.36 \pm 0.30$ & $1.54 \pm 0.17$ & $1.98 \pm 0.03$ & $>2.4$ & $0.50 \pm 0.14$ & $1.26 \pm 0.12$ & $1.12 \pm 0.08$ \\
\hline & & -0 & $>1.8$ & $1.80 \pm 0.11$ & $2.16 \pm 0.05$ & $>2$ & $>2.4$ & $1.44 \pm 0.14$ & $1.56 \pm 0.03$ & $1.45 \pm 0.08$ \\
\hline \multirow[t]{3}{*}{$-\mathrm{Br}$} & $2 d$ & $-m$ & $>1.8$ & $1.37 \pm 0.13$ & $1.65 \pm 0.07$ & $>2$ & $>2.4$ & $0.90 \pm 0.10$ & $1.31 \pm 0.09$ & $1.40 \pm 0.13$ \\
\hline & & $-p$ & $>1.8$ & $1.39 \pm 0.27$ & $1.28 \pm 0.19$ & $>2$ & $>2.4$ & $0.38 \pm 0.15$ & $1.20 \pm 0.16$ & $1.33 \pm 0.18$ \\
\hline & & -0 & $>1.8$ & $>2$ & $2.29 \pm 0.11$ & $>2$ & $>2.4$ & $0.25 \pm 0.42$ & $1.23 \pm 0.17$ & $1.40 \pm 0.14$ \\
\hline \multirow[t]{3}{*}{$-\mathrm{CH}_{3}$} & $2 e$ & $-m$ & $>1.8$ & $1.54 \pm 0.23$ & $>2.4$ & $>2$ & $>2.4$ & $0.69 \pm 0.06$ & $1.25 \pm 0.11$ & $1.81 \pm 0.06$ \\
\hline & & $-p$ & $>1.8$ & $1.56 \pm 0.23$ & $1.66 \pm 0.04$ & $>2$ & $>2.4$ & $0.49 \pm 0.16$ & $1.02 \pm 0.03$ & $1.85 \pm 0.17$ \\
\hline & & -0 & $>1.8$ & $1.39 \pm 0.23$ & $1.33 \pm 0.02$ & $>2$ & $>2.4$ & $1.45 \pm 0.16$ & $1.69 \pm 0.11$ & $1.82 \pm 0.12$ \\
\hline \multirow[t]{3}{*}{$-\mathrm{CF}_{3}$} & $2 f$ & $-m$ & $>1.8$ & $1.19 \pm 0.08$ & $2.33 \pm 0.16$ & $>2$ & $>2.4$ & $0.68 \pm 0.11$ & $1.28 \pm 0.03$ & $1.18 \pm 0.06$ \\
\hline & & $-p$ & $>1.8$ & $1.54 \pm 0.36$ & $>2.4$ & $1.79 \pm 0.35$ & $>2.4$ & $0.61 \pm 0.10$ & $1.32 \pm 0.14$ & $>2$ \\
\hline & & -0 & $>1.8$ & $1.86 \pm 0.15$ & $>2.4$ & $>2$ & $>2.4$ & $0.44 \pm 0.19$ & $>2$ & $1.90 \pm 0.17$ \\
\hline \multirow[t]{3}{*}{$-\mathrm{OCH}_{3}$} & $2 g$ & $-m$ & $>1.8$ & $1.68 \pm 0.07$ & $>2.4$ & $>2$ & $>2.4$ & $0.70 \pm 0.09$ & $1.16 \pm 0.06$ & $1.44 \pm 0.15$ \\
\hline & & $-p$ & $>1.8$ & $1.55 \pm 0.10$ & $1.92 \pm 0.01$ & $>2$ & $>2.4$ & $0.51 \pm 0.12$ & $>2$ & $1.94 \pm 0.16$ \\
\hline & & -0 & $1.52 \pm 0.05$ & $0.88 \pm 0.17$ & $1.55 \pm 0.16$ & $1.13 \pm 0.19$ & $1.52 \pm 0.07$ & $0.70 \pm 0.08$ & $1.27 \pm 0.09$ & $1.27 \pm 0.12$ \\
\hline \multirow[t]{3}{*}{$-\mathrm{OH}$} & $2 \mathrm{~h}$ & $-m$ & $1.67 \pm 0.04$ & $-0.05 \pm 0.24$ & $-0.10 \pm 0.13$ & $1.28 \pm 0.24$ & $1.79 \pm 0.07$ & $0.95 \pm 0.13$ & $1.57 \pm 0.05$ & $1.55 \pm 0.04$ \\
\hline & & $-p$ & $1.70 \pm 0.10$ & $-0.47 \pm 0.44$ & $-0.50 \pm 0.16$ & $1.06 \pm 0.31$ & $1.77 \pm 0.09$ & $1.33 \pm 0.10$ & $1.62 \pm 0.08$ & $1.58 \pm 0.06$ \\
\hline & & -0 & $>1.8$ & $0.56 \pm 0.23$ & $0.49 \pm 0.11$ & $1.88 \pm 0.11$ & $2.29 \pm 0.10$ & $>1.6$ & $1.97 \pm 0.05$ & $1.78 \pm 0.05$ \\
\hline \multirow[t]{3}{*}{$-\mathrm{NO}_{2}$} & $2 \mathbf{i}$ & $-m$ & $>1.8$ & $1.03 \pm 0.67$ & $>2.4$ & $1.78 \pm 0.03$ & $>2.4$ & $1.02 \pm 0.08$ & $1.57 \pm 0.06$ & $1.66 \pm 0.06$ \\
\hline & & $-p$ & $>1.8$ & $1.41 \pm 0.15$ & $>2.4$ & $1.82 \pm 0.24$ & $>2.4$ & $1.19 \pm 0.04$ & $1.56 \pm 0.05$ & $1.77 \pm 0.07$ \\
\hline & & -0 & $>1.8$ & $1.01 \pm 0.26$ & $>2.4$ & $>2$ & $>2.4$ & $0.52 \pm 0.17$ & $1.25 \pm 0.16$ & $1.14 \pm 0.14$ \\
\hline \multirow[t]{3}{*}{$-\mathrm{NH}_{2}$} & $2 j$ & $-m$ & $>1.8$ & $0.45 \pm 0.35$ & $0.98 \pm 0.58$ & $1.94 \pm 0.10$ & $2.10 \pm 0.10$ & $1.18 \pm 0.05$ & $1.48 \pm 0.02$ & $1.76 \pm 0.27$ \\
\hline & & $-p$ & $>1.8$ & $0.16 \pm 0.29$ & $0.22 \pm 0.15$ & $1.83 \pm 0.15$ & $2.35 \pm 0.08$ & $1.34 \pm 0.07$ & $1.58 \pm 0.20$ & $1.77 \pm 0.18$ \\
\hline & & -0 & $>1.8$ & $1.50 \pm 0.17$ & $>2.4$ & $1.93 \pm 0.08$ & $2.29 \pm 0.04$ & $1.37 \pm 0.11$ & $1.97 \pm 0.04$ & $1.87 \pm 0.19$ \\
\hline \multirow[t]{3}{*}{$-\mathrm{CN}$} & $2 k$ & $-m$ & $>1.8$ & $0.88 \pm 0.20$ & $0.61 \pm 0.03$ & $1.96 \pm 0.03$ & $>2.4$ & $1.59 \pm 0.12$ & $1.96 \pm 0.03$ & $1.65 \pm 0.04$ \\
\hline & & $-p$ & $>1.8$ & $1.56 \pm 0.11$ & $>2.4$ & $1.80 \pm 0.19$ & $>2.4$ & $1.20 \pm 0.13$ & $1.89 \pm 0.08$ & $1.66 \pm 0.11$ \\
\hline & & -0 & $>1.8$ & $1.55 \pm 0.10$ & $1.73 \pm 0.10$ & $>2 \pm$ & $>2.4$ & $1.45 \pm 0.25$ & $>2$ & $>2$ \\
\hline \multirow[t]{3}{*}{$-\mathrm{CO}_{2} \mathrm{CH}_{3}$} & $2 \mathbf{I}$ & $-m$ & $>1.8$ & $1.03 \pm 0.47$ & $>2.4$ & $1.98 \pm 0.04$ & $>2.4$ & $>1.6$ & $1.69 \pm 0.22$ & $>2$ \\
\hline & & $-p$ & $>1.8$ & $1.42 \pm 0.11$ & $1.96 \pm 0.03$ & $1.94 \pm 0.08$ & $>2.4$ & $1.36 \pm 0.18$ & $>2$ & $>2$ \\
\hline & & -0 & $>1.8$ & $>2$ & $>2.4$ & $>2$ & $>2.4$ & $>1.6$ & $>2$ & $>2$ \\
\hline$-\mathrm{CO}_{2} \mathrm{H}$ & $2 m$ & $-m$ & $1.62 \pm 0.05$ & $1.78 \pm 0.13$ & $>2.4$ & $1.91 \pm 0.12$ & $>2.4$ & $>1.6$ & $>2$ & $>2$ \\
\hline & & $-p$ & $>1.8$ & $1.92 \pm 0.14$ & $>2.4$ & $>2 \pm$ & $>2.4$ & $>1.6$ & $>2$ & $>2$ \\
\hline Pentamic & & & $>1.8$ & $>2$ & $>2.4$ & $>2$ & $>2.4$ & $<-1.7$ & $1.27 \pm 0.11$ & $>2$ \\
\hline Suram & & & $>1.8$ & $0.90 \pm 0.19$ & $>2.4$ & $1.06 \pm 0.09$ & $>2.4$ & $-0.92 \pm 0.15$ & $>2$ & $>2$ \\
\hline Nifurtim & & & $>1.8$ & $>2$ & $>2.4$ & $>2$ & $>2.4$ & $0.45 \pm 0.09$ & $>2$ & $>2$ \\
\hline Eflornith & & & $>1.8$ & $>2$ & $>2.4$ & $>2$ & $>2.4$ & $>1.6$ & $>2$ & $>2$ \\
\hline
\end{tabular}


Table S2. Log-transformed values for Table $2 \mathbf{I C}_{50}$ and $\mathbf{E C}_{50}$ results. Results are presented as $\log \left(\mathrm{IC}_{50}\right.$ or $\left.\mathrm{EC}_{50} / \mu \mathrm{M}\right)$ values \pm their standard deviations (SD).

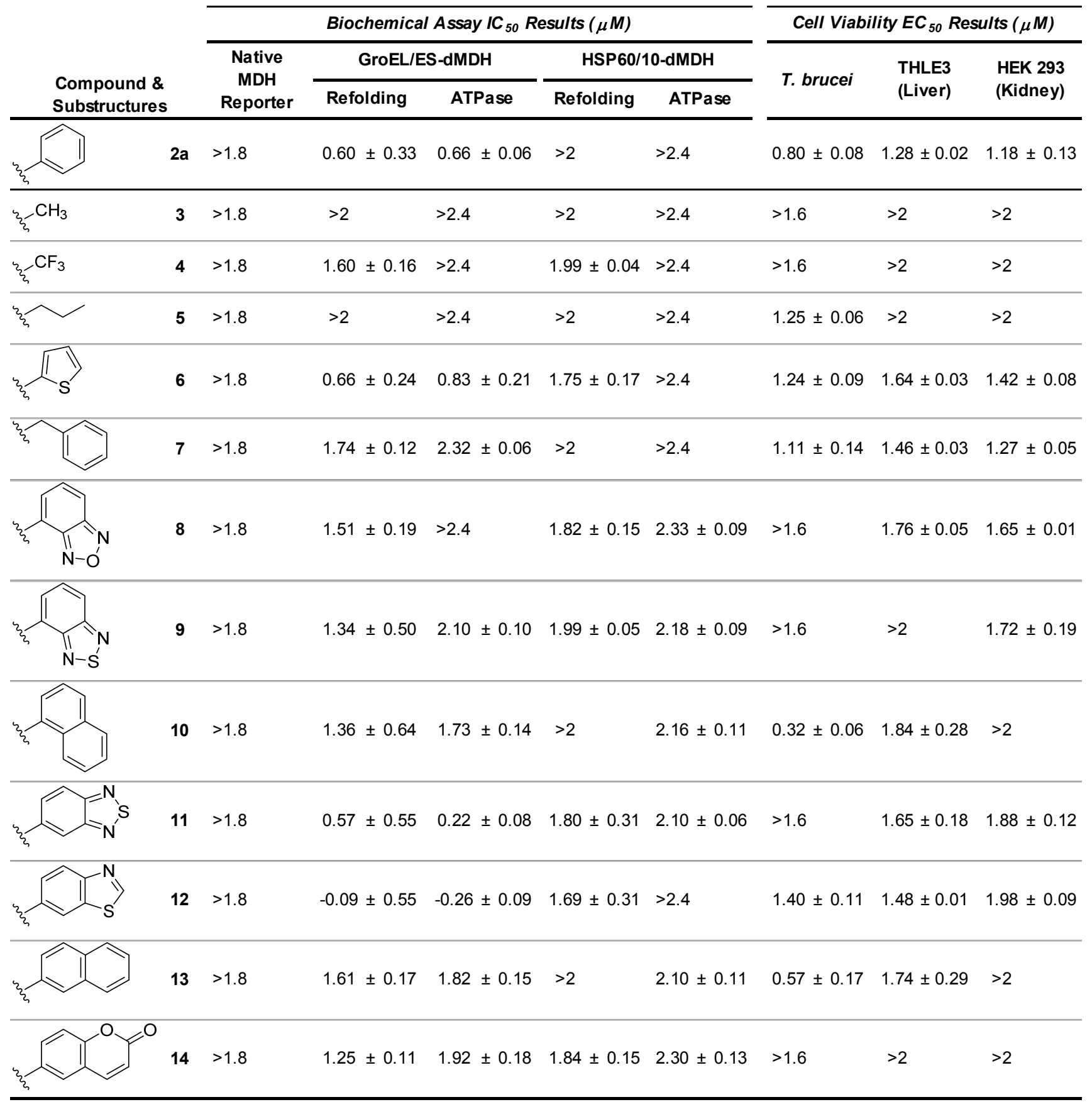




\section{General Materials and Methods.}

DH5 $\alpha$ and BL21 (DE3) E. coli cells were purchased from New England Biolabs, and Rosetta ${ }^{\mathrm{TM}} 2$ (DE3) E. coli cells from EMD Millipore. Trypanosoma brucei brucei Plimmer and Bradford parasites (Lister 427 VSG 221 [TetR T7RNAP] transgenic bloodstream form) were obtained from the ATCC (PRA-383). HEK 293 kidney and THLE-3 liver cells were obtained from the ATCC (CRL-1573 and CRL-11233, respectively). Antibiotics were used in following concentrations when appropriate; Kanamycin $(34 \mu \mathrm{g} / \mathrm{mL})$, ampicillin (50 $\mu \mathrm{g} / \mathrm{mL})$, chloramphenicol $(30 \mu \mathrm{g} / \mathrm{mL})$ and streptomycin $(100 \mu \mathrm{g} / \mathrm{mL})$. Unless otherwise stated, all chemicals were purchased from commercial suppliers and used without further purification. All test compounds were synthesized according to literature procedures for similar molecules. ${ }^{1,2}$ Reaction progress was monitored by thin-layer chromatography on silica gel 60 F254 coated glass plates (EM Sciences). Flash chromatography was performed using a Biotage Isolera One flash chromatography system and eluting through Biotage KP-Sil Zip or Snap silica gel columns for normal phase separations (hexanes:EtOAc gradients) or Snap KP-C18-HS columns for reverse phase separations $\left(\mathrm{H}_{2} \mathrm{O}: \mathrm{MeOH}\right.$ gradients $)$. Reverse phase high performance liquid chromatography (RP-HPLC) was performed using a Waters 1525 binary pump, 2489 tunable UV/Vis detector (254 and $280 \mathrm{~nm}$ detection), and 2707 autosampler. For preparatory HPLC purification, samples were chromatographically separated using a Waters XSelect CSH C18 OBD prep column (part number 186005422, $130 \AA$ pore size, $5 \mu \mathrm{m}$ particle size, $19 \times 150 \mathrm{~mm}$ ), eluting with a $\mathrm{H}_{2} \mathrm{O}: \mathrm{CH}_{3} \mathrm{CN}$ gradient solvent system. Linear gradients were run from either 100:0, 80:20, or 60:40 A:B to 0:100 A:B $\left(\mathrm{A}=95: 5 \mathrm{H}_{2} \mathrm{O}: \mathrm{CH}_{3} \mathrm{CN}, 0.05 \%\right.$ TFA; $\mathrm{B}=5: 95 \mathrm{H}_{2} \mathrm{O}: \mathrm{CH}_{3} \mathrm{CN}$, $0.05 \%$ TFA. For primary purity analyses (HPLC-1), samples were chromatographically separated using a Waters XSelect CSH C18 column (part number 186005282, $130 \AA$ pore size, $5 \mu \mathrm{m}$ particle size, $3.0 \times 150 \mathrm{~mm}$ ), eluting with the above $\mathrm{H}_{2} \mathrm{O}: \mathrm{CH}_{3} \mathrm{CN}$ gradient solvent systems. For secondary purity analyses (HPLC-2), samples were chromatographically separated using a Waters XBridge C18 column (part number 186003027, $130 \AA$ A pore size, $3.5 \mu \mathrm{m}$ particle size, $3.0 \times 100 \mathrm{~mm}$ ), eluting with a $\mathrm{H}_{2} \mathrm{O}: \mathrm{MeOH}$ gradient solvent system. Linear gradients were run from either 100:0, 80:20, 60:40, or 20:80 A:B to 0:100 A:B (A = 95:5 $\mathrm{H}_{2} \mathrm{O}: \mathrm{MeOH}, 0.05 \%$ TFA; $\mathrm{B}=5: 95 \mathrm{H}_{2} \mathrm{O}: \mathrm{MeOH}, 0.05 \%$ TFA). Test compounds were found to be $>95 \%$ in purity from both RPHPLC analyses. Mass spectrometry data were collected using an Agilent analytical LC-MS at the IU Chemical Genomics Core Facility (CGCF). ${ }^{1} \mathrm{H}-\mathrm{NMR}$ spectra were recorded on either a Bruker $300 \mathrm{MHz}$ or Bruker 500 $\mathrm{MHz}$ spectrometer. Chemical shifts are reported in parts per million and calibrated to the $d_{6}$-DMSO solvent peaks at $2.50 \mathrm{ppm}$.

\section{Protein Expression and purification.}

E. coli GroEL and GroES, and human mitochondrial HSP60 and HSP10 were expressed and purified as previously reported. ${ }^{3}$ Protein concentrations were determined using a Coomassie Protein Assay Kit (Thermo Scientific). Proteins were stored at $4^{\circ} \mathrm{C}$ in $50 \mathrm{mM}$ Tris- $\mathrm{HCl}, \mathrm{pH} 7.4,300 \mathrm{mM} \mathrm{NaCl}$, and $1 \mathrm{mM}$ DTT. E. coli GroEL and GroES proteins were discarded after 30 days, and human HSP60 and HSP10 were discarded after 10 days.

\section{Calculation of $\mathrm{IC}_{50}$ and $\mathrm{EC}_{50}$ values.}

All $\mathrm{IC}_{50}$ (or $\mathrm{EC}_{50}$ ) values reported are averages of $\mathrm{IC}_{50}$ (or $\mathrm{EC}_{50}$ ) values determined from individual dose-response curves in replicate assays as follows: 1) Individual IC50 values from replicate assays were first $\log$-transformed and the average $\log \left(\mathrm{I} / \mathrm{EC}_{50}\right)$ values and standard deviations (SD) calculated; 2) Replicate $\log \left(\mathrm{I} / \mathrm{EC}_{50}\right)$ values were evaluated for outliers using the ROUT method in GraphPad Prism 6 (Q of 10\%); and 3) Average $\mathrm{IC}_{50}\left(\right.$ or $\left.\mathrm{EC}_{50}\right)$ values were then back-calculated from the average $\log \left(\mathrm{I} / \mathrm{EC}_{50}\right)$ values.

\section{GroEL/ES and HSP60/10-mediated dMDH refolding assay protocols.}

The GroEL/ES-dMDH and HSP60/10-dMDH refolding assays were conducted as previously reported, ${ }^{3}$ with one minor procedural difference: instead of quenching the refolding reactions with EDTA at the 60 minute time point, the refolding reactions were quenched when they reached $\sim 90 \%$ completion (as determined from refolding time-course control experiments - generally $\sim 20-40 \mathrm{~min}$ for GroEL/ES, and 40-60 min for 
HSP60/10). Compounds were tested in 8-point, 3-fold dilution series (100 $\mu \mathrm{M}$ to $46 \mathrm{nM})$ in clear, flat-bottom 384-well microtiter plates. DMSO was used as negative control, and previously discovered chaperonin inhibitors were used as positive controls. ${ }^{3,4}$ IC50 values for the test compounds were obtained by plotting the \% inhibition results in GraphPad Prism 6 and analyzing by non-linear regression using the log (inhibitor) vs. response (variable slope) equation. Results presented represent the averages of $\mathrm{IC}_{50}$ values obtained from at least triplicate experiments.

\section{Native MDH enzymatic activity counter-screen assay protocol.}

This assay was performed as described above for the GroEL/ES-dMDH refolding assay, but the compounds were pin-transferred after the EDTA quench step. Thus, only the enzymatic portion of the assay was in the presence of test compounds to identify their effects on the native MDH reporter substrate. Compounds were tested in 8-point, 3-fold dilution series $(62.5 \mu \mathrm{M}$ to $29 \mathrm{nM})$ in clear, flat-bottom 384-well microtiter plates. DMSO was used as negative control, and previously discovered native MDH inhibitors were used as positive controls. ${ }^{3,4} \mathrm{IC}_{50}$ values for the test compounds were obtained by plotting the \% inhibition results in GraphPad Prism 6 and analyzing by non-linear regression using the log (inhibitor) vs. response (variable slope) equation. Results presented represent the averages of $\mathrm{IC}_{50}$ values obtained from at least triplicate experiments.

\section{Chaperonin-dependent ATPase activity assay protocol.}

The GroEL/ES-dMDH and HSP60/10-dMDH ATPase assays were conducted as previously reported, ${ }^{3}$ with the procedural differences as noted above that the refolding reactions were quenched when they reached $\sim 90 \%$ completion (as determined from refolding time-course control experiments - generally $\sim 20-40$ min for GroEL/ES, and 40-60 min for HSP60/10). Compounds were tested in 8-point, 3-fold dilution series $(250 \mu \mathrm{M}$ to $114 \mathrm{nM}$ ) in clear, flat-bottom 384-well microtiter plates. DMSO was used as negative control, and previously discovered chaperonin inhibitors were used as positive controls. ${ }^{3,4}$ A second set of baseline control plates were prepared analogously, but without binary solution, to correct for possible interference from compound absorbance or turbidity. IC 50 values for the test compounds were obtained by plotting the OD 600 results in GraphPad Prism 6 and analyzing by non-linear regression using the log(inhibitor) vs. response (variable slope) equation. Results presented represent the averages of $\mathrm{IC}_{50}$ values obtained from at least triplicate experiments.

\section{T. brucei cell viability assay protocol.}

Test compounds were evaluated using a robust $T$. brucei cell viability assay in 384-well plate format as previously reported. ${ }^{5,6}$ Briefly, $55 \mu \mathrm{L}$ of 2000 parasites/mL (110 parasites/well) of Trypanosoma brucei brucei (strain BF427) in HMI-9 medium were dispensed in to clear, 384-well polystyrene plates (BRAND cell culture grade plates, 781980). Plates were sealed with "Breathe Easy" oxygen permeable membranes (Diversified Biotech) and incubated at $37^{\circ} \mathrm{C}, 5 \% \mathrm{CO}_{2}$ for $24 \mathrm{~h}$. Next, $1 \mu \mathrm{L}$ of the compound stocks (10 mM to $4.6 \mu \mathrm{M}, 3-$ fold dilutions in DMSO) were pre-diluted by pin-transfer into $20 \mu \mathrm{L}$ HMI-9 medium, then $5 \mu \mathrm{L}$ of these diluted compounds were added to the parasite assay plates to give an inhibitor concentration range of $42 \mu \mathrm{M}$ to $19 \mathrm{nM}$ during the assay (the final DMSO concentration of $0.42 \%$ was maintained during the assay). Parasites were incubated for an additional $48 \mathrm{~h}$ at $37^{\circ} \mathrm{C}$ and $5 \% \mathrm{CO}_{2}$. Cell viability was then measured by adding $10 \mu \mathrm{L}$ of Alamar Blue reagent to give $10 \% \mathrm{v} / \mathrm{v}$ in the assay. Plates were incubated for $3 \mathrm{~h}$ at $37^{\circ} \mathrm{C}$ and $5 \% \mathrm{CO}_{2}$, then for another $22 \mathrm{~h}$ in dark at room temperature. Sample fluorescence (535 nm excitation, $590 \mathrm{~nm}$ emission) was read using a Molecular Devices FlexStation II 384-well plate reader, and cell viability was calculated as per vendor instructions. $\mathrm{EC}_{50}$ values for the test compounds were obtained by plotting the \% Alamar Blue reduction results in GraphPad Prism 6 and analyzing by non-linear regression using the log(inhibitor) vs. response (variable slope) equation. DMSO was used as negative control, and pentamidine, suramin, and nifurtimox (drugs used to treat HAT) were used as positive controls. Results presented represent the averages of EC50 values obtained from at least triplicate experiments 


\section{HEK 293 and THLE-3 cytotoxicity assay protocol.}

Cell cytotoxicity assays were performed using the Alamar Blue reporter reagents as previously

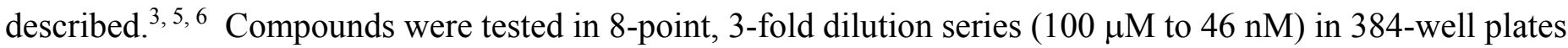
(BRAND cell culture grade plates, 781980). DMSO was used as negative control, and previously discovered cytotoxic chaperonin inhibitors were used as positive controls. ${ }^{3,4}$ Sample fluorescence (535 nm excitation, 590 $\mathrm{nm}$ emission) was read using a Molecular Devices FlexStation II 384-well plate reader, and cell viability was calculated as per vendor instructions. EC50 values for the test compounds were obtained by plotting the \% Alamar Blue reduction results in GraphPad Prism 6 and analyzing by non-linear regression using the $\log$ (inhibitor) vs. response (variable slope) equation. Results presented represent the averages of $\mathrm{EC}_{50}$ values obtained from at least triplicate experiments.

\section{General Synthetic Methods.}
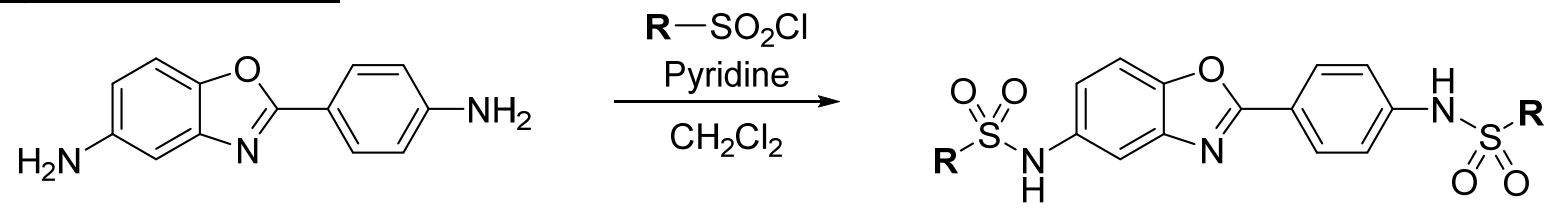

Synthetic Protocol A: General procedure for the synthesis of bis-sulfonamide analogues.

To a stirring mixture of 5-amino-2-(4-aminophenyl) benzoxazole (1 eq.) in anhydrous $\mathrm{CH}_{2} \mathrm{Cl}_{2}(5 \mathrm{~mL})$ was added the respective sulfonyl chloride ( 2.1 eq.) followed by anhydrous pyridine $(2.1$ eq.). The reaction was allowed to stir at room temperature for $18 \mathrm{~h}$ and was then chromatographed over silica and concentrated. If necessary, the product was further purified by preparatory RP-HPLC $\left(\mathrm{H}_{2} \mathrm{O}: \mathrm{CH}_{3} \mathrm{CN}\right.$ gradient), concentrated, and lyophilized. Refer below for individual compound synthesis and characterization data.

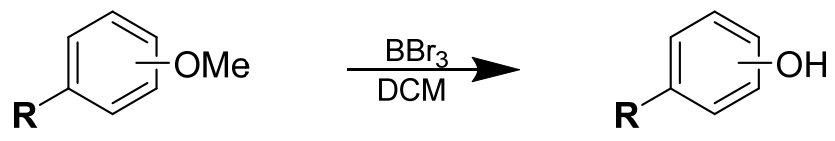

\section{Synthetic Protocol B: General procedure for methoxy-to-hydroxy deprotections.}

To a stirring mixture of the respective bis-sulfonamide (1 eq.) or mono-sulfonamide ( 1 eq.) in anhydrous $\mathrm{CH}_{2} \mathrm{Cl}_{2}$ (5 mL), was added $\mathrm{BBr}_{3}$ (6 eq. or 3 eq., respectively, in $\mathrm{CH}_{2} \mathrm{Cl}_{2}$ ). The reaction was allowed to stir at room temperature for $18 \mathrm{~h}$ and then diluted drop-wise with $\mathrm{MeOH}(2 \mathrm{~mL})$. The reaction was then washed with brine and extracted into EtOAc. The organics were dried over $\mathrm{Na}_{2} \mathrm{SO}_{4}$, filtered, and concentrated. The crude product was chromatographed over silica and concentrated. If necessary, the product was further purified by preparatory RP-HPLC $\left(\mathrm{H}_{2} \mathrm{O}: \mathrm{CH}_{3} \mathrm{CN}\right.$ gradient), concentrated, and lyophilized. Refer below for individual compound synthesis and characterization data.

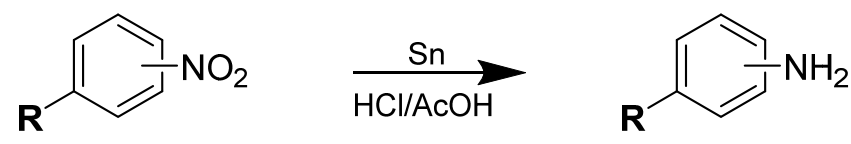

Synthetic Protocol C: General procedure for nitro-to-amine reductions.

To the respective bis-sulfonamide (1 eq.) or mono-sulfonamide ( 1 eq.) was added tin powder (6 eq. or 3 eq., respectively), followed by a 1:10 mixture of $\mathrm{HCl}: \mathrm{AcOH}$ (generally 0.2:2.0 $\mathrm{mL}$ ). The reaction was allowed to stir at room temperature for $18 \mathrm{~h}$, then diluted with EtOAc and $\mathrm{H}_{2} \mathrm{O}$, neutralized with $\mathrm{NaHCO}_{3}$, and filtered. The filtrate was extracted with EtOAc and the organics dried over $\mathrm{Na}_{2} \mathrm{SO}_{4}$, filtered, and concentrated. The crude product was then chromatographed over silica and concentrated. If necessary, the product was further purified 
by preparatory RP-HPLC $\left(\mathrm{H}_{2} \mathrm{O}: \mathrm{CH}_{3} \mathrm{CN}\right.$ gradient $)$, concentrated, and lyophilized. Refer below for individual compound synthesis and characterization data.

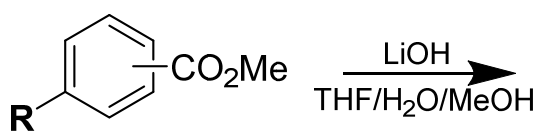<smiles>[R]c1ccc(C(=O)O)cc1</smiles>

\section{Synthetic Protocol D: General procedure for ester-to-acid hydrolyses.}

To a stirring mixture of the respective methyl ester compound (1 eq.) in THF (1.5 mL), MeOH $(0.5 \mathrm{~mL})$, and $\mathrm{H}_{2} \mathrm{O}(0.5 \mathrm{~mL})$, was added $\mathrm{LiOH} \bullet \mathrm{H}_{2} \mathrm{O}(\sim 6-10$ eq. $)$. The reaction was allowed to stir at room temperature for $18 \mathrm{~h}$ and then was diluted with $\mathrm{H}_{2} 0(10 \mathrm{~mL})$ and acidified with $1 \mathrm{M} \mathrm{HCl}$. The precipitate was filtered, washed with $\mathrm{H}_{2} \mathrm{O}$, and dried. If necessary, the product was further purified by preparatory RP-HPLC $\left(\mathrm{H}_{2} \mathrm{O}: \mathrm{CH}_{3} \mathrm{CN}\right.$ gradient), concentrated, and lyophilized. Refer below for individual compound synthesis and characterization data.

\section{Synthesis of specific test molecules.}<smiles>O=S(=O)(Nc1ccc(-c2nc3cc(NS(=O)(=O)c4ccccc4F)ccc3o2)cc1)c1ccccc1F</smiles>

2b-o: 2-fluoro-N-(4-(5-((2-fluorophenyl)sulfonamido)benzo[d]oxazol-2-yl)phenyl)benzenesulfonamide was synthesized from 5-amino-2-(4-aminophenyl)benzoxazole (47.0 mg, $0.209 \mathrm{mmol})$, 2-fluorobenzenesulfonyl chloride $(69.0 \mu \mathrm{L}, 0.52 \mathrm{mmol})$, and anhydrous pyridine $(42.5 \mu \mathrm{L}, 0.52 \mathrm{mmol})$ according to synthetic protocol A. Flash chromatographic purification (hexanes:EtOAc gradient) afforded $\mathbf{2 b - o}$ as a white solid (50.5 mg, $45 \%$ yield). ${ }^{1} \mathrm{H}-\mathrm{NMR}\left(500 \mathrm{MHz}, d_{6}\right.$-DMSO) $\delta 11.21$ (br s, 1H), 10.66 (br s, 1H), 7.97 (d, J=8.5 Hz, $\left.2 \mathrm{H}\right), 7.92(\mathrm{t}, J=$ $6.9 \mathrm{~Hz}, 1 \mathrm{H}), 7.76-7.84(\mathrm{~m}, 1 \mathrm{H}), 7.63-7.70(\mathrm{~m}, 2 \mathrm{H}), 7.60(\mathrm{~d}, J=8.8 \mathrm{~Hz}, 1 \mathrm{H}), 7.35-7.44(\mathrm{~m}, 4 \mathrm{H}), 7.32(\mathrm{td}, J=$

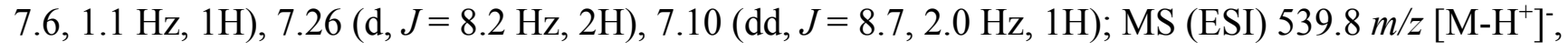
$\mathrm{C}_{25} \mathrm{H}_{16} \mathrm{~F}_{2} \mathrm{~N}_{3} \mathrm{O}_{5} \mathrm{~S}_{2}$ requires 540.0; HPLC-1 = $>99 \%$; HPLC- $2=97 \%$.<smiles>O=S(=O)(Nc1ccc(-c2nc3cc(NS(=O)(=O)c4cccc(F)c4)ccc3o2)cc1)c1cccc(F)c1</smiles>

2b-m: 3-fluoro-N-(4-(5-((2-fluorophenyl)sulfonamido)benzo[d]oxazol-2-yl)phenyl)benzenesulfonamide was synthesized from 5-amino-2-(4-aminophenyl)benzoxazole (59.8 mg, $0.265 \mathrm{mmol})$, 3-fluorobenzenesulfonyl chloride $(89.0 \mu \mathrm{L}, 0.663 \mathrm{mmol})$, and anhydrous pyridine $(54.0 \mu \mathrm{L}, 0.662 \mathrm{mmol})$ according to synthetic protocol A. Flash chromatographic purification (hexanes:EtOAc gradient) afforded $\mathbf{2 b}-\boldsymbol{m}$ as a white solid (131 $\mathrm{mg}, 91 \%$ yield). ${ }^{1} \mathrm{H}-\mathrm{NMR}\left(300 \mathrm{MHz}, d_{6}\right.$-DMSO) $\delta 10.99$ (br s, $\left.1 \mathrm{H}\right), 10.47$ (br s, $\left.1 \mathrm{H}\right), 8.03$ (d, $J=8.8 \mathrm{~Hz}, 2 \mathrm{H}$ ), 7.40-7.77 (m, 10H), 7.31 (d, $J=8.8 \mathrm{~Hz}, 2 \mathrm{H}), 7.08$ (dd, $J=8.7,2.1 \mathrm{~Hz}, 1 \mathrm{H}) ; \mathrm{MS}$ (ESI) $542.0 \mathrm{~m} / z\left[\mathrm{MH}^{+}\right], \mathrm{C}_{25} \mathrm{H}_{18} \mathrm{~F}_{2} \mathrm{~N}_{3} \mathrm{O}_{5} \mathrm{~S}_{2}$ requires 542.1; HPLC-1 $=100 \%$; HPLC-2 $=98 \%$. 


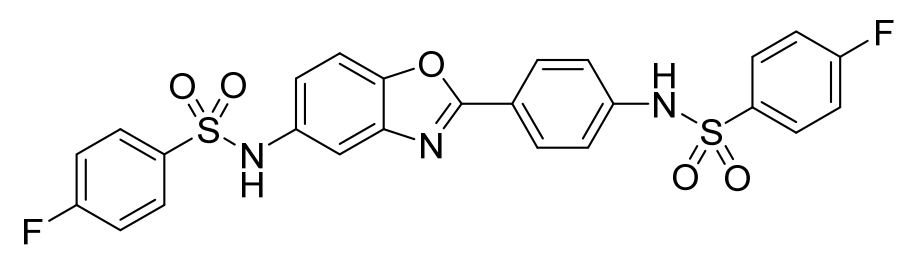

2b-p: 4-fluoro-N-(4-(5-((4-fluorophenyl)sulfonamido)benzo[d]oxazol-2-yl)phenyl)benzenesulfonamide was synthesized from 5-amino-2-(4-aminophenyl)benzoxazole $(55.3 \mathrm{mg}, 0.246 \mathrm{mmol})$, 4-fluorobenzenesulfonyl chloride (124 mg, $0.637 \mathrm{mmol})$, and anhydrous pyridine $(50.0 \mu \mathrm{L}, 0.613 \mathrm{mmol})$ according to synthetic protocol A. Flash chromatographic purification (hexanes:EtOAc gradient) afforded $\mathbf{2 b}-\boldsymbol{p}$ as a white solid (108 $\mathrm{mg}, 81 \%$ yield). ${ }^{1} \mathrm{H}$-NMR (500 MHz, $d_{6}$-DMSO) $\delta 10.93$ (br s, $\left.1 \mathrm{H}\right), 10.35$ (br s, $\left.1 \mathrm{H}\right), 8.00(\mathrm{~d}, J=8.8 \mathrm{~Hz}, 2 \mathrm{H}), 7.83-7.92$ $(\mathrm{m}, 2 \mathrm{H}), 7.75-7.80(\mathrm{~m}, 2 \mathrm{H}), 7.61(\mathrm{~d}, J=8.8 \mathrm{~Hz}, 1 \mathrm{H}), 7.33-7.43(\mathrm{~m}, 5 \mathrm{H}), 7.27(\mathrm{~d}, J=8.8 \mathrm{~Hz}, 2 \mathrm{H}), 7.06(\mathrm{dd}, J=$ 8.8, $2.2 \mathrm{~Hz}, 1 \mathrm{H}$ ); $\mathrm{MS}$ (ESI) $542.0 \mathrm{~m} / z\left[\mathrm{MH}^{+}\right], \mathrm{C}_{25} \mathrm{H}_{18} \mathrm{~F}_{2} \mathrm{~N}_{3} \mathrm{O}_{5} \mathrm{~S}_{2}$ requires 542.1 ; HPLC-1 = 99\%; HPLC-2 = 98\%.<smiles>O=S(=O)(Nc1ccc(-c2nc3cc(NS(=O)(=O)c4ccccc4Cl)ccc3o2)cc1)c1ccccc1Cl</smiles>

2c-o: 2-chloro-N-(4-(5-((2-chlorophenyl)sulfonamido)benzo[d]oxazol-2-yl)phenyl)benzenesulfonamide was synthesized from 5-amino-2-(4-aminophenyl)benzoxazole (59.7 $\mathrm{mg}, 0.265 \mathrm{mmol}), 2-$ chlorobenzenesulfonyl chloride $(90.0 \mu \mathrm{L}, 0.660 \mathrm{mmol})$, and anhydrous pyridine $(54.0 \mu \mathrm{L}, 0.662 \mathrm{mmol})$ according to synthetic protocol A. Flash chromatographic purification (hexanes:EtOAc gradient) afforded 2c-o as a white solid (74.3 mg, 49\% yield). ${ }^{1} \mathrm{H}-\mathrm{NMR}\left(500 \mathrm{MHz}, d_{6}\right.$-DMSO) $\delta 11.21(\mathrm{~s}, 1 \mathrm{H}), 10.67(\mathrm{~s}, 1 \mathrm{H}), 8.11-8.15$ (m, 1H), 8.02 (dd, $J=7.7,1.4 \mathrm{~Hz}, 1 \mathrm{H}), 7.97(\mathrm{~d}, J=8.8 \mathrm{~Hz}, 2 \mathrm{H}), 7.53-7.65(\mathrm{~m}, 6 \mathrm{H}), 7.46-7.50(\mathrm{~m}, 1 \mathrm{H}), 7.39$ (d, $J=2.2 \mathrm{~Hz}, 1 \mathrm{H}), 7.26(\mathrm{~d}, J=8.5 \mathrm{~Hz}, 2 \mathrm{H}), 7.11(\mathrm{dd}, J=8.8,2.2 \mathrm{~Hz}, 1 \mathrm{H}) ; \mathrm{MS}$ (ESI) $571.8 \mathrm{~m} / z\left[\mathrm{M}-\mathrm{H}^{+}\right]$, $\mathrm{C}_{25} \mathrm{H}_{16} \mathrm{Cl}_{2} \mathrm{~N}_{3} \mathrm{O}_{5} \mathrm{~S}_{2}$ requires 572.0; HPLC-1 $=99 \%$; HPLC-2 $=98 \%$.<smiles>O=S(=O)(Nc1ccc(-c2nc3cc(NS(=O)(=O)c4cccc(Cl)c4)ccc3o2)cc1)c1cccc(Cl)c1</smiles>

2c-m: 3-chloro-N-(4-(5-((3-chlorophenyl)sulfonamido)benzo[d]oxazol-2-yl)phenyl)benzenesulfonamide was synthesized from 5-amino-2-(4-aminophenyl)benzoxazole (55.6 $\mathrm{mg}, 0.247 \mathrm{mmol}), 3$ chlorobenzenesulfonyl chloride $(87.0 \mu \mathrm{L}, 0.618 \mathrm{mmol})$, and anhydrous pyridine $(50.0 \mu \mathrm{L}, 0.613 \mathrm{mmol})$ according to synthetic protocol A. Flash chromatographic purification (hexanes:EtOAc gradient) afforded $\mathbf{2 c}-\boldsymbol{m}$ as a white solid (94.0 mg, 66\% yield). ${ }^{1} \mathrm{H}-\mathrm{NMR}\left(500 \mathrm{MHz}, d_{6}\right.$-DMSO) $\delta 10.98(\mathrm{br} \mathrm{s}, 1 \mathrm{H}), 10.45(\mathrm{br} \mathrm{s}, 1 \mathrm{H}), 8.03$ $(\mathrm{d}, J=8.8 \mathrm{~Hz}, 2 \mathrm{H}), 7.83(\mathrm{t}, J=1.9 \mathrm{~Hz}, 1 \mathrm{H}), 7.53-7.80(\mathrm{~m}, 8 \mathrm{H}), 7.41(\mathrm{~d}, J=2.2 \mathrm{~Hz}, 1 \mathrm{H}), 7.31(\mathrm{~d}, J=8.8 \mathrm{~Hz}$, $2 \mathrm{H}$ ), 7.07 (dd, $J=8.5,2.2 \mathrm{~Hz}, 1 \mathrm{H})$; MS (ESI) $571.7 \mathrm{~m} / z\left[{\left.\mathrm{M}-\mathrm{H}^{+}\right]}^{-}, \mathrm{C}_{25} \mathrm{H}_{16} \mathrm{Cl}_{2} \mathrm{~N}_{3} \mathrm{O}_{5} \mathrm{~S}_{2}\right.$ requires 572.0; HPLC-1 = 99\%; HPLC-2 $=99 \%$. 
<smiles>O=S(=O)(Nc1ccc(-c2nc3cc(NS(=O)(=O)c4ccc(Cl)cc4)ccc3o2)cc1)c1ccc(Cl)cc1</smiles>

2c-p: 4-chloro-N-(4-(5-((4-chlorophenyl)sulfonamido)benzo[d]oxazol-2-yl)phenyl)benzenesulfonamide was synthesized from 5-amino-2-(4-aminophenyl)benzoxazole (62.7 mg, $0.278 \mathrm{mmol})$, 4-

chlorobenzenesulfonyl chloride $(146 \mathrm{mg}, 0.693 \mathrm{mmol})$, and anhydrous pyridine $(57.0 \mu \mathrm{L}, 0.699 \mathrm{mmol})$

according to synthetic protocol A. Flash chromatographic purification (hexanes:EtOAc gradient) afforded 2c-p as a white solid (133 mg, 83\% yield). ${ }^{1} \mathrm{H}-\mathrm{NMR}\left(500 \mathrm{MHz}, d_{6}\right.$-DMSO) $\delta 10.95$ (br s, $\left.1 \mathrm{H}\right), 10.42$ (br s, $\left.1 \mathrm{H}\right), 8.00$ $8.04(\mathrm{~m}, 2 \mathrm{H}), 7.81-7.85(\mathrm{~m}, 2 \mathrm{H}), 7.70-7.74(\mathrm{~m}, 2 \mathrm{H}), 7.59-7.67(\mathrm{~m}, 5 \mathrm{H}), 7.40(\mathrm{~d}, J=1.9 \mathrm{~Hz}, 1 \mathrm{H}), 7.27-7.32(\mathrm{~m}$, 2H), 7.07 (dd, $J=8.7,2.0 \mathrm{~Hz}, 1 \mathrm{H}) ; \mathrm{MS}(\mathrm{ESI}) 571.8 \mathrm{~m} / z\left[\mathrm{M}-\mathrm{H}^{+}\right]^{-}, \mathrm{C}_{25} \mathrm{H}_{16} \mathrm{Cl}_{2} \mathrm{~N}_{3} \mathrm{O}_{5} \mathrm{~S}_{2}$ requires 572.0; HPLC-1 = 98\%; HPLC-2 $=97 \%$.

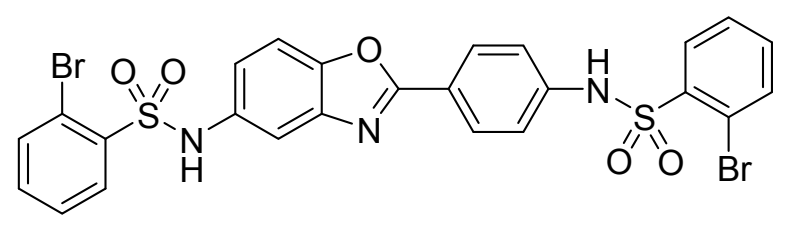

2d-o: 2-bromo-N-(4-(5-((2-bromophenyl)sulfonamido)benzo[d]oxazol-2-yl)phenyl)benzenesulfonamide was synthesized from 5-amino-2-(4-aminophenyl)benzoxazole (49.0 mg, $0.218 \mathrm{mmol}), 2$ -

bromobenzenesulfonyl chloride $(78.5 \mu \mathrm{L}, 0.544 \mathrm{mmol})$, and anhydrous pyridine $(44.0 \mu \mathrm{L}, 0.543 \mathrm{mmol})$ according to synthetic protocol A. Flash chromatographic purification (hexanes:EtOAc gradient) afforded 2d-o as a pink-white solid (84.1 mg, 46\% yield). ${ }^{1} \mathrm{H}-\mathrm{NMR}\left(500 \mathrm{MHz}, d_{6}\right.$-DMSO) $\delta 11.22(\mathrm{~s}, 1 \mathrm{H}), 10.60(\mathrm{~s}, 1 \mathrm{H}), 8.16$ $(\mathrm{dd}, J=7.9,1.6 \mathrm{~Hz}, 1 \mathrm{H}), 8.07(\mathrm{dd}, J=7.6,1.9 \mathrm{~Hz}, 1 \mathrm{H}), 7.98(\mathrm{~d}, J=8.5 \mathrm{~Hz}, 2 \mathrm{H}), 7.82(\mathrm{td}, J=8.0,1.1 \mathrm{~Hz}, 2 \mathrm{H})$, 7.57-7.63 (m, 2H), $7.54(\mathrm{td}, J=7.7,1.3 \mathrm{~Hz}, 2 \mathrm{H}), 7.47-7.51(\mathrm{~m}, 1 \mathrm{H}), 7.28(\mathrm{~d}, J=2.2 \mathrm{~Hz}, 1 \mathrm{H}), 7.26(\mathrm{~d}, J=8.5$ $\mathrm{Hz}, 2 \mathrm{H}), 7.12(\mathrm{dd}, J=8.8,2.2 \mathrm{~Hz}, 1 \mathrm{H})$; MS (ESI) $659.7 \mathrm{~m} / z\left[{\left.\mathrm{M}-\mathrm{H}^{+}\right]}^{-}, \mathrm{C}_{25} \mathrm{H}_{16} \mathrm{Br}_{2} \mathrm{~N}_{3} \mathrm{O}_{5} \mathrm{~S}_{2}\right.$ requires 659.9; HPLC-1 $=>99 \%$; HPLC $-2=>99 \%$.<smiles>O=S(=O)(Nc1ccc(-c2nc3cc(NS(=O)(=O)c4cccc(Br)c4)ccc3o2)cc1)c1cccc(Br)c1</smiles>

2d-m: 3-bromo-N-(4-(5-((3-bromophenyl)sulfonamido)benzo[d]oxazol-2-yl)phenyl)benzenesulfonamide was synthesized from 5-amino-2-(4-aminophenyl)benzoxazole (49.0 mg, $0.218 \mathrm{mmol}), 3$ bromobenzenesulfonyl chloride $(78.5 \mu \mathrm{L}, 0.544 \mathrm{mmol})$, and anhydrous pyridine $(44.5 \mu \mathrm{L}, 0.543 \mathrm{mmol})$ according to synthetic protocol A. Flash chromatographic purification (hexanes:EtOAc gradient) afforded 2d$\boldsymbol{m}$ as a white solid (41.7 mg, 29\% yield). ${ }^{1} \mathrm{H}-\mathrm{NMR}$ (500 MHz, $d_{6}$-DMSO) $\delta 10.97$ (br s, $\left.1 \mathrm{H}\right), 10.43$ (br s, $1 \mathrm{H}$ ), $8.03(\mathrm{~d}, J=8.8 \mathrm{~Hz}, 2 \mathrm{H}), 7.98(\mathrm{~s}, 1 \mathrm{H}), 7.88(\mathrm{t}, J=1.7 \mathrm{~Hz}, 1 \mathrm{H}), 7.80-7.86(\mathrm{~m}, 3 \mathrm{H}), 7.69(\mathrm{dq}, J=7.9,0.8 \mathrm{~Hz}, 1 \mathrm{H})$, $7.64(\mathrm{~d}, J=8.5 \mathrm{~Hz}, 1 \mathrm{H}), 7.53(\mathrm{t}, J=8.0 \mathrm{~Hz}, 1 \mathrm{H}), 7.48(\mathrm{t}, J=8.0 \mathrm{~Hz}, 1 \mathrm{H}), 7.40(\mathrm{~d}, J=1.9 \mathrm{~Hz}, 1 \mathrm{H}), 7.30(\mathrm{~d}, J=$ $7.9 \mathrm{~Hz}, 2 \mathrm{H}), 7.07(\mathrm{dd}, J=8.7,2.0 \mathrm{~Hz}, 1 \mathrm{H})$; MS (ESI) $659.7 \mathrm{~m} / z\left[\mathrm{M}-\mathrm{H}^{+}\right]^{-}, \mathrm{C}_{25} \mathrm{H}_{16} \mathrm{Br}_{2} \mathrm{~N}_{3} \mathrm{O}_{5} \mathrm{~S}_{2}$ requires 659.9; HPLC-1 $=98 \%$; HPLC-2 $=98 \%$. 
<smiles>O=S(=O)(Nc1ccc(-c2nc3cc(NS(=O)(=O)c4ccc(Br)cc4)ccc3o2)cc1)c1ccc(Br)cc1</smiles>

2d-p: 4-bromo-N-(4-(5-((4-bromophenyl)sulfonamido)benzo[d]oxazol-2-yl)phenyl)benzenesulfonamide was synthesized from 5-amino-2-(4-aminophenyl)benzoxazole (53.6 mg, $0.238 \mathrm{mmol})$, 4-

bromobenzenesulfonyl chloride (155 mg, $0.606 \mathrm{mmol})$, and anhydrous pyridine $(48.5 \mu \mathrm{L}, 0.595 \mathrm{mmol})$

according to synthetic protocol A. Flash chromatographic purification (hexanes:EtOAc gradient) afforded 2d-p as a white solid (38.6 mg, 24\% yield). ${ }^{1} \mathrm{H}-\mathrm{NMR}\left(500 \mathrm{MHz}, d_{6}\right.$-DMSO) $\delta 10.95$ (br s, 1H), 10.42 (br s, $\left.1 \mathrm{H}\right), 8.02$ $(\mathrm{d}, J=8.8 \mathrm{~Hz}, 2 \mathrm{H}), 7.77-7.82(\mathrm{~m}, 2 \mathrm{H}), 7.73-7.77(\mathrm{~m}, 4 \mathrm{H}), 7.61-7.65(\mathrm{~m}, 3 \mathrm{H}), 7.40(\mathrm{~d}, J=1.9 \mathrm{~Hz}, 1 \mathrm{H}), 7.29(\mathrm{~d}$, $J=8.8 \mathrm{~Hz}, 2 \mathrm{H}), 7.06(\mathrm{dd}, J=8.8,2.2 \mathrm{~Hz}, 1 \mathrm{H})$; MS (ESI) $661.8 \mathrm{~m} / z\left[\mathrm{MH}^{+}\right], \mathrm{C}_{25} \mathrm{H}_{18} \mathrm{Br}_{2} \mathrm{~N}_{3} \mathrm{O}_{5} \mathrm{~S}_{2}$ requires 661.9; HPLC- $1=98 \%$; HPLC- $2=98 \%$.

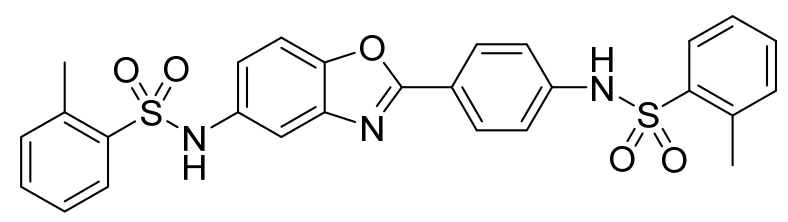

2e-o: 2-methyl-N-(4-(5-((2-methylphenyl)sulfonamido)benzo[d]oxazol-2-yl)phenyl)benzenesulfonamide was synthesized from 5-amino-2-(4-aminophenyl)benzoxazole (51.9 $\mathrm{mg}, 0.230 \mathrm{mmol})$, $o$-toluenesulfonyl chloride $(83.0 \mu \mathrm{L}, 0.575 \mathrm{mmol})$, and anhydrous pyridine $(47.0 \mu \mathrm{L}, 0.576 \mathrm{mmol})$ according to synthetic protocol A. Flash chromatographic purification (hexanes:EtOAc gradient) afforded 2e-o as a white solid (64.5 $\mathrm{mg}, 53 \%$ yield). ${ }^{1} \mathrm{H}-\mathrm{NMR}\left(300 \mathrm{MHz}, d_{6}\right.$-DMSO) $\delta 11.03(\mathrm{~s}, 1 \mathrm{H}), 10.47(\mathrm{~s}, 1 \mathrm{H}), 7.94-8.00(\mathrm{~m}, 3 \mathrm{H}), 7.86(\mathrm{~d}, J=7.6 \mathrm{~Hz}$, $1 \mathrm{H}), 7.58(\mathrm{~d}, J=8.8 \mathrm{~Hz}, 1 \mathrm{H}), 7.30-7.55(\mathrm{~m}, 7 \mathrm{H}), 7.24(\mathrm{~d}, J=8.8 \mathrm{~Hz}, 2 \mathrm{H}), 7.06(\mathrm{dd}, J=8.8,2.1 \mathrm{~Hz}, 1 \mathrm{H}), 2.60$ $(\mathrm{s}, 3 \mathrm{H}), 2.59(\mathrm{~s}, 3 \mathrm{H})$; MS (ESI) $534.0 \mathrm{~m} / z\left[\mathrm{MH}^{+}\right], \mathrm{C}_{27} \mathrm{H}_{24} \mathrm{~N}_{3} \mathrm{O}_{5} \mathrm{~S}_{2}$ requires 534.1; HPLC-1 = 99\%; HPLC-2 = $99 \%$.<smiles>Cc1cccc(S(=O)(=O)Nc2ccc(-c3nc4cc(NS(=O)(=O)c5cccc(C)c5)ccc4o3)cc2)c1</smiles>

2e-m: 3-methyl-N-(4-(5-((2-methylphenyl)sulfonamido)benzo[d]oxazol-2-yl)phenyl)benzenesulfonamide was synthesized from 5-amino-2-(4-aminophenyl)benzoxazole (52.8 mg, $0.234 \mathrm{mmol}), m$-toluenesulfonyl chloride $(85.0 \mu \mathrm{L}, 0.586 \mathrm{mmol})$, and anhydrous pyridine $(48.0 \mu \mathrm{L}, 0.589 \mathrm{mmol})$ according to synthetic protocol A. Flash chromatographic purification (hexanes:EtOAc gradient) afforded $\mathbf{2 e -} \boldsymbol{m}$ as a white solid (101 $\mathrm{mg}, 81 \%$ yield). ${ }^{1} \mathrm{H}-\mathrm{NMR}\left(300 \mathrm{MHz}, d_{6}\right.$-DMSO) $\delta 10.86$ (br s, $\left.1 \mathrm{H}\right), 10.32$ (br s, $\left.1 \mathrm{H}\right), 8.00$ (d, $J=8.8 \mathrm{~Hz}, 2 \mathrm{H}$ ), 7.38-7.69 (m, 10H), $7.30(\mathrm{~d}, J=8.8 \mathrm{~Hz}, 2 \mathrm{H}), 7.07(\mathrm{dd}, J=8.7,2.1 \mathrm{~Hz}, 1 \mathrm{H}), 2.34(\mathrm{~s}, 3 \mathrm{H}), 2.31$ (s, 3H); MS (ESI) 534.0 $m / z\left[\mathrm{MH}^{+}\right], \mathrm{C}_{27} \mathrm{H}_{24} \mathrm{~N}_{3} \mathrm{O}_{5} \mathrm{~S}_{2}$ requires 534.1; HPLC-1 = 98\%; HPLC-2 = 98\%. 


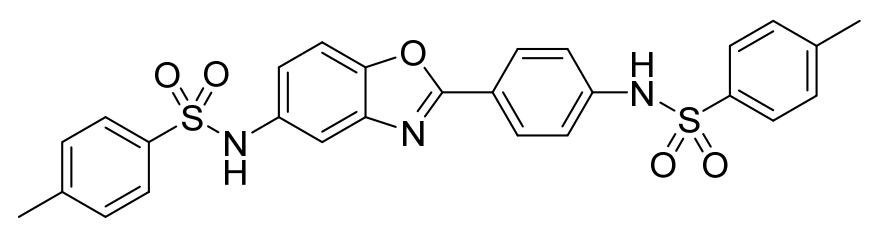

2e-p: 4-methyl-N-(4-(5-((4-methylphenyl)sulfonamido)benzo[d]oxazol-2-yl)phenyl)benzenesulfonamide was synthesized from 5-amino-2-(4-aminophenyl)benzoxazole ( $45.9 \mathrm{mg}, 0.204 \mathrm{mmol}), p$-toluenesulfonyl chloride $(85.1 \mathrm{mg}, 0.466 \mathrm{mmol})$, and anhydrous pyridine $(35.0 \mu \mathrm{L}, 0.429 \mathrm{mmol})$ according to synthetic protocol A. Flash chromatographic purification (hexanes:EtOAc gradient) afforded $\mathbf{2 e - p}$ as a yellow solid $(29.5 \mathrm{mg}$, $27 \%$ yield). ${ }^{1} \mathrm{H}-\mathrm{NMR}\left(500 \mathrm{MHz}, d_{6}\right.$-DMSO) $\delta 10.82(\mathrm{br} \mathrm{s}, 1 \mathrm{H}), 10.26(\mathrm{br} \mathrm{s}, 1 \mathrm{H}), 7.76-8.02(\mathrm{~m}, 2 \mathrm{H}), 7.70-7.75$ (m, 2H), 7.57-7.63 (m, 3H), 7.34-7.39 (m, 3H), 7.26-7.34 (m, 4H), 7.07 (dd, $J=8.5,2.2 \mathrm{~Hz}, 1 \mathrm{H}), 2.32(\mathrm{~s}, 3 \mathrm{H})$, $2.30(\mathrm{~s}, 3 \mathrm{H})$; MS (ESI) $531.9 \mathrm{~m} / z$ [M-H $\left.\mathrm{H}^{+}\right]^{-} \mathrm{C}_{27} \mathrm{H}_{22} \mathrm{~N}_{3} \mathrm{O}_{5} \mathrm{~S}_{2}$ requires 532.1; HPLC-1 = $>99 \%$; HPLC-2 = 98\%.<smiles>O=S(=O)(Nc1ccc(-c2nc3cc(NS(=O)(=O)c4ccccc4C(F)(F)F)ccc3o2)cc1)c1ccccc1C(F)(F)F</smiles>

2f-o: 2-(trifluoromethyl)-N-(4-(5-((2-(trifluoromethyl)phenyl)sulfonamido)benzo[d]oxazol-2-

yl)phenyl)benzenesulfonamide was synthesized from 5-amino-2-(4-aminophenyl)benzoxazole (45.4 mg,0.202 mmol), 2-trifluoromethyl-benzenesulfonyl chloride $(117 \mu \mathrm{L}, 0.785 \mathrm{mmol})$, and anhydrous pyridine $(54.0 \mu \mathrm{L}$, $0.662 \mathrm{mmol}$ ) according to synthetic protocol A. Flash chromatographic purification (hexanes:EtOAc gradient) afforded $2 \mathrm{f}-\boldsymbol{o}$ as a white solid (124 mg, 96\% yield). ${ }^{1} \mathrm{H}-\mathrm{NMR}\left(500 \mathrm{MHz}, d_{6}\right.$-DMSO) $\delta 11.24$ (br s, $\left.1 \mathrm{H}\right), 10.73$ (br s, 1H), 8.13-8.17 (m, 1H), 8.10 (d, $J=7.6 \mathrm{~Hz}, 1 \mathrm{H}), 8.00-8.05(\mathrm{~m}, 3 \mathrm{H}), 7.98$ (dd, $J=7.4,1.4 \mathrm{~Hz}, 1 \mathrm{H}), 7.78-$ $7.90(\mathrm{~m}, 4 \mathrm{H}), 7.64(\mathrm{~d}, J=8.8 \mathrm{~Hz}, 1 \mathrm{H}), 7.41(\mathrm{~d}, J=1.9 \mathrm{~Hz}, 1 \mathrm{H}), 7.29(\mathrm{~d}, J=8.8 \mathrm{~Hz}, 2 \mathrm{H}), 7.12(\mathrm{dd}, J=8.8,2.2$ $\mathrm{Hz}, 1 \mathrm{H})$; MS (ESI) $641.9 \mathrm{~m} / z\left[\mathrm{MH}^{+}\right], \mathrm{C}_{27} \mathrm{H}_{18} \mathrm{~F}_{6} \mathrm{~N}_{3} \mathrm{O}_{5} \mathrm{~S}_{2}$ requires 642.1; HPLC-1 = >99\%; HPLC-2 = 99\%.<smiles>O=S(=O)(Nc1ccc(-c2nc3cc(NS(=O)(=O)c4cccc(C(F)(F)F)c4)ccc3o2)cc1)c1cccc(C(F)(F)F)c1</smiles>

2f-m: 3-(trifluoromethyl)-N-(4-(5-((3-(trifluoromethyl)phenyl)sulfonamido)benzo[d]oxazol-2-

yl)phenyl)benzenesulfonamide was synthesized from 5-amino-2-(4-aminophenyl)benzoxazole (48.5 mg, 0.215 mmol), 3-trifluoromethylbenzenesulfonyl chloride $(86.0 \mu \mathrm{L}, 0.536 \mathrm{mmol})$, and anhydrous pyridine $(39.0 \mu \mathrm{L}$, $0.478 \mathrm{mmol}$ ) according to synthetic protocol A. Flash chromatographic purification (hexanes:EtOAc gradient) afforded $\mathbf{2 f}-\boldsymbol{m}$ as a white solid (74.0 mg, 54\% yield). ${ }^{1} \mathrm{H}-\mathrm{NMR}\left(500 \mathrm{MHz}, d_{6}\right.$-DMSO) $\delta 11.01$ (br s, $\left.1 \mathrm{H}\right), 10.48$ (br s, 1H), 8.05-8.13 (m, 2H), 7.95-8.05 (m, 6H), $7.83(\mathrm{t}, J=7.9 \mathrm{~Hz}, 1 \mathrm{H}), 7.77(\mathrm{t}, J=7.9 \mathrm{~Hz}, 1 \mathrm{H}), 7.64(\mathrm{~d}, J=$ $8.8 \mathrm{~Hz}, 1 \mathrm{H}), 7.40(\mathrm{~d}, J=1.9 \mathrm{~Hz}, 1 \mathrm{H}), 7.31(\mathrm{~d}, J=8.8 \mathrm{~Hz}, 2 \mathrm{H}), 7.06(\mathrm{dd}, J=8.7,2.0 \mathrm{~Hz}, 1 \mathrm{H})$; MS (ESI) 639.9 $m / z\left[\mathrm{M}-\mathrm{H}^{+}\right]^{-}, \mathrm{C}_{27} \mathrm{H}_{16} \mathrm{~F}_{6} \mathrm{~N}_{3} \mathrm{O}_{5} \mathrm{~S}_{2}$ requires 640.0; HPLC-1 = $>99 \%$; HPLC-2 = 98\%. 
<smiles>O=S(=O)(Nc1ccc(-c2nc3cc(NS(=O)(=O)c4ccc(C(F)(F)F)cc4)ccc3o2)cc1)c1ccc(C(F)(F)F)cc1</smiles>

\section{2f-p: 4-(trifluoromethyl)-N-(4-(5-((4-(trifluoromethyl)phenyl)sulfonamido)benzo[d]oxazol-2-}

yl)phenyl)benzenesulfonamide was synthesized from 5-amino-2-(4-aminophenyl)benzoxazole (52.7 $\mathrm{mg}, 0.234$ mmol), 4-trifluoromethylbenzenesulfonyl chloride (144 mg, $0.589 \mathrm{mmol})$, and anhydrous pyridine $(47.5 \mu \mathrm{L}$, $0.582 \mathrm{mmol}$ ) according to synthetic protocol A. Flash chromatographic purification (hexanes:EtOAc gradient) afforded 2f- $\boldsymbol{p}$ as a yellow solid (56.6 mg, $38 \%$ yield). ${ }^{1} \mathrm{H}-\mathrm{NMR}$ (500 MHz, $d_{6}$-DMSO) $\delta 11.09$ (br s, $1 \mathrm{H}$ ), 10.60 (br s, $1 \mathrm{H}), 8.03(\mathrm{dd}, J=8.5,6.0 \mathrm{~Hz}, 4 \mathrm{H}), 7.97(\mathrm{~d}, J=8.5 \mathrm{~Hz}, 2 \mathrm{H}), 7.93(\mathrm{~s}, 4 \mathrm{H}), 7.63(\mathrm{~d}, J=8.8 \mathrm{~Hz}, 1 \mathrm{H}), 7.43$ (d, $J=2.2 \mathrm{~Hz}, 1 \mathrm{H}), 7.31$ (d, $J=8.8 \mathrm{~Hz}, 2 \mathrm{H}), 7.07$ (dd, $J=8.7,2.0 \mathrm{~Hz}, 1 \mathrm{H}) ; \mathrm{MS}$ (ESI) $\left.641.9 \mathrm{~m} / \mathrm{z}^{\mathrm{MH}}{ }^{+}\right]$, $\mathrm{C}_{27} \mathrm{H}_{18} \mathrm{~F}_{6} \mathrm{~N}_{3} \mathrm{O}_{5} \mathrm{~S}_{2}$ requires 642.1; HPLC-1 $=98 \%$; HPLC-2 $=98 \%$.

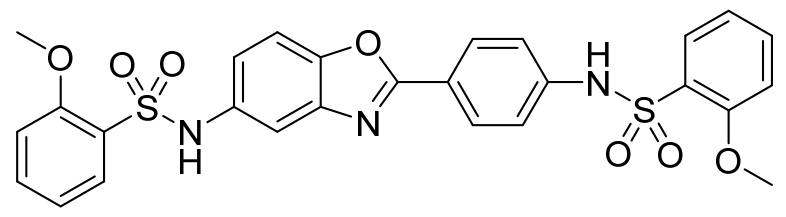

2g-o: 2-methoxy-N-(4-(5-((2-methoxyphenyl)sulfonamido)benzo[d]oxazol-2-

yl)phenyl)benzenesulfonamide was synthesized from 5-amino-2-(4-aminophenyl)benzoxazole (50.5 $\mathrm{mg}, 0.224$ mmol), 2-methoxybenzenesulfonyl chloride $(113 \mathrm{mg}, 0.548 \mathrm{mmol})$, and anhydrous pyridine $(45.5 \mu \mathrm{L}, 0.558$ $\mathrm{mmol}$ ) according to synthetic protocol A. Flash chromatographic purification (hexanes:EtOAc gradient) afforded $2 \mathrm{~g}-\boldsymbol{o}$ as a white solid (66.5 mg, $52 \%$ yield). ${ }^{1} \mathrm{H}$-NMR (500 MHz, $d_{6}$-DMSO) $\delta 10.61(\mathrm{br} \mathrm{s}, 1 \mathrm{H}), 10.04$ $(\mathrm{s}, 1 \mathrm{H}), 7.92-7.96(\mathrm{~m}, 2 \mathrm{H}), 7.85(\mathrm{dd}, J=7.7,1.7 \mathrm{~Hz}, 1 \mathrm{H}), 7.73(\mathrm{dd}, J=7.7,1.7 \mathrm{~Hz}, 1 \mathrm{H}), 7.50-7.58(\mathrm{~m}, 3 \mathrm{H})$, $7.36(\mathrm{~d}, J=1.9 \mathrm{~Hz}, 1 \mathrm{H}), 7.23-7.27(\mathrm{~m}, 2 \mathrm{H}), 7.15(\mathrm{dd}, J=7.9,4.4 \mathrm{~Hz}, 2 \mathrm{H}), 7.10(\mathrm{dd}, J=8.8,2.2 \mathrm{~Hz}, 1 \mathrm{H}), 7.04-$ $7.07(\mathrm{~m}, 1 \mathrm{H}), 6.96-7.00(\mathrm{~m}, 1 \mathrm{H}) 3.89(\mathrm{~s}, 3 \mathrm{H}), 3.84(\mathrm{~s}, 3 \mathrm{H})$; $\mathrm{MS}(\mathrm{ESI}) 566.1 \mathrm{~m} / z\left[\mathrm{MH}^{+}\right], \mathrm{C}_{27} \mathrm{H}_{24} \mathrm{~N}_{3} \mathrm{O}_{7} \mathrm{~S}_{2}$ requires 566.1; HPLC-1 $=97 \%$; HPLC-2 $=96 \%$.<smiles>COc1cccc(S(=O)(=O)Nc2ccc(-c3nc4cc(NS(=O)(=O)c5cccc(OC)c5)ccc4o3)cc2)c1</smiles>

2g-m: 3-methoxy-N-(4-(5-((3-methoxyphenyl)sulfonamido)benzo[d]oxazol-2-

yl)phenyl)benzenesulfonamide was synthesized from 5-amino-2-(4-aminophenyl)benzoxazole (56.3 $\mathrm{mg}, 0.250$ mmol), 3-methoxybenzenesulfonyl chloride $(89.0 \mu \mathrm{L}, 0.629 \mathrm{mmol})$, and anhydrous pyridine $(51.0 \mu \mathrm{L}, 0.625$ $\mathrm{mmol}$ ) according to synthetic protocol A. Flash chromatographic purification (hexanes:EtOAc gradient) afforded $\mathbf{2 g}-\boldsymbol{m}$ as a white solid (126 mg, 89\% yield). ${ }^{1} \mathrm{H}-\mathrm{NMR}\left(500 \mathrm{MHz}, d_{6}\right.$-DMSO) $\delta 10.84(\mathrm{br} \mathrm{s}, 1 \mathrm{H}), 10.32$ (s, 1H), 7.99-8.04 (m, 2H), 7.61 (d, $J=8.8 \mathrm{~Hz}, 1 \mathrm{H}), 7.45-7.50(\mathrm{~m}, 1 \mathrm{H}), 7.37-7.44(\mathrm{~m}, 3 \mathrm{H}), 7.26-7.33(\mathrm{~m}, 4 \mathrm{H})$, 7.23-7.25 (m, 1H), 7.19 (ddd, $J=8.3,2.6,0.8 \mathrm{~Hz}, 1 \mathrm{H}), 7.13-7.16(\mathrm{~m}, 1 \mathrm{H}), 7.09$ (dd, $J=8.8,2.2 \mathrm{~Hz}, 1 \mathrm{H}), 3.77$ $(\mathrm{s}, 3 \mathrm{H}), 3.74(\mathrm{~s}, 3 \mathrm{H})$; MS (ESI) $566.0 \mathrm{~m} / z\left[\mathrm{MH}^{+}\right], \mathrm{C}_{27} \mathrm{H}_{24} \mathrm{~N}_{3} \mathrm{O}_{7} \mathrm{~S}_{2}$ requires 566.1; HPLC-1 = $>99 \%$; HPLC-2 = $>99 \%$. 
<smiles>COc1ccc(S(=O)(=O)Nc2ccc(-c3nc4cc(NS(=O)(=O)c5ccc(OC)cc5)ccc4o3)cc2)cc1</smiles>

\section{2g-p: 4-methoxy-N-(4-(5-((4-methoxyphenyl)sulfonamido)benzo[d]oxazol-2-}

yl)phenyl)benzenesulfonamide was synthesized from 5-amino-2-(4-aminophenyl)benzoxazole ( $57.5 \mathrm{mg}, 0.255$ $\mathrm{mmol})$, 4-methoxybenzenesulfonyl chloride $(130 \mathrm{mg}, 0.630 \mathrm{mmol})$, and anhydrous pyridine $(48.0 \mu \mathrm{L}, 0.589$ $\mathrm{mmol}$ ) according to synthetic protocol A. Flash chromatographic purification (hexanes:EtOAc gradient) afforded $2 \mathrm{~g}-\boldsymbol{p}$ as a white solid (112 mg, 78\% yield). ${ }^{1} \mathrm{H}-\mathrm{NMR}\left(500 \mathrm{MHz}, d_{6}\right.$-DMSO) $\delta 10.73$ (br s, $\left.1 \mathrm{H}\right), 10.20$ (s, 1H), 7.97-8.02 (m, 2H), 7.75-7.80 (m, 2H), 7.64-7.68 (m, 2H), $7.60(\mathrm{~d}, J=8.8 \mathrm{~Hz}, 1 \mathrm{H}), 7.38(\mathrm{~d}, J=2.2 \mathrm{~Hz}$, $1 \mathrm{H}), 7.26-7.31(\mathrm{~m}, 2 \mathrm{H}), 7.05-7.10(\mathrm{~m}, 3 \mathrm{H}), 7.00-7.05(\mathrm{~m}, 2 \mathrm{H}), 3.78(\mathrm{~s}, 3 \mathrm{H}), 3.76(\mathrm{~s}, 3 \mathrm{H})$; MS (ESI) $566.1 \mathrm{~m} / \mathrm{z}$ $\left[\mathrm{MH}^{+}\right], \mathrm{C}_{27} \mathrm{H}_{24} \mathrm{~N}_{3} \mathrm{O}_{7} \mathrm{~S}_{2}$ requires 566.1; HPLC-1 $=98 \%$; HPLC-2 $=97 \%$.

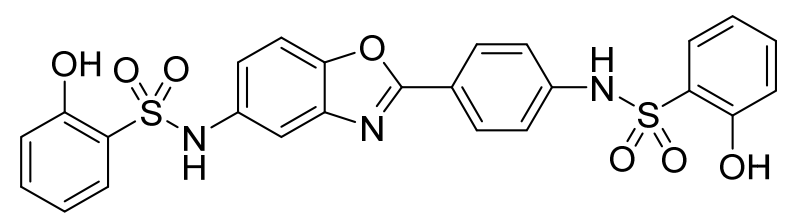

\section{2h-o: 2-hydroxy-N-(4-(5-((2-hydroxyphenyl)sulfonamido)benzo[d]oxazol-2-}

yl)phenyl)benzenesulfonamide was synthesized from $\mathbf{2 g - o}(189 \mathrm{mg}, 0.335 \mathrm{mmol})$ and boron tribromide $(2.00$ $\mathrm{mL}, 2.00 \mathrm{mmol}$ ) according to synthetic protocol B. Flash chromatographic purification (hexanes:EtOAc gradient) afforded $\mathbf{2 h}-\boldsymbol{o}$ as a tan solid (96.0 mg, 53\% yield). ${ }^{1} \mathrm{H}-\mathrm{NMR}\left(300 \mathrm{MHz}, d_{6}\right.$-DMSO) $\delta 10.91$ (br s, 2H), 10.70 (br s, 1H), 9.99 (br s, 1H), $7.93(\mathrm{~d}, J=8.8 \mathrm{~Hz}, 2 \mathrm{H}), 7.78$ (dd, $J=8.1,1.6 \mathrm{~Hz}, 1 \mathrm{H}), 7.65$ (dd, $J=7.9,1.5$ $\mathrm{Hz}, 1 \mathrm{H}), 7.54(\mathrm{~d}, J=8.8 \mathrm{~Hz}, 1 \mathrm{H}), 7.31-7.44(\mathrm{~m}, 3 \mathrm{H}), 7.26(\mathrm{~d}, J=8.8 \mathrm{~Hz}, 2 \mathrm{H}), 7.13(\mathrm{dd}, J=8.8,2.0 \mathrm{~Hz}, 1 \mathrm{H})$, 6.87-6.96 (m, 3H), 6.79-6.86 (m, 1H); MS (ESI) $538.0 \mathrm{~m} / z\left[\mathrm{MH}^{+}\right], \mathrm{C}_{25} \mathrm{H}_{20} \mathrm{~N}_{3} \mathrm{O}_{7} \mathrm{~S}_{2}$ requires 538.1; HPLC-1 = 95\%; HPLC-2 $=96 \%$.<smiles>O=S(=O)(Nc1ccc(-c2nc3cc(NS(=O)(=O)c4cccc(O)c4)ccc3o2)cc1)c1cccc(O)c1</smiles>

\section{2h-m: 3-hydroxy-N-(4-(5-((3-hydroxyphenyl)sulfonamido)benzo[d]oxazol-2-}

yl)phenyl)benzenesulfonamide was synthesized from $\mathbf{2 g}-\boldsymbol{m}(78.1 \mathrm{mg}, 0.138 \mathrm{mmol})$ and boron tribromide $(0.83$ $\mathrm{mL}, 0.83 \mathrm{mmol}$ ) according to synthetic protocol B. Flash chromatographic purification (hexanes:EtOAc gradient) afforded $\mathbf{2 h}-\boldsymbol{m}$ as a yellow solid (31.8 $\mathrm{mg}, 43 \%$ yield). ${ }^{1} \mathrm{H}-\mathrm{NMR}\left(300 \mathrm{MHz}, d_{6}\right.$-DMSO) $\delta 10.84$ (s, $1 \mathrm{H}), 10.30(\mathrm{~s}, 1 \mathrm{H}), 10.19(\mathrm{br} \mathrm{s}, 1 \mathrm{H}), 10.09$ (br s, $1 \mathrm{H}), 8.02(\mathrm{~d}, J=88 \mathrm{~Hz}, 2 \mathrm{H}), 7.62(\mathrm{~d}, J=8.8 \mathrm{~Hz}, 1 \mathrm{H}), 7.23-$ $7.42(\mathrm{~m}, 6 \mathrm{H}), 7.04-7.21(\mathrm{~m}, 4 \mathrm{H}), 6.90-7.01(\mathrm{~m}, 2 \mathrm{H})$; $\mathrm{MS}(\mathrm{ESI}) 538.0 \mathrm{~m} / z\left[\mathrm{MH}^{+}\right], \mathrm{C}_{25} \mathrm{H}_{20} \mathrm{~N}_{3} \mathrm{O}_{7} \mathrm{~S}_{2}$ requires 538.1; HPLC-1 $=97 \%$; HPLC-2 $=97 \%$. 
<smiles>O=S(=O)(Nc1ccc(-c2nc3cc(NS(=O)(=O)c4ccc(O)cc4)ccc3o2)cc1)c1ccc(O)cc1</smiles>

\section{2h-p: 4-hydroxy-N-(4-(5-((4-hydroxyphenyl)sulfonamido)benzo[d]oxazol-2-}

yl)phenyl)benzenesulfonamide was synthesized from $\mathbf{2 g}-\boldsymbol{p}(74.5 \mathrm{mg}, 0.132 \mathrm{mmol})$ and boron tribromide $(0.80$ $\mathrm{mL}, 0.80 \mathrm{mmol}$ ) according to synthetic protocol B. Flash chromatographic purification (hexanes:EtOAc gradient) afforded $\mathbf{2 h}-\boldsymbol{p}$ as a white solid (45.2 mg, 64\% yield). ${ }^{1} \mathrm{H}-\mathrm{NMR}$ (500 MHz, $d_{6}$-DMSO) $\delta 10.41$ (br s, 2H), 10.07 (br s, 1H), $7.96(\mathrm{~d}, J=8.2 \mathrm{~Hz}, 2 \mathrm{H}), 7.65(\mathrm{~d}, J=8.8 \mathrm{~Hz}, 2 \mathrm{H}), 7.53-7.60(\mathrm{~m}, 3 \mathrm{H}), 7.35(\mathrm{~d}, J=1.9 \mathrm{~Hz}$, 1H), 7.22 (d, $J=8.2 \mathrm{~Hz}, 2 \mathrm{H}), 7.04(\mathrm{dd}, J=8.7,2.0 \mathrm{~Hz}, 1 \mathrm{H}), 6.79-6.86(\mathrm{~m}, 4 \mathrm{H})$; MS (ESI) $535.8 \mathrm{~m} / z$ [M-H ${ }^{+}$, $\mathrm{C}_{25} \mathrm{H}_{18} \mathrm{~N}_{3} \mathrm{O}_{7} \mathrm{~S}_{2}$ requires 536.1; HPLC-1 $=95 \%$; HPLC-2 $=95 \%$.<smiles>O=[N+]([O-])c1ccccc1S(=O)(=O)Nc1ccc(-c2nc3cc(NS(=O)(=O)[O-])ccc3o2)cc1</smiles>

2i-o: 2-nitro-N-(4-(5-((2-nitrophenyl)sulfonamido)benzo[d]oxazol-2-yl)phenyl)benzenesulfonamide was synthesized from 5-amino-2-(4-aminophenyl)benzoxazole (53.6 mg, $0.238 \mathrm{mmol})$, 2-nitrobenzenesulfonyl chloride $(185 \mu \mathrm{L}, 0.839 \mathrm{mmol})$, and anhydrous pyridine $(61.0 \mu \mathrm{L}, 0.748 \mathrm{mmol})$ according to synthetic protocol A. Flash chromatographic purification (hexanes:EtOAc gradient), followed by preparatory RP-HPLC purification, afforded $\mathbf{2 i}-\boldsymbol{o}$ as a yellow solid (143 mg, 101\% yield). ${ }^{1} \mathrm{H}-\mathrm{NMR}(500 \mathrm{MHz}, d 6$-DMSO) $\delta 11.28$ (br s, $1 \mathrm{H}), 10.78$ (br s, 1H), 8.03-8.07 (m, 3H), 7.99 (d, $J=7.6 \mathrm{~Hz}, 1 \mathrm{H}), 7.96$ (td, $J=7.5,1.4 \mathrm{~Hz}, 2 \mathrm{H}), 7.77-7.87$ $(\mathrm{m}, 4 \mathrm{H}), 7.67(\mathrm{~d}, J=8.8 \mathrm{~Hz}, 1 \mathrm{H}), 7.43(\mathrm{~d}, \mathrm{~J}=2.2 \mathrm{~Hz}, 1 \mathrm{H}), 7.31(\mathrm{~d}, J=8.5 \mathrm{~Hz}, 2 \mathrm{H}), 7.13(\mathrm{dd}, J=8.8,2.2 \mathrm{~Hz}$, 1H); MS (ESI) $593.8 \mathrm{~m} / z$ [M-H $\left.{ }^{+}\right]^{-} \mathrm{C}_{25} \mathrm{H}_{16} \mathrm{~N}_{5} \mathrm{O}_{9} \mathrm{~S}_{2}$ requires 594.0; HPLC-1 = 98\%; HPLC-2 = 99\%.<smiles>O=[N+]([O-])c1cccc(S(=O)(=O)Nc2ccc(-c3nc4cc(NS(=O)(=O)c5cccc([N+](=O)[O-])c5)ccc4o3)cc2)c1</smiles>

2i-m: 3-nitro-N-(4-(5-((3-nitrophenyl)sulfonamido)benzo[d]oxazol-2-yl)phenyl)benzenesulfonamide was synthesized from 5-amino-2-(4-aminophenyl)benzoxazole (53.9 mg, $0.239 \mathrm{mmol})$, 3-nitrobenzenesulfonyl chloride $(132 \mu \mathrm{L}, 0.593 \mathrm{mmol})$, and anhydrous pyridine $(45.0 \mu \mathrm{L}, 0.552 \mathrm{mmol})$ according to synthetic protocol A. Flash chromatographic purification (hexanes:EtOAc gradient), followed by preparatory RP-HPLC purification, afforded $\mathbf{2 i}-\boldsymbol{m}$ as a yellow-orange solid (42.9 mg, 30\% yield). ${ }^{1} \mathrm{H}-\mathrm{NMR}\left(500 \mathrm{MHz}, d_{6}\right.$-DMSO) $\delta$ 11.11 (br s, 1H), 10.63 (br s, $1 \mathrm{H}), 8.54$ (t, $J=1.9 \mathrm{~Hz}, 1 \mathrm{H}), 8.49$ (t, $J=1.9 \mathrm{~Hz}, 1 \mathrm{H}), 8.40-8.45$ (m, $2 \mathrm{H}), 8.21$ (dq, $J=7.9,0.8 \mathrm{~Hz}, 1 \mathrm{H}), 8.07(\mathrm{dq}, J=7.9,0.8 \mathrm{~Hz}, 1 \mathrm{H}), 8.00(\mathrm{~d}, J=8.5 \mathrm{~Hz}, 2 \mathrm{H}), 7.77-7.87$ (m, 2H), $7.63(\mathrm{~d}, J=8.5$ Hz, 1H), 7.42 (d, $J=2.2 \mathrm{~Hz}, 1 \mathrm{H}), 7.29$ (d, $J=8.5 \mathrm{~Hz}, 2 \mathrm{H}), 7.08$ (dd, $J=8.8,2.2 \mathrm{~Hz}, 1 \mathrm{H})$; MS (ESI) $596.1 \mathrm{~m} / \mathrm{z}$ $\left[\mathrm{MH}^{+}\right], \mathrm{C}_{25} \mathrm{H}_{18} \mathrm{~N}_{5} \mathrm{O}_{9} \mathrm{~S}_{2}$ requires 596.1; HPLC-1 = 95\%; HPLC-2 = 95\%. 
<smiles>O=[N+]([O-])c1ccc(S(=O)(=O)Nc2ccc(-c3nc4cc(NS(=O)(=O)c5ccc([N+](=O)[O-])cc5)ccc4o3)cc2)cc1</smiles>

2i-p: 4-nitro-N-(4-(5-((4-nitrophenyl)sulfonamido)benzo[d]oxazol-2-yl)phenyl)benzenesulfonamide was synthesized from 5-amino-2-(4-aminophenyl)benzoxazole (112 mg, $0.497 \mathrm{mmol})$, 4-nitrobenzenesulfonyl chloride (566 mg, $0.486 \mathrm{mmol})$, and anhydrous pyridine $(100 \mu \mathrm{L}, 0.486 \mathrm{mmol})$ according to synthetic protocol A. Flash chromatographic purification (hexanes:EtOAc gradient) afforded $\mathbf{2 i}-\boldsymbol{p}$ as a yellow solid (91.0 $\mathrm{mg}, 23 \%$ yield). ${ }^{1} \mathrm{H}-\mathrm{NMR}\left(500 \mathrm{MHz}, d_{6}\right.$-DMSO) $\delta 11.16$ (br s, $\left.1 \mathrm{H}\right), 10.67$ (br s, $\left.1 \mathrm{H}\right), 8.36-8.40$ (m, 2H), 8.32-8.36 (m, $2 \mathrm{H}), 8.06-8.10(\mathrm{~m}, 2 \mathrm{H}), 8.01-8.05(\mathrm{~m}, 2 \mathrm{H}), 7.94-7.98(\mathrm{~m}, 2 \mathrm{H}), 7.64(\mathrm{~d}, J=8.8 \mathrm{~Hz}, 1 \mathrm{H}), 7.43(\mathrm{~d}, J=1.9 \mathrm{~Hz}$, $1 \mathrm{H}), 7.30-7.34(\mathrm{~m}, 2 \mathrm{H}), 7.08(\mathrm{dd}, J=8.8,2.2 \mathrm{~Hz}, 1 \mathrm{H})$; MS (ESI) $593.9 \mathrm{~m} / z\left[\mathrm{M}-\mathrm{H}^{+}\right], \mathrm{C}_{25} \mathrm{H}_{16} \mathrm{~N}_{5} \mathrm{O}_{9} \mathrm{~S}_{2}$ requires 594.0; HPLC-1 = 99\%; HPLC-2 = >99\%.<smiles>Nc1ccccc1S(=O)(=O)Nc1ccc(-c2nc3cc(NS(=O)(=O)c4ccccc4N)ccc3o2)cc1</smiles>

2j-o: 2-amino-N-(4-(5-((2-aminophenyl)sulfonamido)benzo[d]oxazol-2-yl)phenyl)benzenesulfonamide was synthesized from $\mathbf{2 i}-\boldsymbol{o}(51.9 \mathrm{mg}, 0.0871 \mathrm{mmol})$ and tin powder $(62.1 \mathrm{mg}, 0.523 \mathrm{mmol})$ according to synthetic protocol C. Flash chromatographic purification (hexanes:EtOAc gradient) afforded $\mathbf{2} \mathbf{j}-\boldsymbol{o}$ as a white solid (35.7 mg, 77\% yield). ${ }^{1} \mathrm{H}-\mathrm{NMR}\left(300 \mathrm{MHz}, d_{6}\right.$-DMSO) $\delta 10.80$ (br s, $\left.1 \mathrm{H}\right), 10.29$ (br s, $\left.1 \mathrm{H}\right), 7.98(\mathrm{~d}, J=8.8 \mathrm{~Hz}, 2 \mathrm{H})$, 7.55-7.64 (m, 2H), 7.43-7.48 (m, 1H), 7.32-7.36 (m, 1H), 7.15-7.25 (m, 4H), $7.04(\mathrm{dd}, J=8.7,2.1 \mathrm{~Hz}, 1 \mathrm{H})$, 6.70-6.78 (m, 2H), 6.48-6.60 (m, 2H), 6.00 (br s, 4H); MS (ESI) $536.0 \mathrm{~m} / z\left[\mathrm{MH}^{+}\right], \mathrm{C}_{2} \mathrm{H}_{22} \mathrm{~N}_{5} \mathrm{O}_{5} \mathrm{~S}_{2}$ requires 536.1; HPLC-1 =>99\%; HPLC-2 = 98\%.<smiles>Nc1cccc(S(=O)(=O)Nc2ccc(-c3nc4cc(NS(=O)(=O)c5cccc(N)c5)ccc4o3)cc2)c1</smiles>

2j-m: 3-amino-N-(4-(5-((3-aminophenyl)sulfonamido)benzo[d]oxazol-2-yl)phenyl)benzenesulfonamide was synthesized using a different reduction procedure, with addition of $\mathrm{NaBH}_{4}(62.3 \mathrm{mg}, 1.65 \mathrm{mmol})$, to a stirring mixture of $\mathbf{2 i}-\boldsymbol{m}$ (135 mg, $0.227 \mathrm{mmol})$ and $\mathrm{NiSO}_{4}$ hexahydrate (11.9 $\left.\mathrm{mg}, 0.045 \mathrm{mmol}\right)$. After 15 minutes, the reaction was diluted with $1 \mathrm{M} \mathrm{HCl}$ and the precipitate was filtered, rinsed with water, and collected. Preparatory RP-HPLC purification afforded $\mathbf{2 j}-\boldsymbol{m}$ as a white solid (29.0 $\mathrm{mg}, 24 \%$ yield). ${ }^{1} \mathrm{H}-\mathrm{NMR}$ $\left(300 \mathrm{MHz}, d_{6}\right.$-DMSO) $\delta 10.76(\mathrm{~s}, 1 \mathrm{H}), 10.23(\mathrm{~s}, 1 \mathrm{H}), 7.97-8.04(\mathrm{~m}, 2 \mathrm{H}), 7.57-7.64(\mathrm{~m}, 1 \mathrm{H}), 7.39(\mathrm{~d}, J=2.0 \mathrm{~Hz}$, 1H), 7.25-7.32 (m, 2H), 7.12-7.22 (m, 2H), 7.04-7.10 (m, 2H), 6.88-7.00 (m, 3H), 6.72-7.79 (m, 2H); MS (ESI) $536.1 \mathrm{~m} / z\left[\mathrm{MH}^{+}\right], \mathrm{C}_{25} \mathrm{H}_{22} \mathrm{~N}_{5} \mathrm{O}_{5} \mathrm{~S}_{2}$ requires 536.0; HPLC-1 $=>99 \%$; HPLC-2 $=98 \%$. 


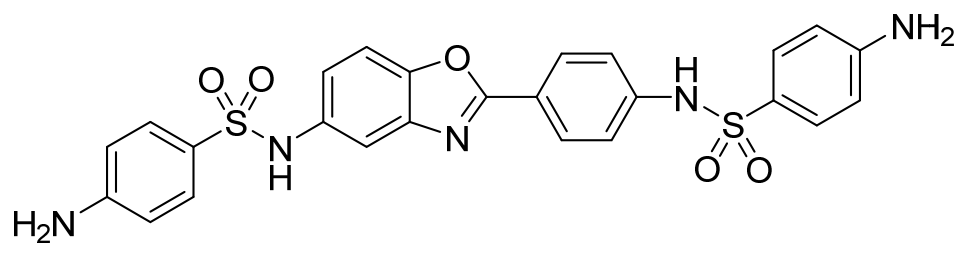

2j-p: 4-amino-N-(4-(5-((4-aminophenyl)sulfonamido)benzo[d]oxazol-2-yl)phenyl)benzenesulfonamide was synthesized from $\mathbf{2} \mathbf{i}-\boldsymbol{p}(72.4 \mathrm{mg}, 0.122 \mathrm{mmol})$ and tin powder $(126 \mathrm{mg}, 1.06 \mathrm{mmol})$ according to synthetic protocol C. Flash chromatographic purification (hexanes:EtOAc gradient) afforded $\mathbf{2} \mathbf{j}-\boldsymbol{p}$ as a pink solid (32.3 mg, 49\% yield). ${ }^{1} \mathrm{H}-\mathrm{NMR}\left(500 \mathrm{MHz}, d_{6}\right.$-DMSO) $\delta 10.50$ (br s, 1H), $9.88(\mathrm{~s}, 1 \mathrm{H}), 7.97(\mathrm{~d}, J=8.5 \mathrm{~Hz}, 2 \mathrm{H}), 7.56$ $(\mathrm{d}, J=8.8 \mathrm{~Hz}, 1 \mathrm{H}), 7.46(\mathrm{~d}, J=8.8 \mathrm{~Hz}, 2 \mathrm{H}), 7.34-7.37(\mathrm{~m}, 3 \mathrm{H}), 7.23(\mathrm{~d}, J=8.5 \mathrm{~Hz}, 2 \mathrm{H}), 7.04(\mathrm{dd}, J=8.7,2.0$ $\mathrm{Hz}, 1 \mathrm{H}), 6.54$ (d, $J=8.8 \mathrm{~Hz}, 2 \mathrm{H}), 6.50$ (d, $J=8.8 \mathrm{~Hz}, 2 \mathrm{H}), 6.00$ (br s, 2H), 5.95 (br s, 2H); MS (ESI) $536.0 \mathrm{~m} / z$ $\left[\mathrm{MH}^{+}\right], \mathrm{C}_{25} \mathrm{H}_{22} \mathrm{~N}_{5} \mathrm{O}_{5} \mathrm{~S}_{2}$ requires 536.1; HPLC-1 = 98\%; HPLC-2 $=97 \%$.<smiles>N#Cc1ccccc1S(=O)(=O)Nc1ccc(-c2nc3cc(NS(=O)(=O)c4ccccc4C#N)ccc3o2)cc1</smiles>

2k-o: 2-cyano-N-(4-(5-((2-cyanophenyl)sulfonamido)benzo[d]oxazol-2-yl)phenyl)benzenesulfonamide was synthesized from 5-amino-2-(4-aminophenyl)benzoxazole (55.7 mg, $0.247 \mathrm{mmol})$, 2-cyanobenzenesulfonyl chloride $(127 \mathrm{mg}, 0.627 \mathrm{mmol})$, and anhydrous pyridine $(50.5 \mu \mathrm{L}, 0.619 \mathrm{mmol})$ according to synthetic protocol A. Flash chromatographic purification (hexanes:EtOAc gradient) afforded 2 k-o as a white solid (59.9 mg, $44 \%$ yield). ${ }^{1} \mathrm{H}-\mathrm{NMR}\left(500 \mathrm{MHz}, d_{6}\right.$-DMSO) $\delta 11.40(\mathrm{~s}, 1 \mathrm{H}), 10.81(\mathrm{~s}, 1 \mathrm{H}), 8.07-8.14(\mathrm{~m}, 2 \mathrm{H}), 8.01-8.06(\mathrm{~m}, 4 \mathrm{H})$, 7.77-7.94 (m, 4H), $7.65(\mathrm{~d}, J=8.8 \mathrm{~Hz}, 1 \mathrm{H}), 7.40(\mathrm{~d}, J=2.2 \mathrm{~Hz}, 1 \mathrm{H}), 7.29(\mathrm{~d}, J=8.5 \mathrm{~Hz}, 2 \mathrm{H}), 7.08(\mathrm{dd}, J=8.7$, $2.0 \mathrm{~Hz}, 1 \mathrm{H})$; MS (ESI) $556.1 \mathrm{~m} / z\left[\mathrm{MH}^{+}\right], \mathrm{C}_{27} \mathrm{H}_{18} \mathrm{~N}_{5} \mathrm{O}_{5} \mathrm{~S}_{2}$ requires 556.1; HPLC-1 = 95\%; HPLC-2 = 95\%.<smiles>N#Cc1cccc(S(=O)(=O)Nc2ccc(-c3nc4cc(NS(=O)(=O)c5cccc(C#N)c5)ccc4o3)cc2)c1</smiles>

2k-m: 3-cyano-N-(4-(5-((3-cyanophenyl)sulfonamido)benzo[d]oxazol-2-yl)phenyl)benzenesulfonamide was synthesized from 5-amino-2-(4-aminophenyl)benzoxazole (49.4 mg, $0.219 \mathrm{mmol})$, 3-cyanobenzenesulfonyl chloride $(109 \mathrm{mg}, 0.540 \mathrm{mmol})$, and anhydrous pyridine $(39.0 \mu \mathrm{L}, 0.478 \mathrm{mmol})$ according to synthetic protocol A. Flash chromatographic purification (hexanes:EtOAc gradient) afforded $\mathbf{2 k - \boldsymbol { m }}$ as an off-white solid (89.2 $\mathrm{mg}$, 73\% yield). ${ }^{1} \mathrm{H}-\mathrm{NMR}\left(500 \mathrm{MHz}, d_{6}\right.$-DMSO) $\delta 11.05$ (br s, $\left.1 \mathrm{H}\right), 10.52$ (br s, $\left.1 \mathrm{H}\right), 8.28$ (s, $\left.1 \mathrm{H}\right), 8.16$ (s, $\left.1 \mathrm{H}\right)$, 8.07-8.14 (m, 3H), $8.03(\mathrm{~d}, J=8.8 \mathrm{~Hz}, 2 \mathrm{H}), 7.98(\mathrm{dd}, J=8.0,1.1 \mathrm{~Hz}, 1 \mathrm{H}), 7.79(\mathrm{t}, J=8.0 \mathrm{~Hz}, 1 \mathrm{H}), 7.74(\mathrm{t}, J=$ $7.9 \mathrm{~Hz}, 1 \mathrm{H}), 7.64(\mathrm{~d}, J=8.8 \mathrm{~Hz}, 1 \mathrm{H}), 7.42(\mathrm{~d}, J=2.2 \mathrm{~Hz}, 1 \mathrm{H}), 7.32(\mathrm{~d}, J=8.8 \mathrm{~Hz}, 2 \mathrm{H}), 7.07(\mathrm{dd}, J=8.8,2.2$ $\mathrm{Hz}, 1 \mathrm{H})$; MS (ESI) $556.0 \mathrm{~m} / z\left[\mathrm{MH}^{+}\right], \mathrm{C}_{27} \mathrm{H}_{18} \mathrm{~N}_{5} \mathrm{O}_{5} \mathrm{~S}_{2}$ requires 556.1; HPLC-1 = >99\%; HPLC-2 = >99\%. 
<smiles>N#Cc1ccc(S(=O)(=O)Nc2ccc(-c3nc4cc(NS(=O)(=O)c5ccc(C#N)cc5)ccc4o3)cc2)cc1</smiles>

2k-p: 4-cyano-N-(4-(5-((4-cyanophenyl)sulfonamido)benzo[d]oxazol-2-yl)phenyl)benzenesulfonamide was synthesized from 5-amino-2-(4-aminophenyl)benzoxazole (44.3 mg, $0.197 \mathrm{mmol})$, 4-cyanobenzenesulfonyl chloride $(96.0 \mathrm{mg}, 0.476 \mathrm{mmol})$, and anhydrous pyridine $(32.0 \mu \mathrm{L}, 0.392 \mathrm{mmol})$ according to synthetic protocol A. Flash chromatographic purification (hexanes:EtOAc gradient) afforded $\mathbf{2 k - p}$ as a yellow-orange solid (80.3 mg, 73\% yield). ${ }^{1} \mathrm{H}-\mathrm{NMR}\left(500 \mathrm{MHz}, d_{6}\right.$-DMSO) $\delta 11.11$ (br s, 1H), 10.60 (br s, 1H), 8.05-8.09 (m, 2H), 8.00$8.05(\mathrm{~m}, 4 \mathrm{H}), 7.97-8.00(\mathrm{~m}, 2 \mathrm{H}), 7.87(\mathrm{~d}, J=8.5 \mathrm{~Hz}, 2 \mathrm{H}), 7.64(\mathrm{~d}, J=8.5 \mathrm{~Hz}, 1 \mathrm{H}), 7.41(\mathrm{~d}, J=1.9 \mathrm{~Hz}, 1 \mathrm{H})$,

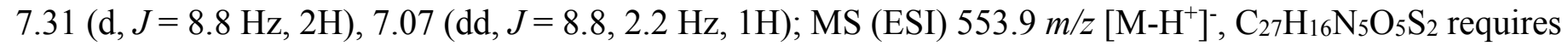
554.1; HPLC-1 = >99\%; HPLC-2 = 98\%.<smiles>COC(=O)c1ccccc1S(=O)(=O)Nc1ccc(-c2nc3cc(NS(=O)(=O)c4ccccc4C(=O)OC)ccc3o2)cc1</smiles>

21-o: methyl 2-(N-(4-(5-((2-(methoxycarbonyl)phenyl)sulfonamido)benzo[d]oxazol-2-

yl)phenyl)sulfamoyl)benzoate was synthesized from 5-amino-2-(4-aminophenyl)benzoxazole (55.4 mg, 0.246 $\mathrm{mmol})$, methyl-2-chlorosulfonylbenzoate $(147 \mathrm{mg}, 0.627 \mathrm{mmol})$, and anhydrous pyridine $(50.0 \mu \mathrm{L}, 0.613$ $\mathrm{mmol}$ ) according to synthetic protocol A. Flash chromatographic purification (hexanes:EtOAc gradient) afforded $2 \mathrm{l}-\boldsymbol{o}$ as a white solid (69.3 mg, 45\% yield). ${ }^{1} \mathrm{H}-\mathrm{NMR}\left(500 \mathrm{MHz}, d_{6}\right.$-DMSO) $\delta 10.84$ (br s, $\left.1 \mathrm{H}\right), 10.29$ (br s, 1H), $8.00(\mathrm{~d}, J=8.8 \mathrm{~Hz}, 2 \mathrm{H}), 7.91-7.94(\mathrm{~m}, 1 \mathrm{H}), 7.84-7.87(\mathrm{~m}, 1 \mathrm{H}), 7.58-7.72(\mathrm{~m}, 7 \mathrm{H}), 7.38(\mathrm{~d}, J=2.2$ $\mathrm{Hz}, 1 \mathrm{H}), 7.26(\mathrm{~d}, J=8.5 \mathrm{~Hz}, 2 \mathrm{H}), 7.08(\mathrm{dd}, J=8.7,2.0 \mathrm{~Hz}, 1 \mathrm{H}), 3.87(\mathrm{~s}, 3 \mathrm{H}), 3.83(\mathrm{~s}, 3 \mathrm{H})$; MS (ESI) $622.0 \mathrm{~m} / \mathrm{z}$ $\left[\mathrm{MH}^{+}\right], \mathrm{C}_{29} \mathrm{H}_{24} \mathrm{~N}_{3} \mathrm{O}_{9} \mathrm{~S}_{2}$ requires 622.1; HPLC-1 = 99\%; HPLC-2 = 99\%.<smiles>COC(=O)c1cccc(S(=O)(=O)Nc2ccc(-c3nc4cc(NS(=O)(=O)c5cccc(C(=O)OC)c5)ccc4o3)cc2)c1</smiles>

\section{2l-m: methyl 3-(N-(4-(5-((3-(methoxycarbonyl)phenyl)sulfonamido)benzo[d]oxazol-2-}

yl)phenyl)sulfamoyl)benzoate was synthesized from 5-amino-2-(4-aminophenyl)benzoxazole (59.5 mg, 0.264 $\mathrm{mmol})$, 3-chlorosulfonicbenzoic acid methyl ester (156 mg, $0.664 \mathrm{mmol})$, and anhydrous pyridine $(54.0 \mu \mathrm{L}$, $0.662 \mathrm{mmol}$ ) according to synthetic protocol A. Flash chromatographic purification (hexanes:EtOAc gradient) afforded $2 \mathbf{2 l} \boldsymbol{m}$ as a white solid (121 mg, 74\% yield). ${ }^{1} \mathrm{H}-\mathrm{NMR}(500 \mathrm{MHz}, d 6$-DMSO) $\delta 11.00$ (br s, $1 \mathrm{H}), 10.48$ (br s, $1 \mathrm{H}), 8.37(\mathrm{~d}, J=1.6 \mathrm{~Hz}, 1 \mathrm{H}), 8.30(\mathrm{~d}, J=1.3 \mathrm{~Hz}, 1 \mathrm{H}), 8.10-8.18(\mathrm{~m}, 2 \mathrm{H}), 8.07$ (dd, $J=7.9,0.9 \mathrm{~Hz}, 1 \mathrm{H})$, $8.00(\mathrm{~d}, J=8.5 \mathrm{~Hz}, 2 \mathrm{H}), 7.91-7.95(\mathrm{~m}, 1 \mathrm{H}), 7.73(\mathrm{t}, J=7.9 \mathrm{~Hz}, 1 \mathrm{H}), 7.67(\mathrm{t}, J=7.9 \mathrm{~Hz}, 1 \mathrm{H}), 7.61(\mathrm{~d}, J=8.8$ $\mathrm{Hz}, 1 \mathrm{H}), 7.38$ (s, 1H), 7.29 (d, J=8.5 Hz, 2H), 7.05 (dd, J=8.7, 2.0 Hz, 1H), 3.87 (s, 3H), 3.85 (s, 3H); MS (ESI) $622.0 \mathrm{~m} / z\left[\mathrm{MH}^{+}\right], \mathrm{C}_{29} \mathrm{H}_{24} \mathrm{~N}_{3} \mathrm{O}_{9} \mathrm{~S}_{2}$ requires 622.1 ; HPLC-1 $=98 \%$; HPLC-2 $=99 \%$. 


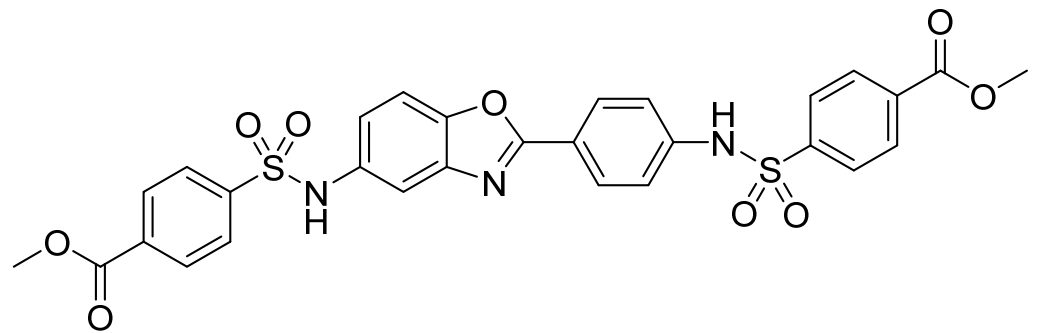

\section{2l-p: methyl 4-(N-(4-(5-((4-(methoxycarbonyl)phenyl)sulfonamido)benzo[d]oxazol-2-}

9yl)phenyl)sulfamoyl)benzoate was synthesized from 5-amino-2-(4-aminophenyl)benzoxazole (60.8 $\mathrm{mg}$, $0.270 \mathrm{mmol}$ ), methyl-4-chlorosulfonylbenzoate $(163 \mathrm{mg}, 0.694 \mathrm{mmol})$, and anhydrous pyridine (55.0 $\mu \mathrm{L}, 0.674$ $\mathrm{mmol}$ ) according to synthetic protocol A. Flash chromatographic purification (hexanes:EtOAc gradient) afforded $2 \mathrm{l}-\boldsymbol{p}$ as a yellow solid $\left(19.7 \mathrm{mg}, 20 \%\right.$ yield). ${ }^{1} \mathrm{H}-\mathrm{NMR}\left(300 \mathrm{MHz}, d_{6}\right.$-DMSO) $\delta 11.05(\mathrm{~s}, 1 \mathrm{H}), 10.51$ (s, 1H), 7.93-8.13 (m, 8H), 7.82-7.87 (m, 2H), 7.62 (d, $J=8.8 \mathrm{~Hz}, 1 \mathrm{H}), 7.39$ (d, $J=2.0 \mathrm{~Hz}, 2 \mathrm{H}), 7.30$ (d, $J=8.8$ $\mathrm{Hz}, 1 \mathrm{H}), 7.06$ (dd, $J=8.8,2.1 \mathrm{~Hz}, 1 \mathrm{H}), 3.84$ (s, 3H), 3.83 (s, 3H); MS (ESI) $622.2 \mathrm{~m} / z\left[\mathrm{MH}^{+}\right], \mathrm{C}_{29} \mathrm{H}_{24} \mathrm{~N}_{3} \mathrm{O}_{9} \mathrm{~S}_{2}$ requires 622.1 ; HPLC- $1=95 \%$; HPLC-2 $=95 \%$.<smiles>O=C(O)c1ccccc1S(=O)(=O)Nc1ccc(-c2nc3cc(NS(=O)(=O)c4ccccc4C(=O)O)ccc3o2)cc1</smiles>

2m-o: 2-(N-(4-(5-((2-carboxyphenyl)sulfonamido)benzo[d]oxazol-2-yl)phenyl)sulfamoyl)benzoic acid was synthesized from $\mathbf{2 l - o}(147 \mathrm{mg}, 0.236 \mathrm{mmol})$ and lithium hydroxide monohydrate $(100 \mathrm{mg}, 2.39 \mathrm{mmol})$ according to synthetic protocol D. Filtration of the precipitate, followed by preparatory RP-HPLC purification, afforded $\mathbf{2 m - o}$ as a white solid (48.7 mg, 35\% yield). ${ }^{1} \mathrm{H}-\mathrm{NMR}\left(300 \mathrm{MHz}, d_{6}\right.$-DMSO) $\delta 13.65$ (br s, $\left.1 \mathrm{H}\right), 10.66$ (br s, 1H), $10.05(\mathrm{~s}, 1 \mathrm{H}), 8.00(\mathrm{~m}, J=8.8 \mathrm{~Hz}, 2 \mathrm{H}), 7.89(\mathrm{~d}, J=7.5 \mathrm{~Hz}, 1 \mathrm{H}), 7.78(\mathrm{~d}, \mathrm{~J}=7.5 \mathrm{~Hz}, 1 \mathrm{H}), 7.53-7.70$ (m, 7H), $7.41(\mathrm{~d}, \mathrm{~J}=2.0 \mathrm{~Hz}, 1 \mathrm{H}), 7.30(\mathrm{~m}, J=8.8 \mathrm{~Hz}, 2 \mathrm{H}), 7.10(\mathrm{dd}, J=8.8,2.1 \mathrm{~Hz}, 1 \mathrm{H}) ; \mathrm{MS}(\mathrm{ESI}) 591.8 \mathrm{~m} / \mathrm{z}$ $\left[\mathrm{M}-\mathrm{H}^{+}\right]^{-}, \mathrm{C}_{27} \mathrm{H}_{18} \mathrm{~N}_{3} \mathrm{O} 9 \mathrm{~S}_{2}$ requires 592.1; HPLC-1 $=>99 \%$; HPLC-2 $=95 \%$.<smiles>O=C(O)c1cccc(S(=O)(=O)Nc2ccc(-c3nc4cc(NS(=O)(=O)c5cccc(C(=O)O)c5)ccc4o3)cc2)c1</smiles>

2m-m: 3-(N-(4-(5-((3-carboxyphenyl)sulfonamido)benzo[d]oxazol-2-yl)phenyl)sulfamoyl)benzoic acid was synthesized from $\mathbf{2 l -} \boldsymbol{m}(76.8 \mathrm{mg}, 0.124 \mathrm{mmol})$ and lithium hydroxide monohydrate $(29.6 \mathrm{mg}, 0.705 \mathrm{mmol})$ according to synthetic protocol D. Filtration of the precipitate afforded $\mathbf{2 m}-\boldsymbol{m}$ as a white solid $(64.8 \mathrm{mg}, 88 \%$ yield). ${ }^{1} \mathrm{H}-\mathrm{NMR}\left(500 \mathrm{MHz}, d_{6}\right.$-DMSO) $\delta 13.52$ (br s, 2H), 10.99 (br s, $\left.1 \mathrm{H}\right), 10.45(\mathrm{~s}, 1 \mathrm{H}), 8.36$ (t, $J=1.6 \mathrm{~Hz}$, $1 \mathrm{H}), 8.29(\mathrm{t}, J=0.9 \mathrm{~Hz}, 1 \mathrm{H}), 8.15(\mathrm{~d}, J=7.9 \mathrm{~Hz}, 1 \mathrm{H}), 8.11(\mathrm{~d}, J=7.9 \mathrm{~Hz}, 1 \mathrm{H}), 8.00-8.07(\mathrm{~m}, 3 \mathrm{H}), 7.91(\mathrm{~d}, J=$ $8.5 \mathrm{~Hz}, 1 \mathrm{H}), 7.71(\mathrm{t}, J=7.9 \mathrm{~Hz}, 1 \mathrm{H}), 7.60-7.67(\mathrm{~m}, 2 \mathrm{H}), 7.39(\mathrm{~d}, J=2.2 \mathrm{~Hz}, 1 \mathrm{H}), 7.30(\mathrm{~d}, J=8.8 \mathrm{~Hz}, 2 \mathrm{H}), 7.06$ (dd, $J=8.8,1.9 \mathrm{~Hz}, 1 \mathrm{H}$ ); MS (ESI) $594.0 \mathrm{~m} / z\left[\mathrm{MH}^{+}\right], \mathrm{C}_{27} \mathrm{H}_{20} \mathrm{~N}_{3} \mathrm{O}_{9} \mathrm{~S}_{2}$ requires 594.1; HPLC-1 = 99\%; HPLC-2 = $98 \%$. 
<smiles>O=C(O)c1ccc(S(=O)(=O)Nc2ccc(-c3nc4cc(NS(=O)(=O)c5ccc(C(=O)O)cc5)ccc4o3)cc2)cc1</smiles>

2m-p: 4-(N-(4-(5-((4-carboxyphenyl)sulfonamido)benzo[d]oxazol-2-yl)phenyl)sulfamoyl)benzoic acid was synthesized from $\mathbf{2 l}-\boldsymbol{p}(316 \mathrm{mg}, 0.508 \mathrm{mmol})$ and lithium hydroxide monohydrate $(245 \mathrm{mg}, 5.84 \mathrm{mmol})$ according to synthetic protocol D. Filtration of the precipitate afforded $\mathbf{2 m}-\boldsymbol{p}$ as a pale-yellow solid $(281 \mathrm{mg}$, 85\% yield). ${ }^{1} \mathrm{H}-\mathrm{NMR}\left(300 \mathrm{MHz}, d_{6}\right.$-DMSO) $\delta 13.44$ (br s, 2H), 11.04 (s, 1H), 10.50 (s, 1H), 8.00-8.12 (m, 6H), $7.94(\mathrm{~d}, J=8.6 \mathrm{~Hz}, 2 \mathrm{H}), 7.83(\mathrm{~d}, J=8.5 \mathrm{~Hz}, 2 \mathrm{H}), 7.62(\mathrm{~d}, J=8.8 \mathrm{~Hz}, 1 \mathrm{H}), 7.40(\mathrm{~d}, J=2.0 \mathrm{~Hz}, 1 \mathrm{H}), 7.30(\mathrm{~d}, J=$ $8.8 \mathrm{~Hz}, 2 \mathrm{H}), 7.07(\mathrm{dd}, \mathrm{J}=8.8,2.0 \mathrm{~Hz}, 1 \mathrm{H})$; MS (ESI) $591.8 \mathrm{~m} / z\left[{\left.\mathrm{M}-\mathrm{H}^{+}\right]}^{-}, \mathrm{C}_{27} \mathrm{H}_{20} \mathrm{~N}_{3} \mathrm{O}_{9} \mathrm{~S}_{2}\right.$ requires 592.1 ; HPLC-1 $=96 \% ;$ HPLC $-2=96 \%$.<smiles>O=S(=O)(Nc1ccc(-c2nc3cc(NS(=O)(=O)c4ccccc4)ccc3o2)cc1)c1ccccc1</smiles>

2a: N-(4-(5-(phenylsulfonamido)benzo[d]oxazol-2-yl)phenyl)benzenesulfonamide was synthesized from 5amino-2-(4-aminophenyl)benzoxazole $(43.1 \mathrm{mg}, 0.191 \mathrm{mmol})$, benzenesulfonyl chloride $(55.0 \mu \mathrm{L}, 0.431$ $\mathrm{mmol})$, and anhydrous pyridine $(30.0 \mu \mathrm{L}, 0.368 \mathrm{mmol})$ according to synthetic protocol A. Flash chromatographic purification (hexanes:EtOAc gradient) afforded 6 as a white solid $\left(79.5 \mathrm{mg}, 82 \%\right.$ yield). ${ }^{1} \mathrm{H}-$ NMR (500 MHz, d6-DMSO) $\delta 10.90$ (br s, 1H), 10.34 (br s, 1H), 8.00 (d, $J=8.8 \mathrm{~Hz}, 2 \mathrm{H}), 7.82-7.86$ (m, 2H), 7.72-7.76 (m, 2H), 7.50-7.65 (m, 7H), $7.39(\mathrm{~d}, J=2.2 \mathrm{~Hz}, 1 \mathrm{H}), 7.29(\mathrm{~d}, J=8.5 \mathrm{~Hz}, 2 \mathrm{H}), 7.07(\mathrm{dd}, J=8.8,2.2$ $\mathrm{Hz}, 1 \mathrm{H}$ ); MS (ESI) $506.0 \mathrm{~m} / z\left[\mathrm{MH}^{+}\right], \mathrm{C}_{25} \mathrm{H}_{20} \mathrm{~N}_{3} \mathrm{O}_{5} \mathrm{~S}_{2}$ requires 506.1; HPLC-1 = 100\%; HPLC-2 = 99\%.<smiles>CS(=O)(=O)Nc1ccc(-c2nc3cc(NS(C)(=O)=O)ccc3o2)cc1</smiles>

3: N-(4-(5-(methylsulfonamido)benzo[d]oxazol-2-yl)phenyl)methanesulfonamide was synthesized from 5amino-2-(4-aminophenyl)benzoxazole (104.3 mg, $0.463 \mathrm{mmol})$, methanesulfonyl chloride (108 $\mu \mathrm{L}, 1.39$ $\mathrm{mmol})$, and anhydrous pyridine $(113 \mu \mathrm{L}, 1.39 \mathrm{mmol})$ according to synthetic protocol A. Flash chromatographic purification (hexanes:EtOAc gradient) afforded 2 as a pinkish-white solid $\left(79.1 \mathrm{mg}, 45 \%\right.$ yield). ${ }^{1} \mathrm{H}-\mathrm{NMR}(500$ $\mathrm{MHz}, d_{6}$-DMSO) $\delta 10.38(\mathrm{~s}, 1 \mathrm{H}), 9.79(\mathrm{~s}, 1 \mathrm{H}), 8.15(\mathrm{~d}, J=8.9 \mathrm{~Hz}, 1 \mathrm{H}), 7.85(\mathrm{~d}, J=8.7,1 \mathrm{H}), 7.75(\mathrm{~d}, J=9.1$ $\mathrm{Hz}, 1 \mathrm{H}), 7.60(\mathrm{~d}, J=2.2 \mathrm{~Hz}, 1 \mathrm{H}), 7.40(\mathrm{~d}, J=8.9 \mathrm{~Hz}, 1 \mathrm{H}), 7.26(\mathrm{dd}, J=8.6,2.1 \mathrm{~Hz}, 2 \mathrm{H}), 3.33(\mathrm{~s}, 6 \mathrm{H})$; MS (ESI) $382.0 \mathrm{~m} / z\left[\mathrm{MH}^{+}\right], \mathrm{C}_{15} \mathrm{H}_{16} \mathrm{~N}_{3} \mathrm{O}_{5} \mathrm{~S}_{2}$ requires 382.1; HPLC-1 $=100 \%$; HPLC-2 $=99 \%$. 
<smiles>O=S(=O)(Nc1ccc(-c2nc3cc(NS(=O)(=O)C(F)(F)F)ccc3o2)cc1)C(F)(F)F</smiles>

4: 1,1,1-trifluoro-N-(4-(5-((trifluoromethyl)sulfonamido)benzo[d]oxazol-2-yl)phenyl)methanesulfonamide was synthesized from 5-amino-2-(4-aminophenyl)benzoxazole (52.6 mg, $0.234 \mathrm{mmol})$, trifluoromethanesulfonic anhydride $(90.0 \mu \mathrm{L}, 0.535 \mathrm{mmol})$, and anhydrous pyridine $(38.0 \mu \mathrm{L}, 0.466 \mathrm{mmol})$ according to synthetic protocol A. Flash chromatographic purification (hexanes:EtOAc gradient) afforded $\mathbf{3}$ as an orange solid (102 mg, 89\% yield). ${ }^{1} \mathrm{H}-\mathrm{NMR}\left(500 \mathrm{MHz}, d_{6}\right.$-DMSO) $\delta 8.19(\mathrm{~d}, J=8.5 \mathrm{~Hz}, 1 \mathrm{H}), 7.85(\mathrm{~d}, J=$ $8.6 \mathrm{~Hz}, 1 \mathrm{H}), 7.67(\mathrm{~d}, J=2.1,1 \mathrm{H}), 7.46(\mathrm{~d}, J=8.7 \mathrm{~Hz}, 2 \mathrm{H}), 7.31(\mathrm{dd}, J=8.7,2.1 \mathrm{~Hz}, 2 \mathrm{H})$; MS (ESI) $490.1 \mathrm{~m} / z$ $\left[\mathrm{MH}^{+}\right], \mathrm{C}_{15} \mathrm{H}_{10} \mathrm{~F}_{6} \mathrm{~N}_{3} \mathrm{O}_{5} \mathrm{~S}_{2}$ requires 490.0; HPLC-1 = 97\%; HPLC-2 = 97\%.<smiles>CCCS(=O)(=O)Nc1ccc(-c2nc3cc(NS(=O)(=O)CCC)ccc3o2)cc1</smiles>

5: N-(4-(5-(propylsulfonamido)benzo[d]oxazol-2-yl)phenyl)propane-1-sulfonamide was synthesized from 5-amino-2-(4-aminophenyl)benzoxazole $(51.7 \mathrm{mg}, 0.230 \mathrm{mmol}),{ }^{\mathrm{n}}$ propylsulfonyl chloride $(112 \mu \mathrm{L}, 0.999$ mmol), and anhydrous pyridine $(76.0 \mu \mathrm{L}, 0.932 \mathrm{mmol})$ according to synthetic protocol A. Flash chromatographic purification (hexanes:EtOAc gradient) afforded 4 as a white solid $\left(59.4 \mathrm{mg}, 59 \%\right.$ yield). ${ }^{1} \mathrm{H}-$ NMR (500 MHz, d6-DMSO) $\delta 10.41($ br s, 1H), 9.85 (br s, 1H), 8.12 (d, J=8.2 Hz, 2H), 7.73 (d, $J=8.8 \mathrm{~Hz}$, $1 \mathrm{H}), 7.58(\mathrm{~d}, J=2.2 \mathrm{~Hz}, 1 \mathrm{H}), 7.39(\mathrm{~d}, J=8.8 \mathrm{~Hz}, 2 \mathrm{H}), 7.25(\mathrm{dd}, J=8.8,2.2 \mathrm{~Hz}, 1 \mathrm{H}), 3.16-3.24(\mathrm{~m}, 2 \mathrm{H}), 3.04-$ 3.09 (m, 2H), 1.66-1.75 (m, 4H), 0.90-0.98 (m, 6H); MS (ESI) 438.2 m/z [MH $\left.{ }^{+}\right], \mathrm{C}_{19} \mathrm{H}_{24} \mathrm{~N}_{3} \mathrm{O}_{5} \mathrm{~S}_{2}$ requires 438.1; HPLC-1 $=98 \%$; HPLC-2 = 99\%.<smiles>O=S(=O)(Nc1ccc(-c2nc3cc(NS(=O)(=O)c4cccs4)ccc3o2)cc1)c1cccs1</smiles>

6: N-(4-(5-(thiophene-2-sulfonamido)benzo[d]oxazol-2-yl)phenyl)thiophene-2-sulfonamide was synthesized from 5-amino-2-(4-aminophenyl)benzoxazole (45.0 mg, $0.200 \mathrm{mmol})$, 2-thiophenesulfonyl chloride $(212 \mathrm{mg}, 1.16 \mathrm{mmol})$, and anhydrous pyridine $(66.0 \mu \mathrm{L}, 0.810 \mathrm{mmol})$ according to synthetic protocol A. Flash chromatographic purification (hexanes:EtOAc gradient) afforded 5 as a white solid $\left(65.6 \mathrm{mg}, 63 \%\right.$ yield). ${ }^{1} \mathrm{H}-$ NMR (500 MHz, d $d_{6}$-DMSO) $\delta 11.01(\mathrm{~s}, 1 \mathrm{H}), 10.46(\mathrm{~s}, 1 \mathrm{H}), 8.06(\mathrm{~d}, J=8.2 \mathrm{~Hz}, 2 \mathrm{H}), 7.92(\mathrm{~d}, J=4.7 \mathrm{~Hz}, 1 \mathrm{H})$, $7.88(\mathrm{dd}, J=4.9,1.4 \mathrm{~Hz}, 1 \mathrm{H}), 7.65-7.68(\mathrm{~m}, 2 \mathrm{H}), 7.51(\mathrm{dd}, J=3.8,1.6 \mathrm{~Hz}, 1 \mathrm{H}), 7.46(\mathrm{~d}, J=1.9 \mathrm{~Hz}, 1 \mathrm{H}), 7.35$ $(\mathrm{d}, J=8.5 \mathrm{~Hz}, 2 \mathrm{H}), 7.07-7.15(\mathrm{~m}, 3 \mathrm{H}) ; \mathrm{MS}(\mathrm{ESI}) 517.9 \mathrm{~m} / z\left[\mathrm{MH}^{+}\right], \mathrm{C}_{21} \mathrm{H}_{16} \mathrm{~N}_{3} \mathrm{O}_{5} \mathrm{~S}_{4}$ requires $518.0 ; \mathrm{HPLC}-1=$ 98\%; HPLC-2 = 99\%. 


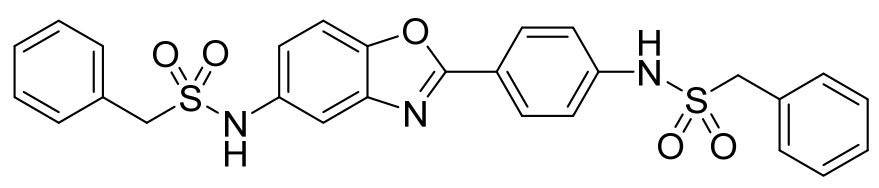

7: 1-phenyl-N-(4-(5-((phenylmethyl)sulfonamido)benzo[d]oxazol-2-yl)phenyl)methanesulfonamide was synthesized from 5-amino-2-(4-aminophenyl)benzoxazole $(41.1 \mathrm{mg}, 0.182 \mathrm{mmol})$, a-toluenesulfonyl chloride $(145 \mathrm{mg}, 0.759 \mathrm{mmol})$, and anhydrous pyridine $(51.0 \mu \mathrm{L}, 0.625 \mathrm{mmol})$ according to synthetic protocol A. Flash chromatographic purification (hexanes:EtOAc gradient) afforded 7 as a white solid $\left(29.2 \mathrm{mg}, 30 \%\right.$ yield). ${ }^{1} \mathrm{H}-$ NMR (500 MHz, $d_{6}$-DMSO) $\delta 10.42(\mathrm{br} \mathrm{s}, 1 \mathrm{H}), 9.92(\mathrm{br} \mathrm{s}, 1 \mathrm{H}), 8.10-8.14(\mathrm{~m}, 2 \mathrm{H}), 7.73(\mathrm{~d}, J=8.8 \mathrm{~Hz}, 1 \mathrm{H})$, $7.59(\mathrm{~d}, J=1.9 \mathrm{~Hz}, 1 \mathrm{H}), 7.33-7.38(\mathrm{~m}, 8 \mathrm{H}), 7.27-7.31(\mathrm{~m}, 4 \mathrm{H}), 7.23(\mathrm{dd}, J=8.8,2.2 \mathrm{~Hz}, 1 \mathrm{H}), 4.60(\mathrm{~s}, 2 \mathrm{H}), 4.49$ (s, 2H); MS (ESI) $534.0 \mathrm{~m} / z\left[\mathrm{MH}^{+}\right], \mathrm{C}_{27} \mathrm{H}_{24} \mathrm{~N}_{3} \mathrm{O}_{5} \mathrm{~S}_{2}$ requires 534.1; HPLC-1 $=99 \%$; HPLC-2 $=97 \%$.

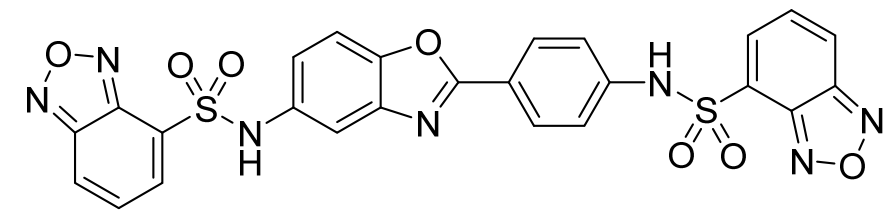

8: N-(4-(5-(benzo[c][1,2,5]oxadiazole-4-sulfonamido)benzo[d]oxazol-2-

yl)phenyl)benzo[c] [1,2,5]oxadiazole-4-sulfonamide was synthesized from 5-amino-2-(4-

aminophenyl)benzoxazole ( $56.3 \mathrm{mg}, 0.250 \mathrm{mmol}$ ), 2,1,3-benzoxadiazolesulfonyl chloride (119 mg, 0.546 $\mathrm{mmol})$, and anhydrous pyridine $(45.0 \mu \mathrm{L}, 0.552 \mathrm{mmol})$ according to synthetic protocol A. Flash chromatographic purification (hexanes:EtOAc gradient) afforded $\mathbf{8}$ as a yellow solid (115 $\mathrm{mg}, 78 \%$ yield). ${ }^{1} \mathrm{H}-$ NMR (500 MHz, $d_{6}$-DMSO) $\delta 11.56(\mathrm{br} \mathrm{s}, 1 \mathrm{H}), 11.00(\mathrm{br} \mathrm{s}, 1 \mathrm{H}), 8.31-8.36(\mathrm{~m}, 2 \mathrm{H}), 8.23(\mathrm{~d}, J=5.0 \mathrm{~Hz}, 1 \mathrm{H})$, 8.09-8.14 (m, 1H), $7.94(\mathrm{~d}, J=8.5 \mathrm{~Hz}, 2 \mathrm{H}), 7.70-7.75(\mathrm{~m}, 1 \mathrm{H}), 7.65-7.69(\mathrm{~m}, 1 \mathrm{H}), 7.56(\mathrm{~d}, J=8.8 \mathrm{~Hz}, 1 \mathrm{H})$, $7.40(\mathrm{~d}, J=1.9 \mathrm{~Hz}, 1 \mathrm{H}), 7.27$ (d, $J=7.9 \mathrm{~Hz}, 2 \mathrm{H}), 7.04$ (dd, $J=8.7,2.0 \mathrm{~Hz}, 1 \mathrm{H}) ; \mathrm{MS}$ (ESI) $590.1 \mathrm{~m} / z$ [MH $\mathrm{MH}^{+}$, $\mathrm{C}_{15} \mathrm{H}_{16} \mathrm{~N}_{7} \mathrm{O}_{7} \mathrm{~S}_{2}$ requires 590.1; HPLC-1 $=95 ; \mathrm{HPLC}-2=95 \%$.<smiles>O=S(=O)(Nc1cccc2nsnc12)c1ccc2oc(-c3ccc(NS(=O)(=O)c4cccc5nsnc45)cc3)nc2c1</smiles>

\section{9: N-(4-(5-(benzo[c][1,2,5]thiadiazole-4-sulfonamido)benzo[d]oxazol-2-}

yl)phenyl)benzo[c] $[\mathbf{1 , 2 , 5}]$ thiadiazole-4-sulfonamide was synthesized from 5-amino-2-(4aminophenyl)benzoxazole $(59.7 \mathrm{mg}, 0.265 \mathrm{mmol}), 2,1,3$-benzothiadiazole-4-sulfonyl chloride $(156.5 \mathrm{mg}$, $0.667 \mathrm{mmol})$, and anhydrous pyridine $(54.0 \mu \mathrm{L}, 0.662 \mathrm{mmol})$ according to synthetic protocol A. Flash chromatographic purification (hexanes:EtOAc gradient) afforded 9 as a white solid (157 mg, $95 \%$ yield). ${ }^{1} \mathrm{H}-$ NMR (500 MHz, $d_{6}$-DMSO) $\delta 11.34(\mathrm{br} \mathrm{s}, 1 \mathrm{H}), 10.75(\mathrm{br} \mathrm{s}, 1 \mathrm{H}), 8.33-8.38(\mathrm{~m}, 3 \mathrm{H}), 8.24(\mathrm{dd}, J=7.1,1.1 \mathrm{~Hz}$, $1 \mathrm{H}), 7.83-7.89(\mathrm{~m}, 3 \mathrm{H}), 7.79(\mathrm{dd}, J=8.8,6.9 \mathrm{~Hz}, 1 \mathrm{H}), 7.47(\mathrm{dd}, J=8.8 \mathrm{~Hz}, 1 \mathrm{H}), 7.33(\mathrm{~d}, J=1.9 \mathrm{~Hz}, 1 \mathrm{H}), 7.22-$ 7.27 (m, 2H), $7.01(\mathrm{dd}, J=8.8,2.2 \mathrm{~Hz}, 1 \mathrm{H})$; MS (ESI) $621.9 \mathrm{~m} / z\left[\mathrm{MH}^{+}\right], \mathrm{C}_{23} \mathrm{H}_{16} \mathrm{~N}_{7} \mathrm{O}_{5} \mathrm{~S}_{4}$ requires 622.0; HPLC$1=98 ;$ HPLC $-2=97 \%$. 
<smiles>O=S(=O)(Nc1ccc(-c2nc3cc(NS(=O)(=O)c4cccc5ccccc45)ccc3o2)cc1)c1cccc2ccccc12</smiles>

10: N-(4-(5-(naphthalene-1-sulfonamido)benzo[d] oxazol-2-yl)phenyl)naphthalene-1-sulfonamide was synthesized from 5-amino-2-(4-aminophenyl)benzoxazole $(54.2 \mathrm{mg}, 0.241 \mathrm{mmol}), 1$-naphthalenesulfonyl chloride $(135 \mathrm{mg}, 0.594 \mathrm{mmol})$, and anhydrous pyridine $(45.0 \mu \mathrm{L}, 0.552 \mathrm{mmol})$ according to synthetic protocol A. Flash chromatographic purification (hexanes:EtOAc gradient) afforded $\mathbf{1 0}$ as a white solid (139 $\mathrm{mg}, 95 \%$ yield). ${ }^{1} \mathrm{H}$ NMR (500 MHz, DMSO) $\delta 11.26$ (br s, $\left.1 \mathrm{H}\right), 10.70$ (br s, $\left.1 \mathrm{H}\right), 8.73$ (d, $\left.J=8.5 \mathrm{~Hz}, 2 \mathrm{H}\right), 8.29$ (d, $J=$ $7.3 \mathrm{~Hz}, 1 \mathrm{H}), 8.15-8.23(\mathrm{~m}, 3 \mathrm{H}), 8.03-8.07(\mathrm{~m}, 2 \mathrm{H}), 7.86(\mathrm{~d}, J=8.5 \mathrm{~Hz}, 2 \mathrm{H}), 7.70-7.76(\mathrm{~m}, 2 \mathrm{H}), 7.61-7.67$ (m, $3 \mathrm{H}), 7.57(\mathrm{t}, J=7.7 \mathrm{~Hz}, 1 \mathrm{H}), 7.47(\mathrm{~d}, J=8.8 \mathrm{~Hz}, 1 \mathrm{H}), 7.26(\mathrm{~d}, J=1.9 \mathrm{~Hz}, 1 \mathrm{H}), 7.18(\mathrm{~d}, J=8.5 \mathrm{~Hz}, 2 \mathrm{H}), 6.95$ $(\mathrm{dd}, J=8.8,2.2 \mathrm{~Hz}, 1 \mathrm{H})$; MS (ESI) $606.0 \mathrm{~m} / z\left[\mathrm{MH}^{+}\right], \mathrm{C}_{33} \mathrm{H}_{24} \mathrm{~N}_{3} \mathrm{O}_{5} \mathrm{~S}_{2}$ requires 606.1 HPLC-1 = 99; HPLC-2 = $99 \%$.<smiles>O=S(=O)(Nc1ccc(-c2nc3cc(S(=O)(=O)Nc4ccc5nsnc5c4)ccc3o2)cc1)c1ccc2nsnc2c1</smiles>

\section{1: N-(4-(5-(benzo[c][1,2,5]thiadiazole-5-sulfonamido)benzo[d]oxazol-2-}

yl)phenyl)benzo[c] $[1,2,5]$ thiadiazole-5-sulfonamide was synthesized from 5-amino-2-(4-

aminophenyl)benzoxazole (59.1 mg, $0.262 \mathrm{mmol})$, 2,1,3-benzothiadiazole-5-sulfonyl chloride (153 $\mathrm{mg}, 0.651$ $\mathrm{mmol})$, and anhydrous pyridine $(53.5 \mu \mathrm{L}, 0.656 \mathrm{mmol})$ according to synthetic protocol A. Flash chromatographic purification (hexanes:EtOAc gradient) afforded 11 as a yellow solid $\left(56.6 \mathrm{mg}, 35 \%\right.$ yield). ${ }^{1} \mathrm{H}-$ NMR (500 MHz, $d_{6}$-DMSO) $\delta 11.18$ (br s, 1H), 10.68 (br s, 1H), 8.59 (s, 1H), 8.45 (dd, J=1.9, 0.6 Hz, 1H), 8.27-8.30 (m, 2H), 7.93-7.99 (m, 4H), $7.58(\mathrm{~d}, J=8.8 \mathrm{~Hz}, 1 \mathrm{H}), 7.44(\mathrm{~d}, \mathrm{~J}=1.9 \mathrm{~Hz}, 1 \mathrm{H}), 7.32(\mathrm{~d}, J=8.8 \mathrm{~Hz}$, 2H), $7.10(\mathrm{dd}, J=8.8,2.2 \mathrm{~Hz}, 1 \mathrm{H})$; MS (ESI) $621.9 \mathrm{~m} / z\left[\mathrm{MH}^{+}\right], \mathrm{C}_{25} \mathrm{H}_{16} \mathrm{~N}_{7} \mathrm{O}_{5} \mathrm{~S}_{4}$ requires 622.1; HPLC-1 = 98; HPLC-2 $=98 \%$.<smiles>O=S(=O)(Nc1ccc(-c2nc3cc(NS(=O)(=O)c4ccc5ncsc5c4)ccc3o2)cc1)C1=CC2SC=NC2C=C1</smiles>

12: N-(4-(5-(benzo[d]thiazole-6-sulfonamido)benzo[d]oxazol-2-yl)phenyl)benzo[d]thiazole-6-sulfonamide was synthesized from 5-amino-2-(4-aminophenyl)benzoxazole ( $57.5 \mathrm{mg}, 0.255 \mathrm{mmol}), 1,3$-benzothazole-6sulfonyl chloride $(148 \mathrm{mg}, 0.634 \mathrm{mmol})$, and anhydrous pyridine $(52.0 \mu \mathrm{L}, 0.638 \mathrm{mmol})$ according to synthetic protocol A. Flash chromatographic purification (hexanes:EtOAc gradient) afforded $\mathbf{1 2}$ as a white solid (65.1 $\mathrm{mg}, 41 \%$ yield). ${ }^{1} \mathrm{H}-\mathrm{NMR}\left(500 \mathrm{MHz}, d_{6}\right.$-DMSO) $\delta 11.01$ (br s, 1H), 10.45 (br s, 1H), $9.60(\mathrm{~s}, 1 \mathrm{H}), 9.57$ (s, 1H), $8.80(\mathrm{~d}, J=1.9 \mathrm{~Hz}, 1 \mathrm{H}), 8.67(\mathrm{~d}, J=1.6 \mathrm{~Hz}, 1 \mathrm{H}), 8.23(\mathrm{~d}, J=8.5 \mathrm{~Hz}, 1 \mathrm{H}), 8.21(\mathrm{~d}, J=9.1 \mathrm{~Hz}, 1 \mathrm{H}), 7.95-7.98$ $(\mathrm{m}, 2 \mathrm{H}), 7.92-7.95(\mathrm{~m}, 1 \mathrm{H}), 7.84-7.88(\mathrm{~m}, 1 \mathrm{H}), 7.57(\mathrm{~d}, J=8.8 \mathrm{~Hz}, 1 \mathrm{H}), 7.41(\mathrm{~d}, J=1.9 \mathrm{~Hz}, 1 \mathrm{H}), 7.30(\mathrm{~d}, J=$ $8.8 \mathrm{~Hz}, 2 \mathrm{H}), 7.06(\mathrm{dd}, J=8.8,2.2 \mathrm{~Hz}, 1 \mathrm{H})$; MS (ESI) $619.8 \mathrm{~m} / z\left[\mathrm{MH}^{+}\right], \mathrm{C}_{27} \mathrm{H}_{18} \mathrm{~N}_{5} \mathrm{O}_{5} \mathrm{~S}_{4}$ requires 620.0 ; HPLC-1 $=99 ;$ HPLC $-2=98 \%$. 
<smiles>O=S(=O)(Nc1ccc(-c2nc3cc(NS(=O)(=O)c4ccc5ccccc5c4)ccc3o2)cc1)c1ccc2ccccc2c1</smiles>

13: N-(4-(5-(naphthalene-2-sulfonamido)benzo[d]oxazol-2-yl)phenyl)naphthalene-2-sulfonamide was synthesized from 5-amino-2-(4-aminophenyl)benzoxazole (56.1 mg, $0.249 \mathrm{mmol})$, 2-naphthalenesulfonyl chloride (142 mg, $0.624 \mathrm{mmol})$, and anhydrous pyridine $(51.0 \mu \mathrm{L}, 0.625 \mathrm{mmol})$ according to synthetic protocol A. Flash chromatographic purification (hexanes:EtOAc gradient) afforded $\mathbf{1 3}$ as a white solid (127 $\mathrm{mg}, 84 \%$ yield). ${ }^{1} \mathrm{H}$ NMR (500 MHz, DMSO) $\delta 11.01$ (br s, $\left.1 \mathrm{H}\right), 10.43$ (br s, $\left.1 \mathrm{H}\right), 8.53$ (s, 1H), 8.39 (s, 1H), 8.12-8.16 $(\mathrm{m}, 1 \mathrm{H}), 8.04-8.10(\mathrm{~m}, 3 \mathrm{H}), 7.97(\mathrm{t}, J=7.9 \mathrm{~Hz}, 2 \mathrm{H}), 7.92(\mathrm{~d}, J=8.8 \mathrm{~Hz}, 2 \mathrm{H}), 7.80(\mathrm{dd}, J=8.8,1.9 \mathrm{~Hz}, 1 \mathrm{H})$, $7.75(\mathrm{dd}, J=8.5,1.9 \mathrm{~Hz}, 1 \mathrm{H}), 7.58-7.69(\mathrm{~m}, 4 \mathrm{H}), 7.53(\mathrm{~d}, J=8.8 \mathrm{~Hz}, 1 \mathrm{H}), 7.40(\mathrm{~d}, J=2.2 \mathrm{~Hz}, 1 \mathrm{H}), 7.29(\mathrm{~d}, J=$ $8.8 \mathrm{~Hz}, 2 \mathrm{H}), 7.06(\mathrm{dd}, J=8.8,2.2 \mathrm{~Hz}, 1 \mathrm{H})$; MS (ESI) $606.2 \mathrm{~m} / z\left[\mathrm{MH}^{+}\right], \mathrm{C}_{33} \mathrm{H}_{24} \mathrm{~N}_{3} \mathrm{O}_{5} \mathrm{~S}_{2}$ requires 606.1; HPLC-1 $=99 \%$; HPLC $-2=99 \%$.<smiles>O=c1ccc2cc(S(=O)(=O)Nc3ccc(-c4nc5cc(NS(=O)(=O)c6ccc7oc(=O)ccc7c6)ccc5o4)cc3)ccc2o1</smiles>

14: 2-oxo-N-(4-(5-((2-oxo-2H-chromene)-6-sulfonamido)benzo[d]oxazol-2-yl)phenyl)-2H-chromene-6sulfonamide was synthesized from 5-amino-2-(4-aminophenyl)benzoxazole (52.7 mg, $0.234 \mathrm{mmol})$, coumarin6-sulfonyl chloride (144 mg, $0.588 \mathrm{mmol}$ ), and anhydrous pyridine ( $47.5 \mu \mathrm{L}, 0.582 \mathrm{mmol})$ according to synthetic protocol A. Flash chromatographic purification (EtOAc:methanol gradient) afforded $\mathbf{1 4}$ as a tan solid (102 mg, 68\% yield). ${ }^{1} \mathrm{H}-\mathrm{NMR}\left(500 \mathrm{MHz}, d_{6}\right.$-DMSO) $\delta 11.04$ (br s, $\left.1 \mathrm{H}\right), 10.47$ (br s, $\left.1 \mathrm{H}\right), 8.28$ (d, $J=2.2 \mathrm{~Hz}$, $1 \mathrm{H}), 8.12-8.18(\mathrm{~m}, 3 \mathrm{H}), 7.95-7.98(\mathrm{~m}, 3 \mathrm{H}), 7.88(\mathrm{dd}, J=8.8,2.2 \mathrm{~Hz}, 1 \mathrm{H}), 7.60(\mathrm{~d}, J=8.8 \mathrm{~Hz}, 1 \mathrm{H}), 7.54(\mathrm{dd}, J$ $=8.5,6.6 \mathrm{~Hz}, 2 \mathrm{H}), 7.42(\mathrm{~d}, J=1.9 \mathrm{~Hz}, 1 \mathrm{H}), 7.28(\mathrm{~d}, J=8.8 \mathrm{~Hz}, 2 \mathrm{H}), 7.06(\mathrm{dd}, J=8.7,2.0 \mathrm{~Hz}, 1 \mathrm{H}), 6.55-6.61$ $(\mathrm{m}, 2 \mathrm{H})$; MS (ESI) $641.9 \mathrm{~m} / z\left[\mathrm{MH}^{+}\right], \mathrm{C}_{31} \mathrm{H}_{20} \mathrm{~N}_{3} \mathrm{O}_{9} \mathrm{~S}_{2}$ requires 642.1 ; HPLC-1 = 97\%; HPLC-2 = 97\%. 


\section{$\underline{\text { References: }}$}

1. Johnson, S. M.; Connelly, S.; Wilson, I. A.; Kelly, J. W. Journal of medicinal chemistry 2008, 51, 6348.

2. Johnson, S. M.; Connelly, S.; Wilson, I. A.; Kelly, J. W. Journal of medicinal chemistry 2009, $52,1115$.

3. Abdeen, S.; Salim, N.; Mammadova, N.; Summers, C. M.; Frankson, R.; Ambrose, A. J.; Anderson, G. G.; Schultz, P. G.; Horwich, A. L.; Chapman, E.; Johnson, S. M. Bioorganic \& medicinal chemistry letters 2016, $26,3127$.

4. Johnson, S. M.; Sharif, O.; Mak, P. A.; Wang, H. T.; Engels, I. H.; Brinker, A.; Schultz, P. G.; Horwich, A. L.; Chapman, E. Bioorganic \& medicinal chemistry letters 2014, 24, 786.

5. Sykes, M. L.; Baell, J. B.; Kaiser, M.; Chatelain, E.; Moawad, S. R.; Ganame, D.; loset, J. R.; Avery, V. M. PLoS Negl Trop Dis 2012, 6, e1896.

6. Sykes, M. L.; Avery, V. M. Am J Trop Med Hyg 2009, 81, 665. 